Supporting Information for

\title{
Chromophore Quench Labeling: Simulated Snapshots of Molar Mass Distributions for the Rapid Mechanistic Analysis of Catalytic Alkene Polymerization
}

\author{
Eric S. Cueny* \\ Department of Chemistry, University of Pennsylvania, 231 South $34^{\text {th }}$ Street, Philadelphia, Pennsylvania \\ 19104, United States \\ Corresponding Author \\ *ecueny@sas.upenn.edu
}

\section{Contents}

General considerations for kinetic simulations

Kinetic simulation of a living polymerization reaction

Kinetic simulation of polymerization reactions featuring slow rates of initiation

Kinetic simulation of polymerization reactions featuring B-hydride elimination

Kinetic simulation of polymerization reactions featuring irreversible chain transfer

Kinetic simulation of polymerization reactions featuring reversible chain transfer where $k_{\text {ex } 1}=k_{\text {ex2 }}$

Kinetic simulation of polymerization reactions featuring reversible chain transfer where $\mathrm{k}_{\mathrm{ex} 1} \neq \mathrm{k}_{\mathrm{ex} 2}$

Kinetic simulation of polymerization reactions featuring reversible chain transfer where $k_{\mathrm{ex} 1}=k_{\mathrm{ex} 2}$ with a continuous monomer feed

Kinetic simulation of polymerization reactions featuring reversible chain transfer where $k_{\text {ex1 }}=k_{\text {ex2 }}=30 \mathrm{M}^{-1} \mathrm{~s}^{-1}$ with varying initial monomer concentrations

Kinetic simulation of polymerization reactions featuring slow initiation along with reversible chain transfer

Kinetic simulation of polymerization reactions featuring ß-hydride elimination along with reversible chain transfer 


\section{General considerations for kinetic simulations}

Herein, the program Copasi is used for all kinetic simulations. The kinetic models for these simulations were constructed in Mathematica using systems biology markup language (SBML) and subsequently imported into Copasi. This protocol for constructing kinetic models has been reported previously by the Landis group. ${ }^{1-3}$ The general mechanism used in these kinetic simulations is shown in Scheme S1. It is worth noting here the step size used in propagation was 25 (i.e. during each propagation step, 25 alkenes are inserted into the catalyst-polymeryl). While some detail of the overall molar mass distribution (MMD) is lost as a result, this truncation reduces the number of differential equations required in the kinetic model. Even with such simplifications, and only 60 total monomer insertion steps accounted for, nearly 4,000 differential equations are involved in these simulations. This simplification is most apparent when low molar mass (MM) polymer is produced, typically early in a simulation of polymerization behavior. Despite the loss of detail at low MM, the simulations manage to provide sufficient data for the purposes of this manuscript. Similar approaches to kinetic modeling using multiple insertions per propagation step have been successfully undertaken by the Landis group. ${ }^{2}$

For a more accurate comparison of the shapes of the distributions, the UV-signal is "mass scaled". The mass scaling of the UV-signal is required because while the UV-signal is solely dependent on the concentration of the analyte (in this case a polymer chain labeled by CQL), the RI-signal is dependent on both the concentration and MM of the analyte. This mass scaling is performed by multiplying the UV-signal at each discrete point by the MM of the polymer at that point. Mass scaling has been previously described by the Landis group., ${ }^{2,4}$

The initial rate constants and concentrations of monomer, catalyst, and CTA were chosen based upon previous kinetic studies of polymerization reactions conducted in the Landis group where similar rate constants for polymerization were observed and similar concentration ranges of monomer, catalyst, and CTA were used. ${ }^{1,3}$

\section{Scheme S1. Kinetic Model Used to Simulate UV- and RI-GPC Traces.}

\section{Initiation}

$[\mathrm{M}]-\mathrm{R}$

Propagation

$[\mathrm{M}]-\mathrm{Pol}[\mathrm{n}]+>_{\text {butyl }}$

Chain Transfer

$[\mathrm{M}]-\mathrm{Pol}[\mathrm{n}]+\mathrm{Zn}-\mathrm{Et}$

Chain Transfer

$[\mathrm{M}]-\mathrm{Pol}[\mathrm{n}]+\mathrm{Zn}-\mathrm{Pol}[\mathrm{m}]$

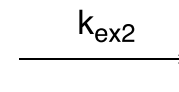

$[\mathrm{M}]-\mathrm{Pol}[\mathrm{m}]+\mathrm{Zn}-\mathrm{Pol}[\mathrm{n}]$

$\beta$-Hydride Elimination

$[\mathrm{M}]-\mathrm{Pol}[\mathrm{n}] \stackrel{\mathrm{k}_{\beta-\mathrm{H}}}{\longrightarrow}[\mathrm{M}]-\mathrm{H}+\mathrm{Pol}[\mathrm{n}]$ 


\section{Kinetic simulation of a living polymerization reaction}

In this kinetic simulation, a truly living polymerization is considered. Chain transfer, in the form of B-hydride elimination or chain transfer to a metal alkyl, is not considered. To achieve this, the rate constants for $k_{e x 1}, k_{e x 2}$, and $k_{H}$ are set to 0 . The rate constant for initiation $\left(k_{i}\right)$ is treated equivalently to propagation (i.e., $\mathrm{k}_{\mathrm{i}}=1.0 \mathrm{M}^{-1} \mathrm{~s}^{-1}$ and $\mathrm{k}_{\mathrm{p}}=1.0 \mathrm{M}^{-1} \mathrm{~s}^{-1}$ ). The catalyst concentration is set to 0.75 $\mathrm{mM}$ and the monomer concentration is set to $1.0 \mathrm{M}$. The results of the kinetic simulation are shown in Figures S1 - S2. In Figure S1, the "typical" catalytic information is shown (monomer consumption with time, $\mathrm{M}_{\mathrm{n}}$ vs conversion, and $\mathrm{MMD}$ at different monomer conversions). In Figure S2, the unique information in this study (simulated UV- and RI-GPC traces at different monomer conversions) are shown.

As described in the General Considerations section, the current kinetic model accounts for 1,500 total insertions of monomer. These 1,500 insertions of monomer would account for a theoretical molecular weight of poly $(1$-octene) of $168,360 \mathrm{~g} / \mathrm{mol}$. Under the living polymerization conditions simulated here, beyond $75 \%$ monomer conversion the polymer produced is too high in molecular weight (i.e., too many insertions of monomer have occurred) to provide valid MMD data. Therefore, simulated data up to a maximum of $75 \%$ monomer conversion is shown here. In later simulations, where chain transfer to $\mathrm{Zn}$-alkyls occurs, higher conversions (up to $80 \%$ ) can be accurately simulated due to the overall lower molecular weight of polymer produced when chain transfer occurs.

a)

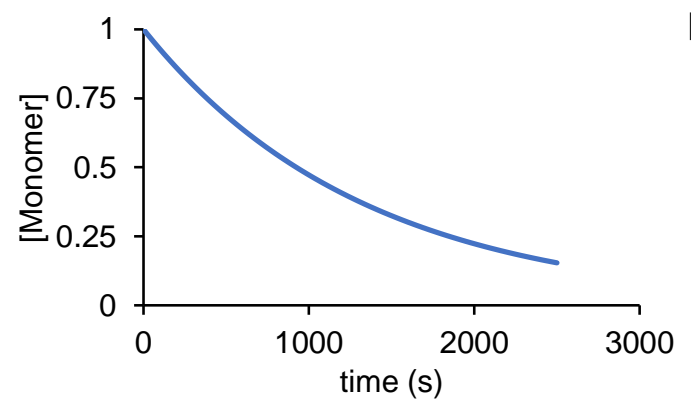

b)

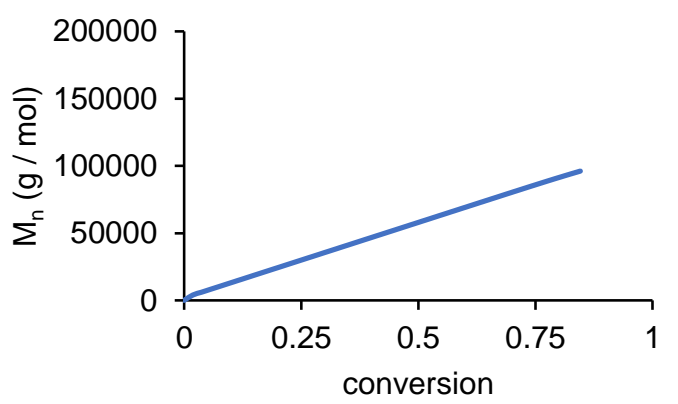

c)

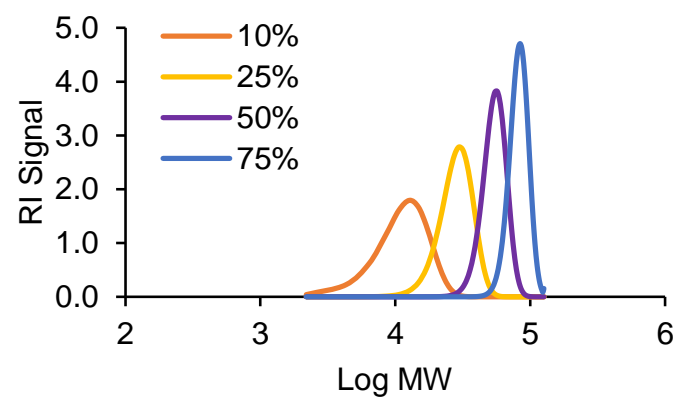

Figure S1. Data from the simulation of a living polymerization reaction where $\mathrm{k}_{\mathrm{i}}=1.0 \mathrm{M}^{-1} \mathrm{~s}^{-1}, \mathrm{k}_{\mathrm{p}}=$ $1.0 \mathrm{M}^{-1} \mathrm{~s}^{-1}$, [cat] $0=0.75 \mathrm{mM}$, and [monomer] $]_{0}=1.0 \mathrm{M}$. For calculations of $\mathrm{M}_{\mathrm{n}}$, the molar mass of 1-hexene as the monomer is used. (a) Temporal profile of monomer consumption. (b) Number average MM $\left(\mathrm{M}_{\mathrm{n}}\right)$ vs conversion of monomer. (c) Simulated Rl-traces at varying conversion of monomer (10\% conversion after 150 s, $25 \%$ conversion after 400 s, $50 \%$ conversion after $900 \mathrm{~s}$, and $75 \%$ conversion after $1800 \mathrm{~s})$. 
a)

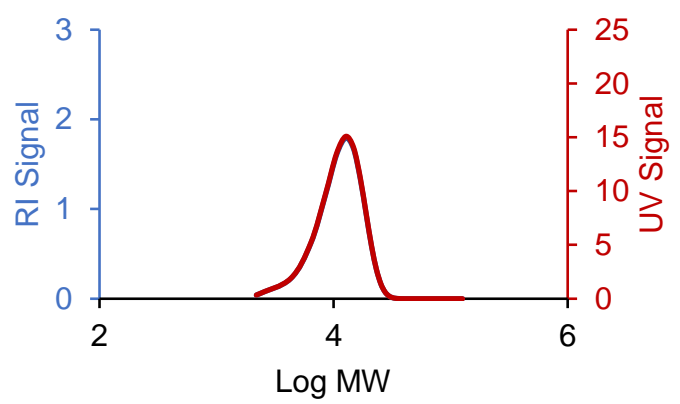

c)

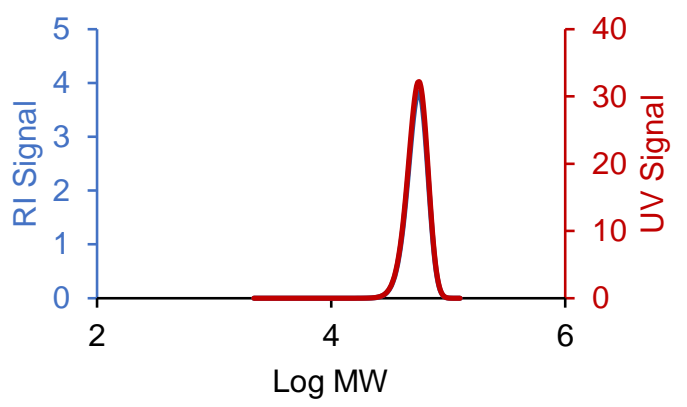

b)

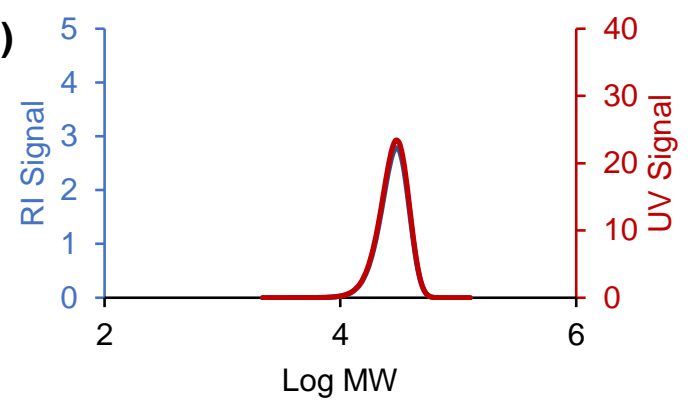

d)

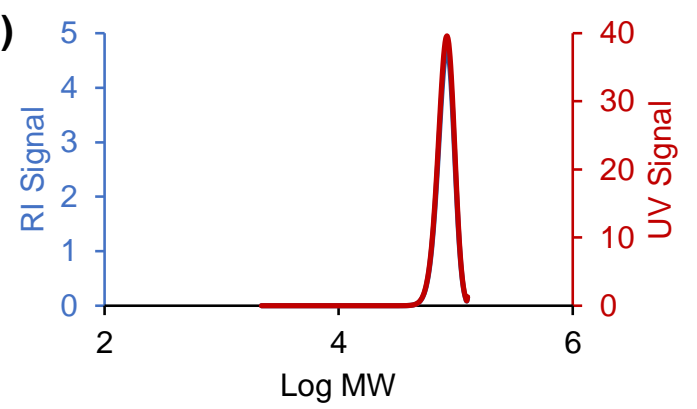

Figure S2. Data from the simulation of a living polymerization reaction where $k_{i}=1.0 \mathrm{M}^{-1} \mathrm{~s}^{-1}, \mathrm{k}_{\mathrm{p}}=$ $1.0 \mathrm{M}^{-1} \mathrm{~s}^{-1}$, [cat $]_{0}=0.75 \mathrm{mM}$, and [monomer] $0=1.0 \mathrm{M}$. The UV signal is "mass scaled" for a more accurate comparison of the trace shape to the RI signal. For each simulated GPC trace, the UV signal is shown in red and the RI signal shown in blue. (a) Simulated UV-and RI-GPC traces at $10 \%$ monomer conversion (150 s). (b) Simulated UV- and RI-GPC traces at $25 \%$ monomer conversion (400 s). (c) Simulated UV- and RI-GPC traces at 50\% monomer conversion (900 s). (d) Simulated UV- and RI-GPC traces at 75\% monomer conversion (1800 s).

\section{Kinetic simulation of polymerization reactions featuring slow rates of initiation}

In these kinetic simulations, polymerizations with slow rate constants for initiation (relative to propagation) are considered. Chain transfer, in the form of B-hydride elimination or chain transfer to a metal alkyl, is not considered here. To achieve this, the rate constants for $\mathrm{k}_{\mathrm{ex} 1}, \mathrm{k}_{\mathrm{ex} 2}$, and $\mathrm{k}_{\mathrm{H}}$ are set to 0 . The catalyst concentration is set to $0.75 \mathrm{mM}$, the monomer concentration is set to $1.0 \mathrm{M}$, and $\mathrm{k}_{\mathrm{p}}$ is set to $1.0 \mathrm{M}^{-1} \mathrm{~s}^{-1}$. The results of these kinetic simulations are shown in Figures S3 $-\mathrm{S} 11$. 
a)

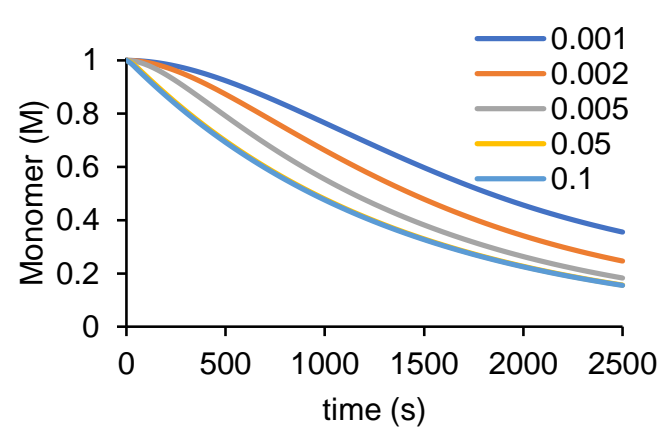

b)

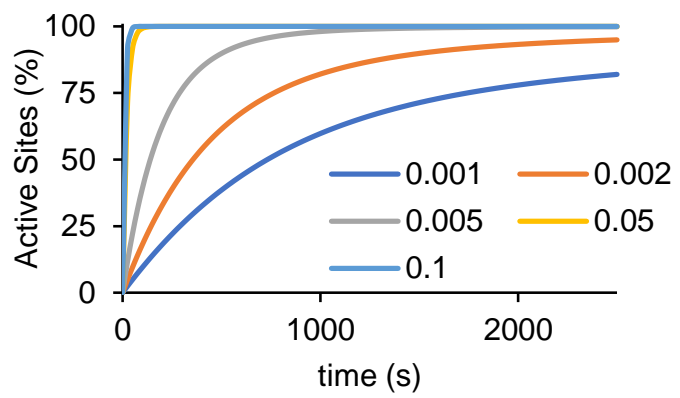

Figure S3. Data from simulations of polymerization reactions where initiation is slow, relative to propagation. The conditions for this simulation are as follows: $\mathrm{k}_{\mathrm{i}}=$ varied, $\mathrm{k}_{\mathrm{p}}=1.0 \mathrm{M}^{-1} \mathrm{~s}^{-1}$, [cat $]_{0}=$ $0.75 \mathrm{mM}$, and [monomer] $]_{0}=1.0 \mathrm{M}$. (a) Temporal profile of monomer consumption when $\mathrm{k}_{\mathrm{i}}=0.001$, $0.002,0.005,0.05$, and $0.1 \mathrm{M}^{-1} \mathrm{~s}^{-1}$. (b) Temporal profile of the percentage of active catalyst (relative to [cat $\left.]_{0}\right)$ when $\mathrm{k}_{\mathrm{i}}=0.001,0.002,0.005,0.05$, and $0.1 \mathrm{M}^{-1} \mathrm{~s}^{-1}$.

a)

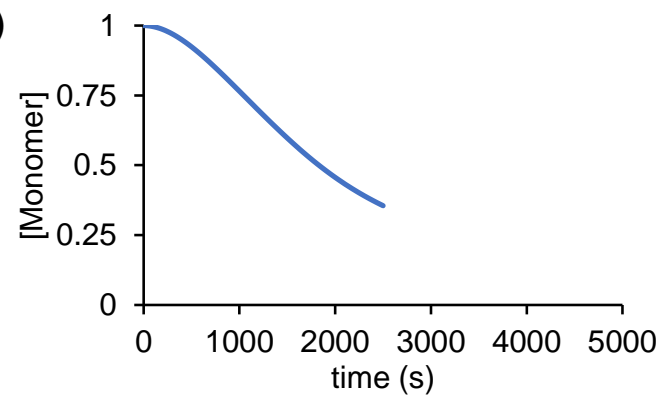

b)

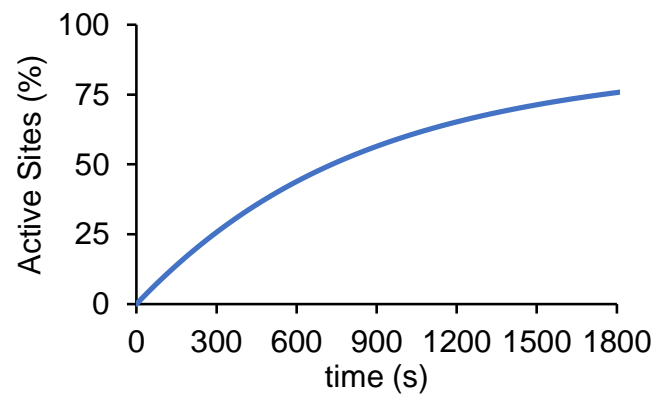

c)

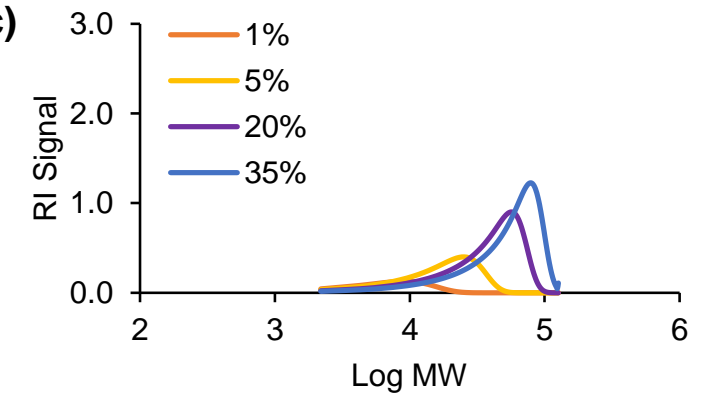

Figure S4. Data from the simulation of a polymerization reaction where initiation is slow, relative to propagation. The conditions for this simulation are as follows: $\mathrm{k}_{\mathrm{i}}=0.001 \mathrm{M}^{-1} \mathrm{~s}^{-1}, \mathrm{k}_{\mathrm{p}}=1.0 \mathrm{M}^{-1} \mathrm{~s}^{-1}$, [cat $]_{0}=0.75 \mathrm{mM}$, and [monomer] $]_{0}=1.0 \mathrm{M}$. (a) Temporal profile of monomer consumption. (b) Temporal profile of the percentage of active catalyst during polymerization. (c) Simulated RItraces at varying conversion of monomer (1\% conversion after $150 \mathrm{~s}, 5 \%$ conversion after $400 \mathrm{~s}$, $20 \%$ conversion after 900 s, and $35 \%$ conversion after 1300 s). 
a)

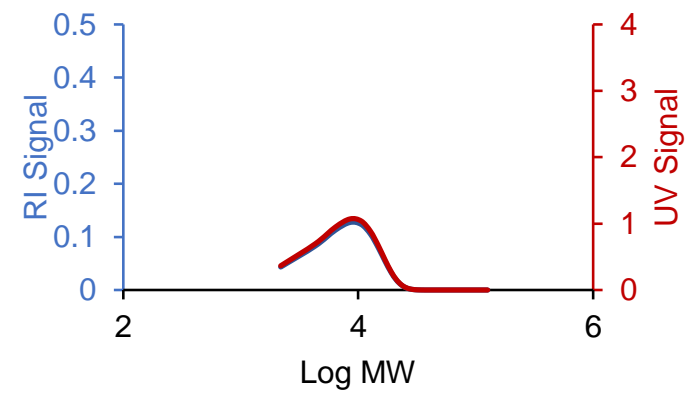

c)

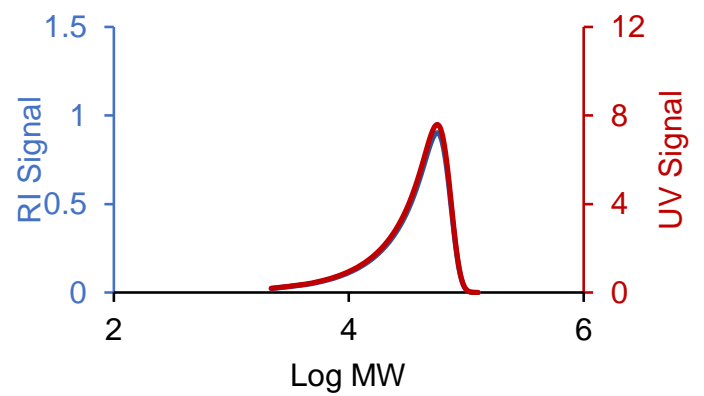

b)

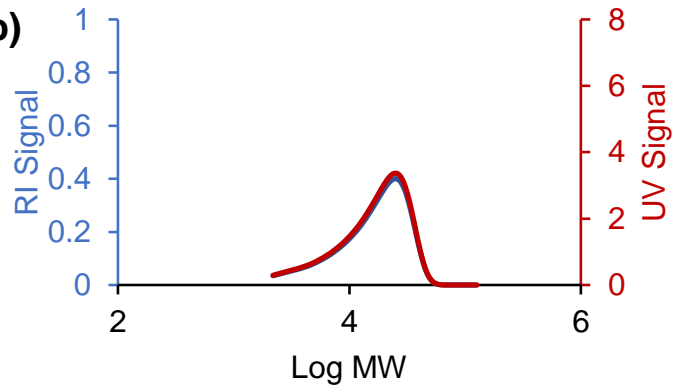

d)

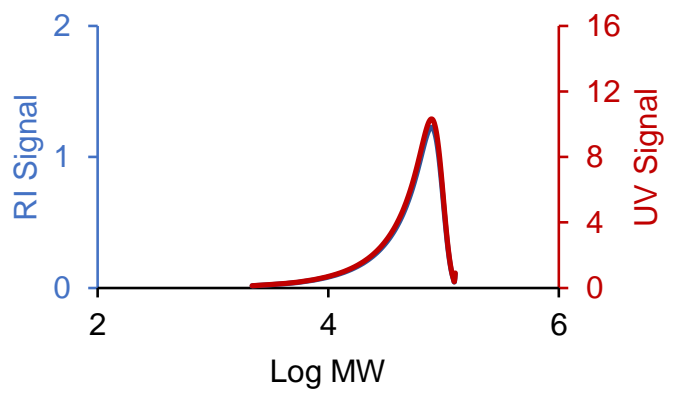

Figure S5. Data from the simulation of a polymerization reaction where initiation is slow, relative to propagation. The conditions for this simulation are as follows: $k_{i}=0.001 \mathrm{M}^{-1} \mathrm{~s}^{-1}, \mathrm{k}_{\mathrm{p}}=1.0 \mathrm{M}^{-1} \mathrm{~s}^{-1}$, $[\text { cat }]_{0}=0.75 \mathrm{mM}$, and [monomer $]_{0}=1.0 \mathrm{M}$. The UV signal is "mass scaled" for a more accurate comparison of the trace shape to the RI signal. For each simulated GPC trace, the UV signal is shown in red and the RI signal shown in blue. (a) Simulated UV- and RI-GPC traces at $1 \%$ monomer conversion (150 s). (b) Simulated UV- and RI-GPC traces at $5 \%$ monomer conversion (400 s). (c) Simulated UV- and RI-GPC traces at 20\% monomer conversion (900 s). (d) Simulated UV- and RI-GPC traces at 35\% monomer conversion (1300 s). 
a)

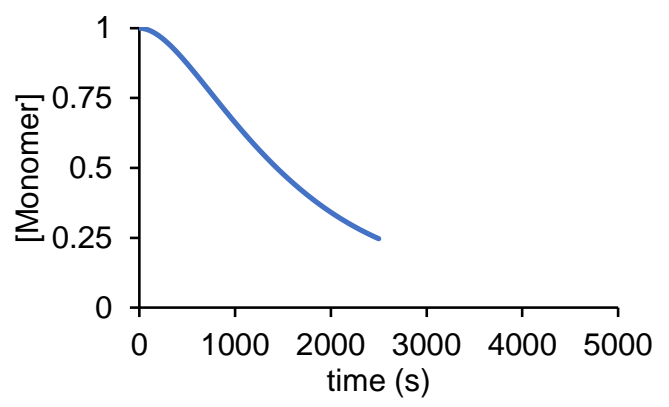

b)

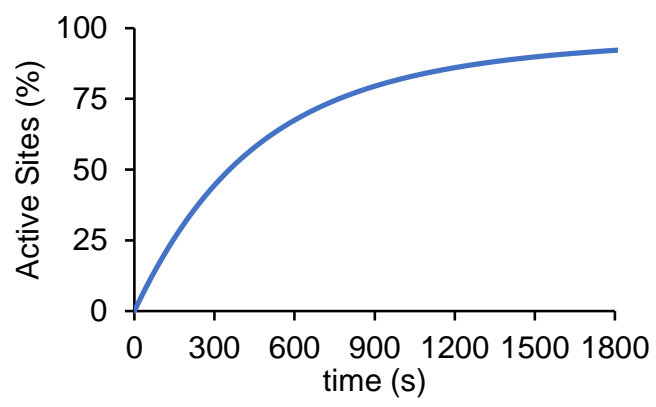

c)

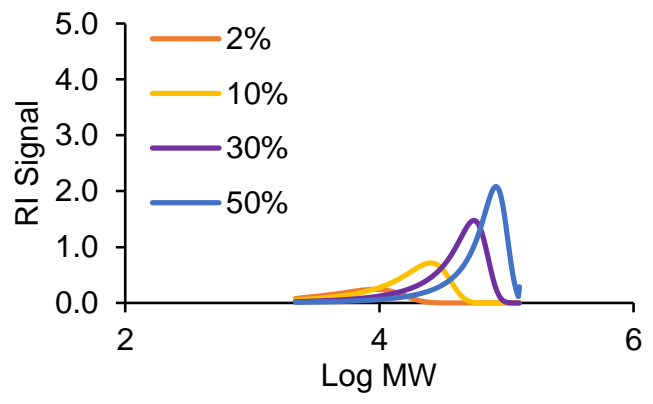

Figure S6. Data from the simulation of a polymerization reaction where initiation is slow, relative to propagation. The conditions for this simulation are as follows: $\mathrm{k}_{\mathrm{i}}=0.002 \mathrm{M}^{-1} \mathrm{~s}^{-1}, \mathrm{k}_{\mathrm{p}}=1.0 \mathrm{M}^{-1} \mathrm{~s}^{-1}$, [cat $_{0}=0.75 \mathrm{mM}$, and [monomer] $]_{0}=1.0 \mathrm{M}$. (a) Temporal profile of monomer consumption. (b) Temporal profile of the percentage of active catalyst during polymerization. (c) Simulated RItraces at varying conversion of monomer ( $2 \%$ conversion after $150 \mathrm{~s}, 10 \%$ conversion after 400 s, $30 \%$ conversion after 900 s, and $50 \%$ conversion after 1500 s). 
a)

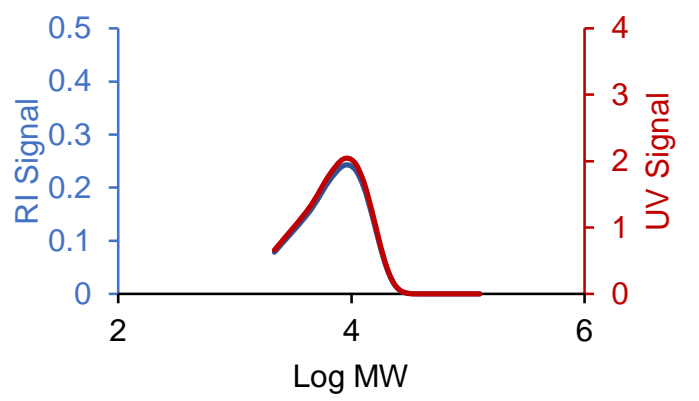

c)

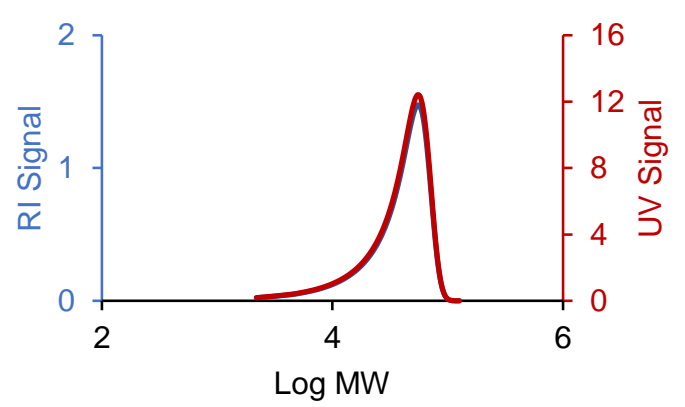

b)

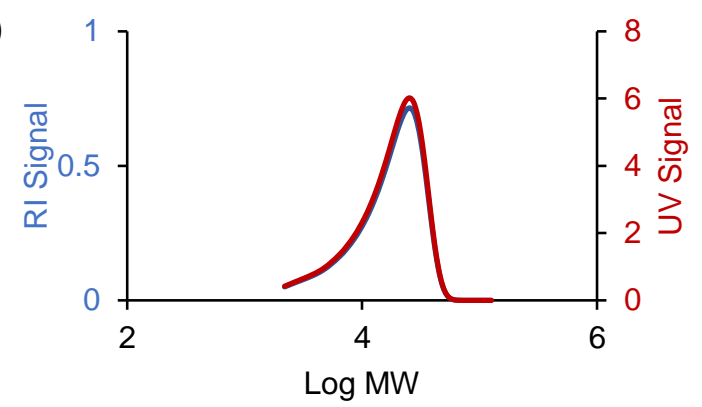

d)

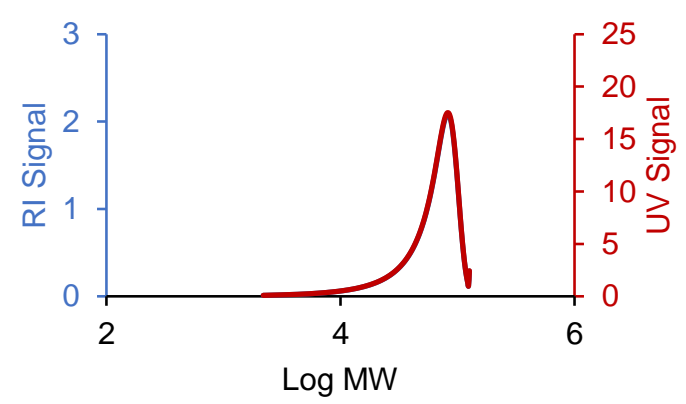

Figure S7. Data from the simulation of a polymerization reaction where initiation is slow, relative to propagation. The conditions for this simulation are as follows: $\mathrm{k}_{\mathrm{i}}=0.002 \mathrm{M}^{-1} \mathrm{~s}^{-1}, \mathrm{k}_{\mathrm{p}}=1.0 \mathrm{M}^{-1} \mathrm{~s}^{-1}$, [cat $]_{0}=0.75 \mathrm{mM}$, and [monomer $]_{0}=1.0 \mathrm{M}$. The UV signal is "mass scaled" for a more accurate comparison of the trace shape to the RI signal. For each simulated GPC trace, the UV signal is shown in red and the RI signal shown in blue. (a) Simulated UV- and RI-GPC traces at $2 \%$ monomer conversion (150 s). (b) Simulated UV- and RI-GPC traces at 10\% monomer conversion (400 s). (c) Simulated UV- and RI-GPC traces at 30\% monomer conversion (900 s). (d) Simulated UV- and RI-GPC traces at 50\% monomer conversion (1500 s). 
a)

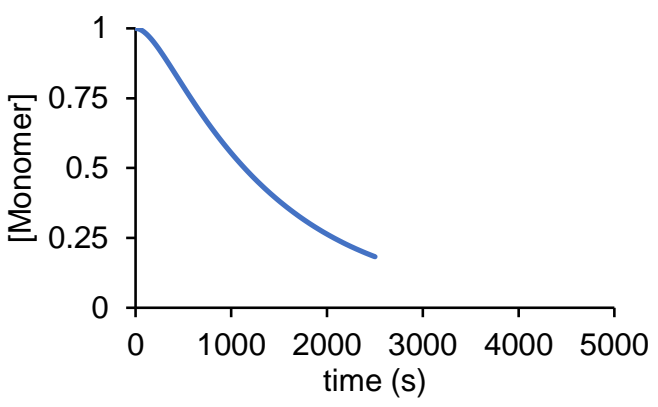

b)

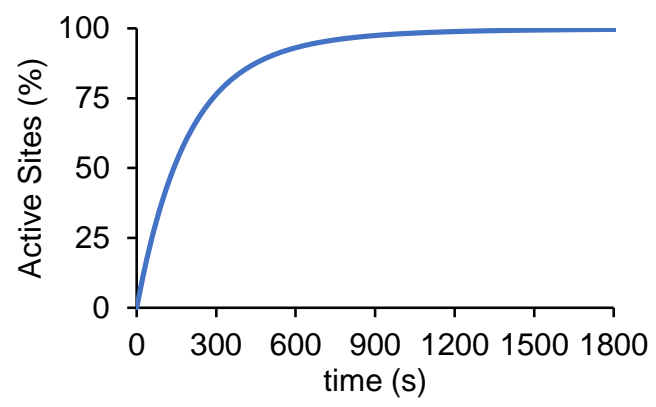

c)

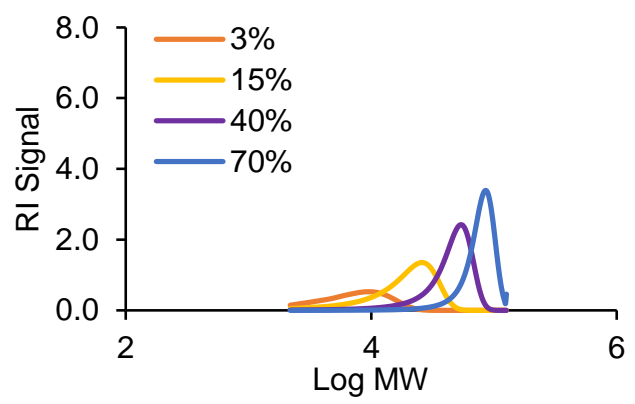

Figure S8. Data from the simulation of a polymerization reaction where initiation is slow, relative to propagation. The conditions for this simulation are as follows: $\mathrm{k}_{\mathrm{i}}=0.005 \mathrm{M}^{-1} \mathrm{~s}^{-1}, \mathrm{k}_{\mathrm{p}}=1.0 \mathrm{M}^{-1} \mathrm{~s}^{-1}$, [cat $]_{0}=0.75 \mathrm{mM}$, and [monomer] $]_{0}=1.0 \mathrm{M}$. (a) Temporal profile of monomer consumption. (b) Temporal profile of the percentage of active catalyst during polymerization. (c) Simulated RItraces at varying conversion of monomer ( $3 \%$ conversion after $150 \mathrm{~s}, 15 \%$ conversion after 400 s, $40 \%$ conversion after $900 \mathrm{~s}$, and $70 \%$ conversion after $1800 \mathrm{~s})$. 
a)

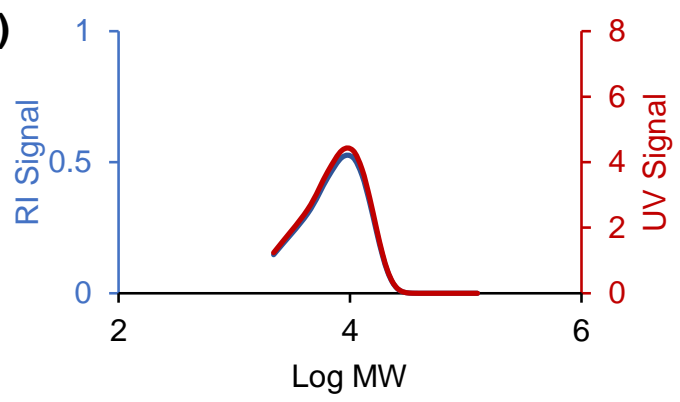

c)

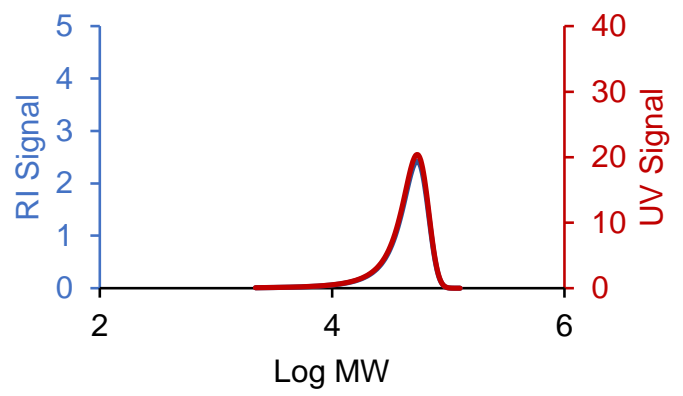

b)

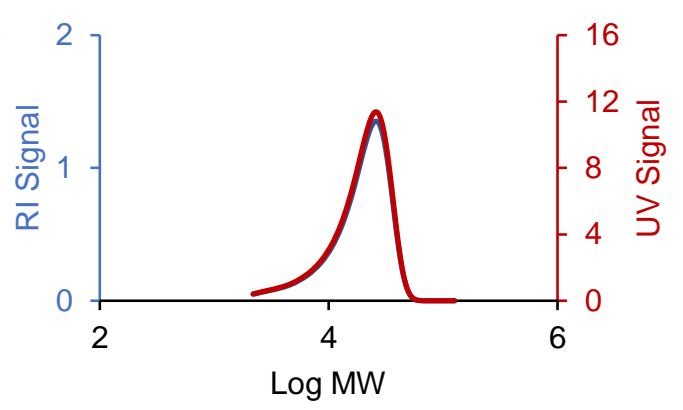

d)

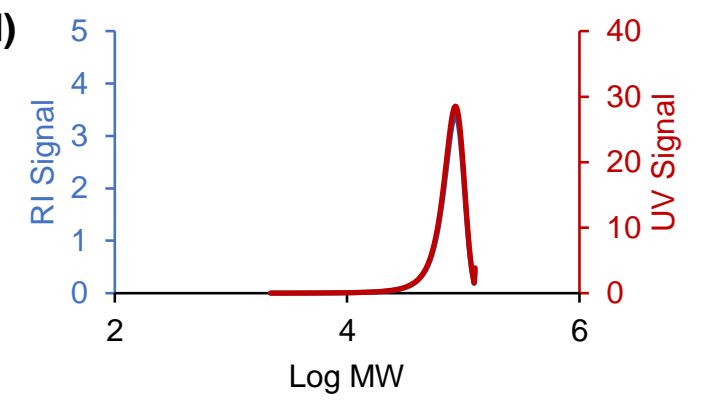

Figure S9. Data from the simulation of a polymerization reaction where initiation is slow, relative to propagation. The conditions for this simulation are as follows: $\mathrm{k}_{\mathrm{i}}=0.005 \mathrm{M}^{-1} \mathrm{~s}^{-1}, \mathrm{k}_{\mathrm{p}}=1.0 \mathrm{M}^{-1} \mathrm{~s}^{-1}$, [cat $]_{0}=0.75 \mathrm{mM}$, and [monomer $]_{0}=1.0 \mathrm{M}$. The UV signal is "mass scaled" for a more accurate comparison of the trace shape to the RI signal. For each simulated GPC trace, the UV signal is shown in red and the RI signal shown in blue. (a) Simulated UV- and RI-GPC traces at 3\% monomer conversion (150 s). (b) Simulated UV- and RI-GPC traces at 15\% monomer conversion (400 s). (c) Simulated UV- and RI-GPC traces at 40\% monomer conversion (900 s). (d) Simulated UV- and RI-GPC traces at 70\% monomer conversion (1800 s). 
a)

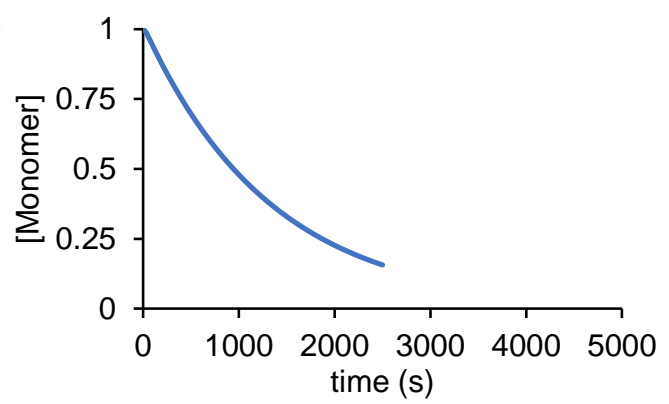

b)

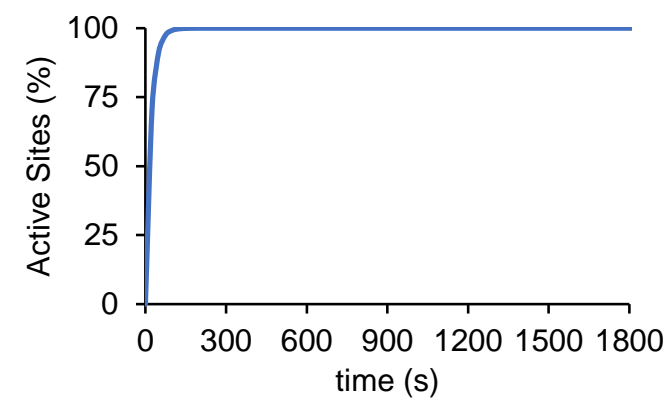

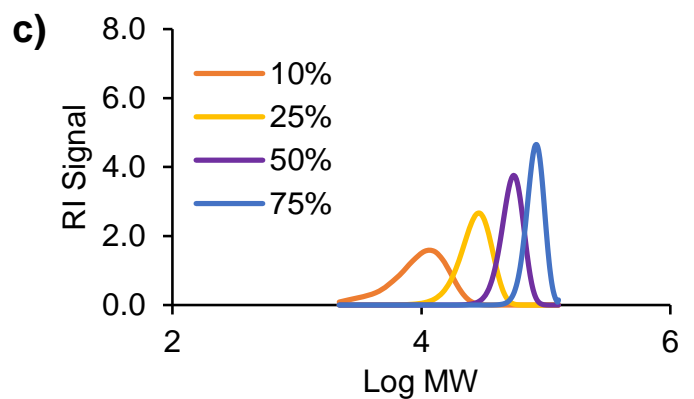

Figure S10. Data from the simulation of a polymerization reaction where initiation is slow, relative to propagation. The conditions for this simulation are as follows: $k_{i}=0.05 \mathrm{M}^{-1} \mathrm{~s}^{-1}, \mathrm{k}_{\mathrm{p}}=1.0 \mathrm{M}^{-1} \mathrm{~s}^{-1}$, [cat $]_{0}=0.75 \mathrm{mM}$, and [monomer] $]_{0}=1.0 \mathrm{M}$. (a) Temporal profile of monomer consumption. (b) Temporal profile of the percentage of active catalyst during polymerization. (c) Simulated RItraces at varying conversion of monomer (10\% conversion after $150 \mathrm{~s}, 25 \%$ conversion after 400 s, $50 \%$ conversion after $900 \mathrm{~s}$, and $75 \%$ conversion after $1800 \mathrm{~s}$ ). 
a)

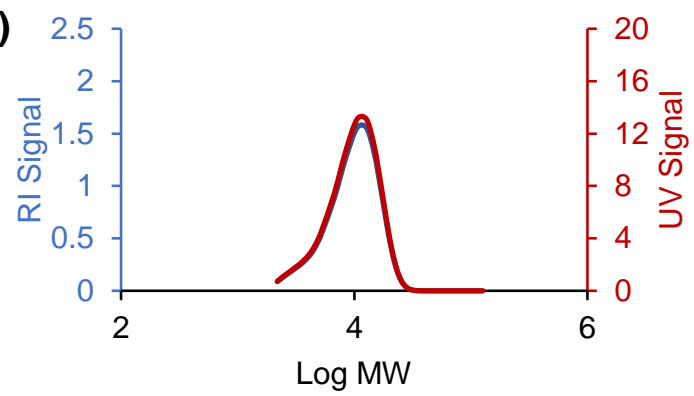

c)

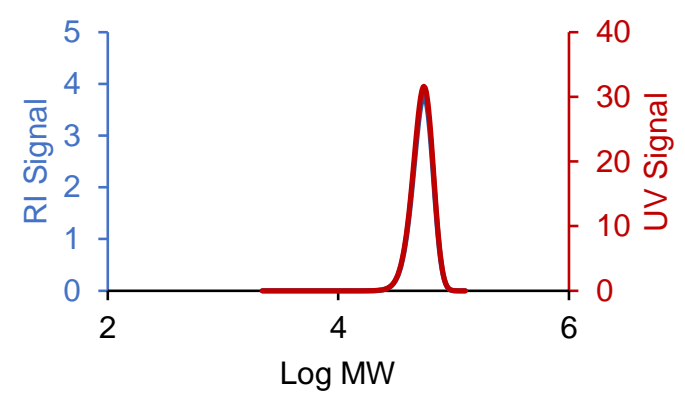

b)

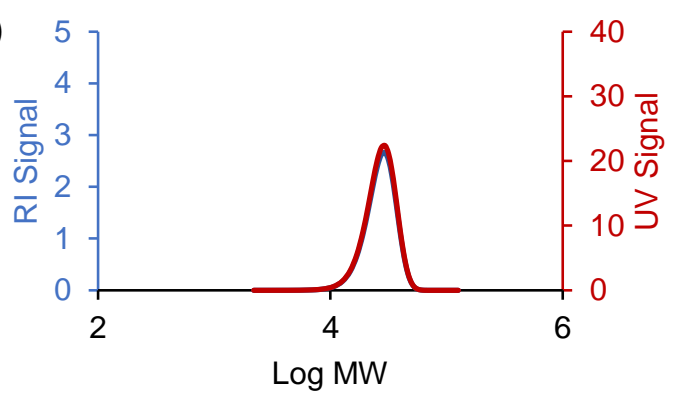

d)

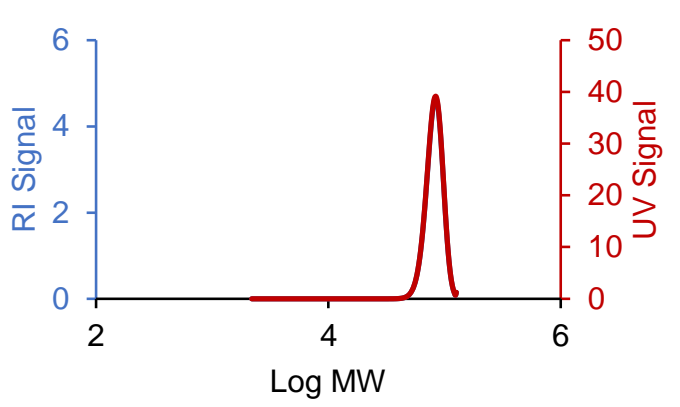

Figure S11. Data from the simulation of a polymerization reaction where initiation is slow, relative to propagation. The conditions for this simulation are as follows: $k_{i}=0.05 \mathrm{M}^{-1} \mathrm{~s}^{-1}, \mathrm{k}_{\mathrm{p}}=1.0 \mathrm{M}^{-1} \mathrm{~s}^{-1}$, $[\text { cat }]_{0}=0.75 \mathrm{mM}$, and [monomer $]_{0}=1.0 \mathrm{M}$. The UV signal is "mass scaled" for a more accurate comparison of the trace shape to the RI signal. For each simulated GPC trace, the UV signal is shown in red and the RI signal shown in blue. (a) Simulated UV- and RI-GPC traces at $10 \%$ monomer conversion (150 s). (b) Simulated UV- and RI-GPC traces at 25\% monomer conversion (400 s). (c) Simulated UV- and RI-GPC traces at 50\% monomer conversion (900 s). (d) Simulated UV- and RI-GPC traces at 75\% monomer conversion (1800 s).

\section{Kinetic simulation of polymerization reactions featuring B-hydride elimination}

In these kinetic simulations, polymerization reactions with slow rate constants for B-hydride elimination (relative to propagation) are considered. Chain transfer to a metal alkyl is not considered. To achieve this, the rate constants for $k_{\text {ex } 1}$ and $k_{\text {ex2 }}$ are set to 0 . The catalyst concentration is set to $0.75 \mathrm{mM}$, the monomer concentration is set to $1.0 \mathrm{M}, \mathrm{k}_{\mathrm{i}}$ is set to $1.0 \mathrm{M}^{-1} \mathrm{~s}^{-1}$, and $\mathrm{k}_{\mathrm{p}}$ is set to $1.0 \mathrm{M}^{-1} \mathrm{~s}^{-1}$. The results of these kinetic simulations are shown in Figures S12 S17. 
a)

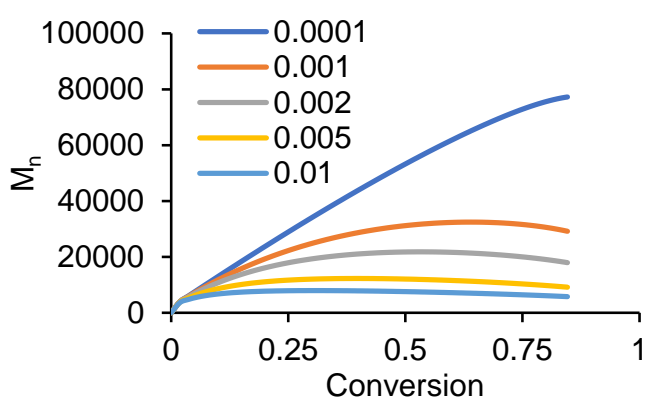

b)

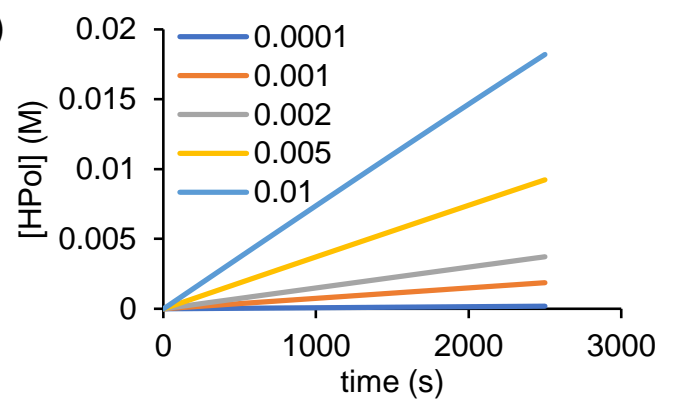

c)

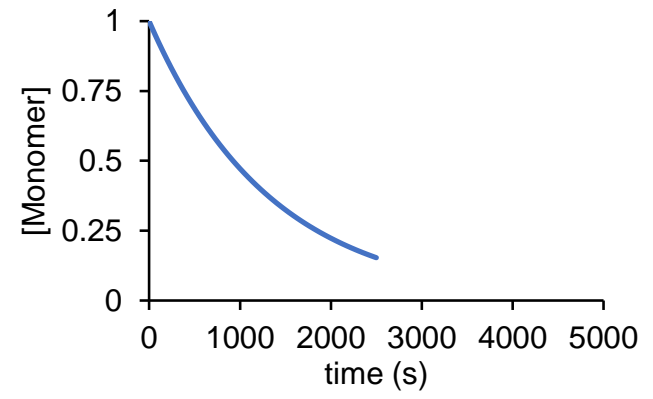

Figure S12. Data from simulations of polymerization reactions with slow rate constants for Bhydride elimination. The conditions for this simulation are as follows: $k_{i}=1.0 \mathrm{M}^{-1} \mathrm{~s}^{-1}, \mathrm{k}_{\mathrm{p}}=1.0 \mathrm{M}^{-1} \mathrm{~s}^{-}$ 1 , $[\text { cat }]_{0}=0.75 \mathrm{mM}$, and [monomer] $]_{0}=1.0 \mathrm{M}$. The rate constants for B-hydride elimination $\left(\mathrm{k}_{\mathrm{H}}\right)$ used in these simulations are $0.0001 \mathrm{~s}^{-1}, 0.001 \mathrm{~s}^{-1}, 0.002 \mathrm{~s}^{-1}, 0.005 \mathrm{~s}^{-1}$, and $0.01 \mathrm{~s}^{-1}$. (a) The simulated $M_{n}$ vs monomer conversion for different rate constants of B-hydride elimination. (b) The temporal profile of simulated concentration of B-hydride eliminated polymers for different rate constants of B-hydride elimination. (c) The temporal profile of monomer consumption. 


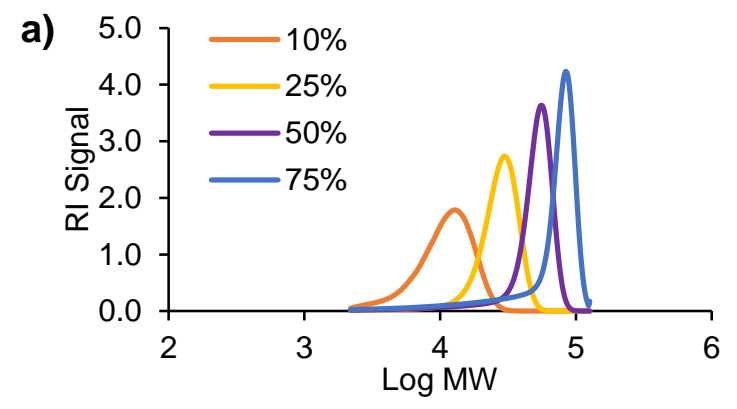

b)

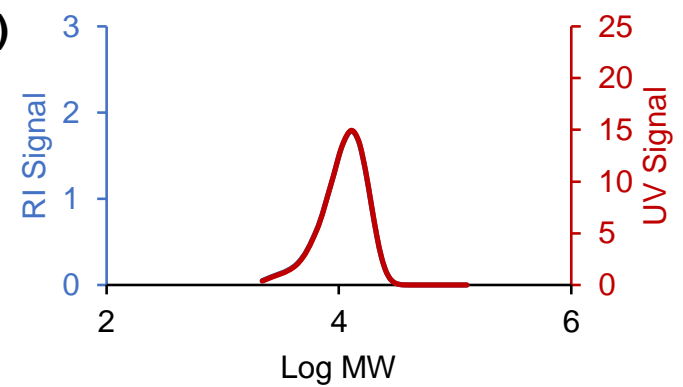

d)

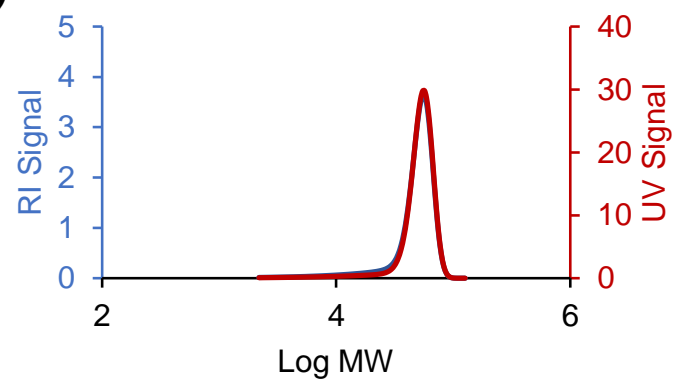

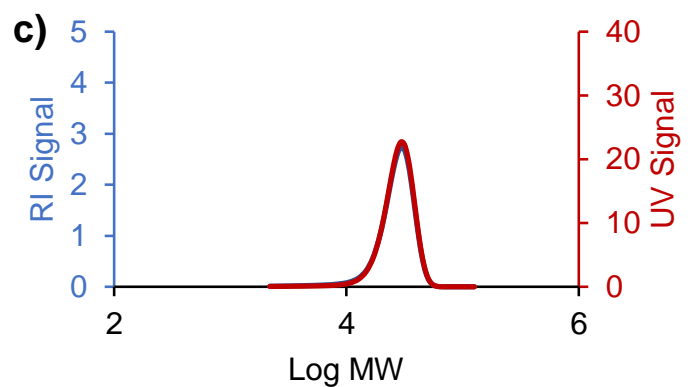

e)

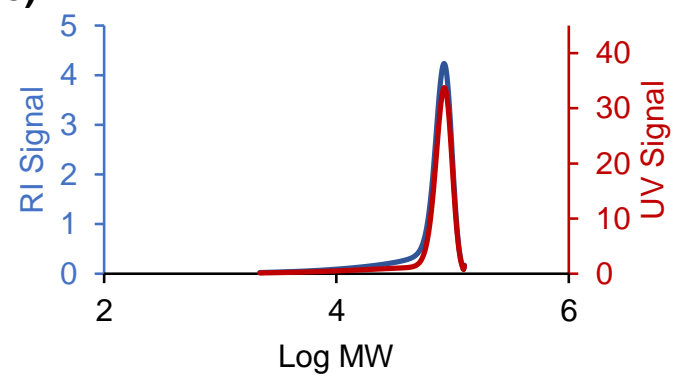

Figure S13. Data from the simulation of a polymerization reaction with a slow rate constant for $B$ hydride elimination $\left(\mathrm{k}_{\mathrm{H}}=0.0001 \mathrm{~s}^{-1}\right)$. The conditions for this simulation are as follows: $\mathrm{k}_{\mathrm{i}}=1.0 \mathrm{M}^{-}$ ${ }^{1} \mathrm{~s}^{-1}, \mathrm{k}_{\mathrm{p}}=1.0 \mathrm{M}^{-1} \mathrm{~s}^{-1}, \mathrm{k}_{\mathrm{H}}=0.0001 \mathrm{~s}^{-1}$, [cat $]_{0}=0.75 \mathrm{mM}$, and [monomer] $]_{0}=1.0 \mathrm{M}$. The UV signal is "mass scaled" for a more accurate comparison of the trace shape to the RI signal. For each simulated GPC trace, the UV signal is shown in red and the RI signal shown in blue. (a) Simulated RI-traces at varying conversion of monomer $(10 \%$ conversion after $150 \mathrm{~s}, 25 \%$ conversion after 400 s, $50 \%$ conversion after 900 s, and $75 \%$ conversion after 1800 s). (b) Simulated UV- and RIGPC traces at 10\% monomer conversion (150 s). (c) Simulated UV- and RI-GPC traces at $25 \%$ monomer conversion (400 s). (d) Simulated UV- and RI-GPC traces at 50\% monomer conversion (900 s). (e) Simulated UV- and RI-GPC traces at $75 \%$ monomer conversion (1800 s). 


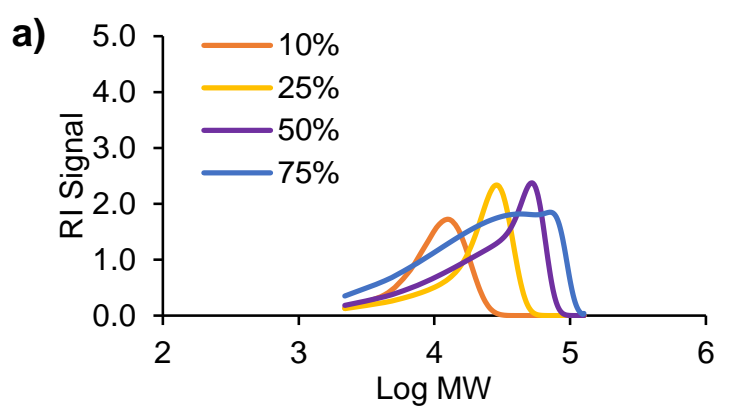

b)

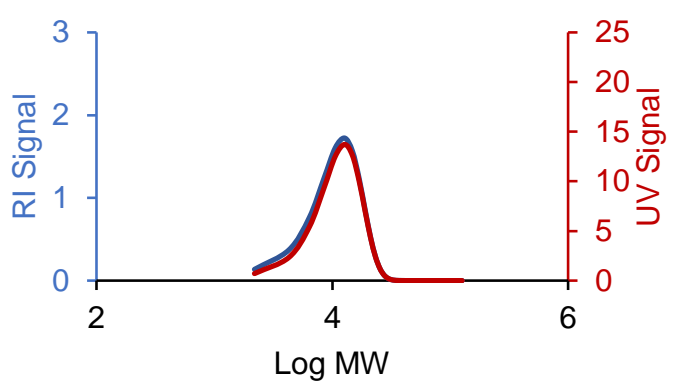

d)

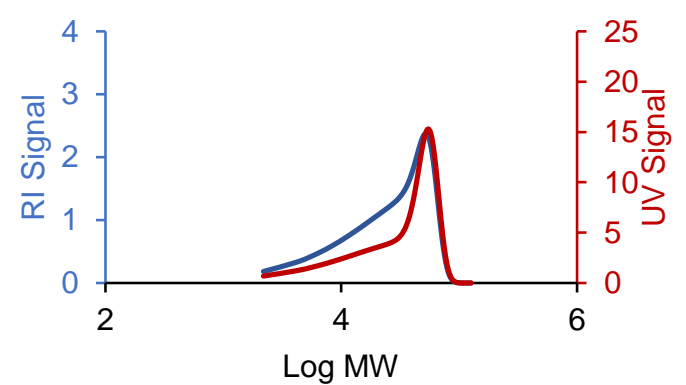

c)

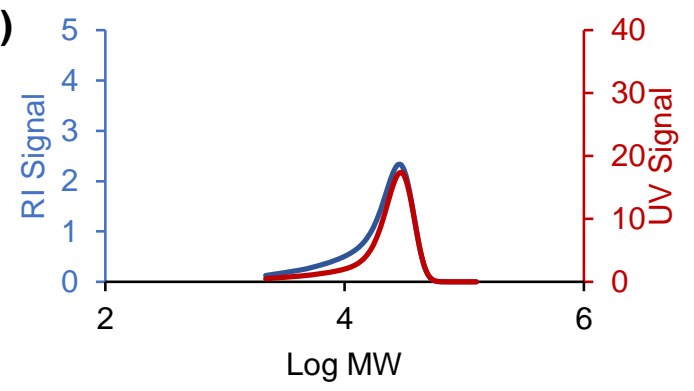

e)

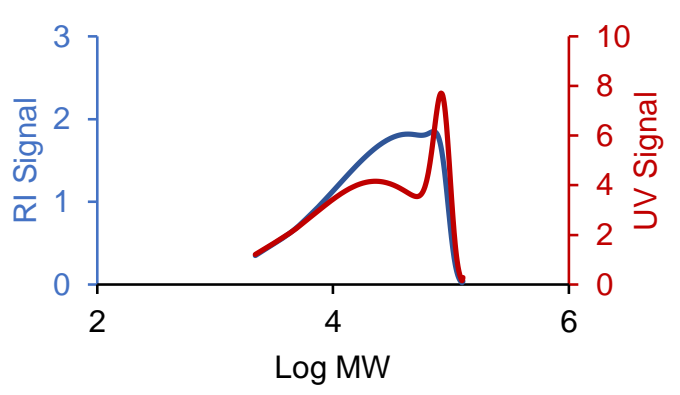

Figure S14. Data from the simulation of a polymerization reaction with a slow rate constant for $B-$ hydride elimination $\left(\mathrm{k}_{\mathrm{H}}=0.001 \mathrm{~s}^{-1}\right)$. The conditions for this simulation are as follows: $\mathrm{k}_{\mathrm{i}}=1.0 \mathrm{M}^{-1} \mathrm{~s}^{-}$ ${ }^{1}, \mathrm{k}_{\mathrm{p}}=1.0 \mathrm{M}^{-1} \mathrm{~s}^{-1}, \mathrm{k}_{\mathrm{H}}=0.001 \mathrm{~s}^{-1}$, [cat] $0=0.75 \mathrm{mM}$, and [monomer] $]_{0}=1.0 \mathrm{M}$. The UV signal is "mass scaled" for a more accurate comparison of the trace shape to the RI signal. For each simulated GPC trace, the UV signal is shown in red and the RI signal shown in blue. (a) Simulated RI-traces at varying conversion of monomer (10\% conversion after 150 s, $25 \%$ conversion after 400 s, $50 \%$ conversion after $900 \mathrm{~s}$, and $75 \%$ conversion after $1800 \mathrm{~s}$ ). (b) Simulated UV- and RI-GPC traces at $10 \%$ monomer conversion (150 s). (c) Simulated UV- and RI-GPC traces at $25 \%$ monomer conversion (400 s). (d) Simulated UV- and RI-GPC traces at 50\% monomer conversion (900 s). (e) Simulated UV- and RI-GPC traces at 75\% monomer conversion (1800 s). 


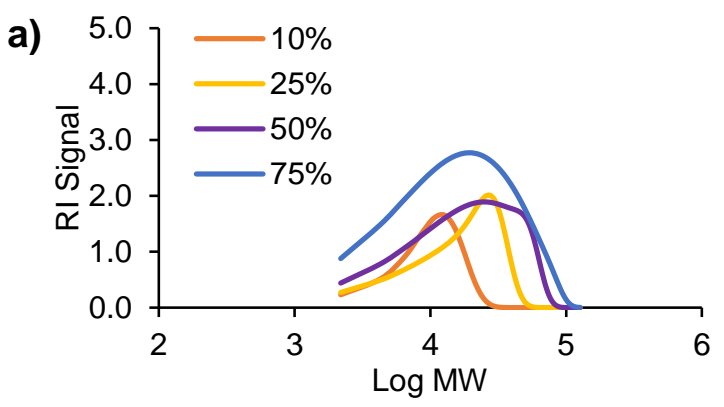

b)

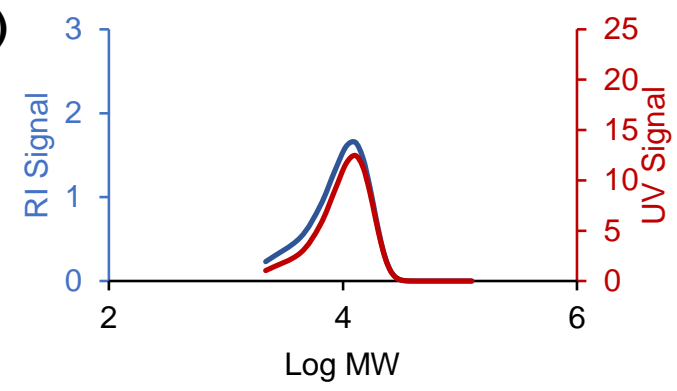

d)

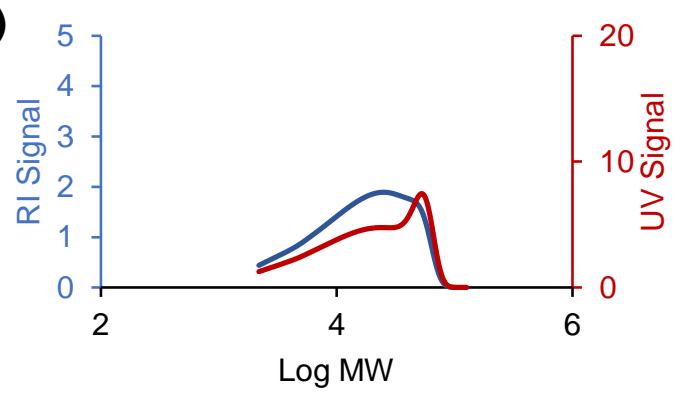

c)

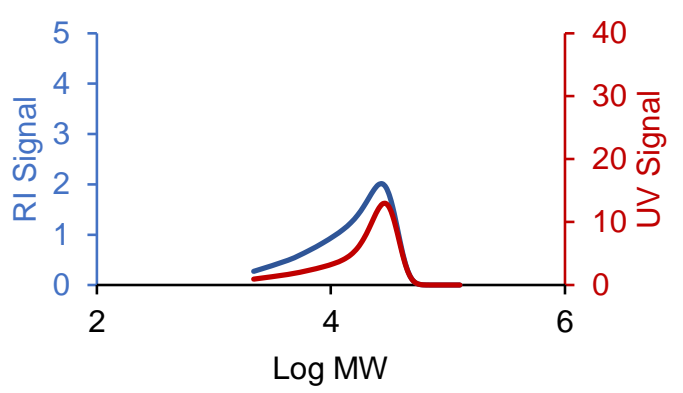

e)

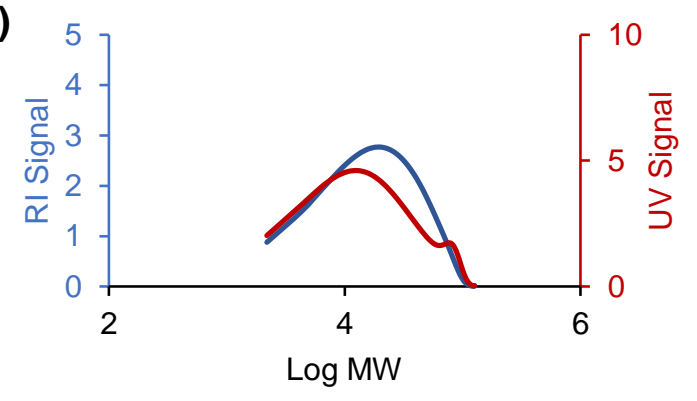

Figure S15. Data from the simulation of a polymerization reaction with a slow rate constant for $B-$ hydride elimination $\left(\mathrm{k}_{\mathrm{H}}=0.002 \mathrm{~s}^{-1}\right)$. The conditions for this simulation are as follows: $\mathrm{k}_{\mathrm{i}}=1.0 \mathrm{M}^{-1} \mathrm{~s}^{-}$ ${ }^{1}, \mathrm{k}_{\mathrm{p}}=1.0 \mathrm{M}^{-1} \mathrm{~s}^{-1}, \mathrm{k}_{\mathrm{H}}=0.002 \mathrm{~s}^{-1}$, [cat $]_{0}=0.75 \mathrm{mM}$, and [monomer] $0=1.0 \mathrm{M}$. The UV signal is "mass scaled" for a more accurate comparison of the trace shape to the RI signal. For each simulated GPC trace, the UV signal is shown in red and the RI signal shown in blue. (a) Simulated RI-traces at varying conversion of monomer (10\% conversion after $150 \mathrm{~s}, 25 \%$ conversion after $400 \mathrm{~s}, 50 \%$ conversion after $900 \mathrm{~s}$, and $75 \%$ conversion after $1800 \mathrm{~s}$ ). (b) Simulated UV- and RI-GPC traces at $10 \%$ monomer conversion (150 s). (c) Simulated UV- and RI-GPC traces at $25 \%$ monomer conversion (400 s). (d) Simulated UV- and RI-GPC traces at 50\% monomer conversion (900 s). (e) Simulated UV- and RI-GPC traces at 75\% monomer conversion (1800 s). 


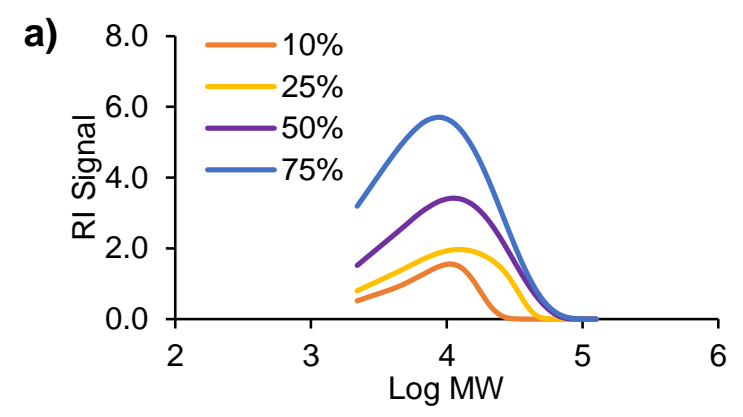

b)

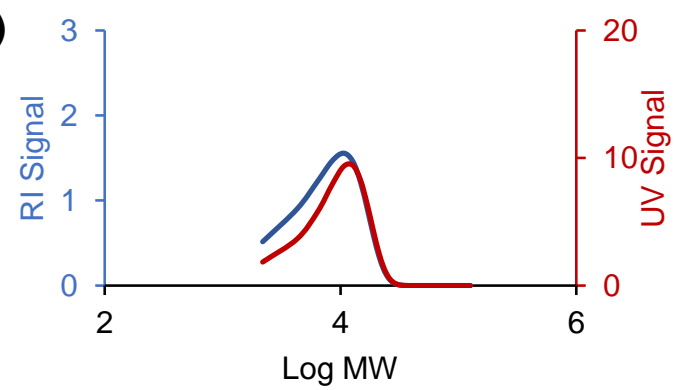

d)

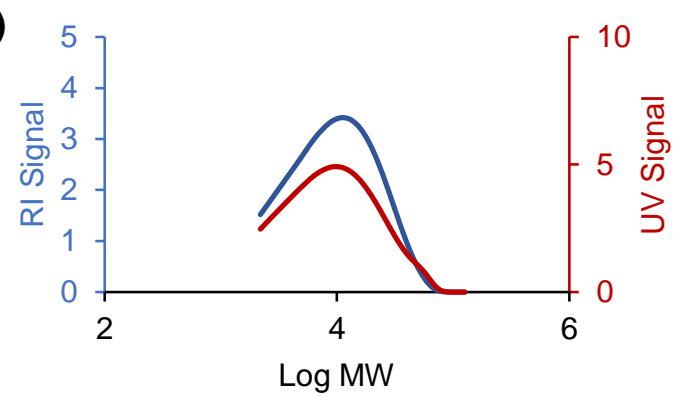

c)

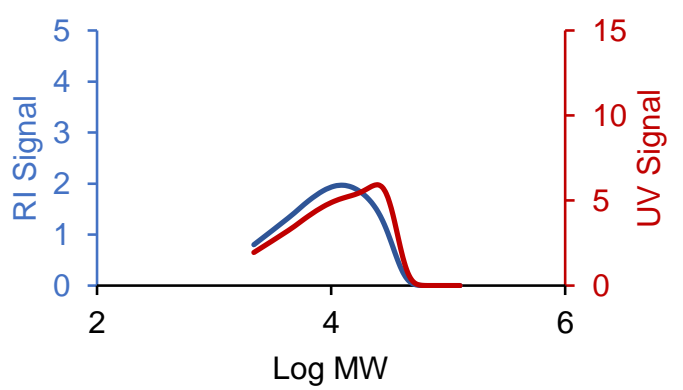

e)

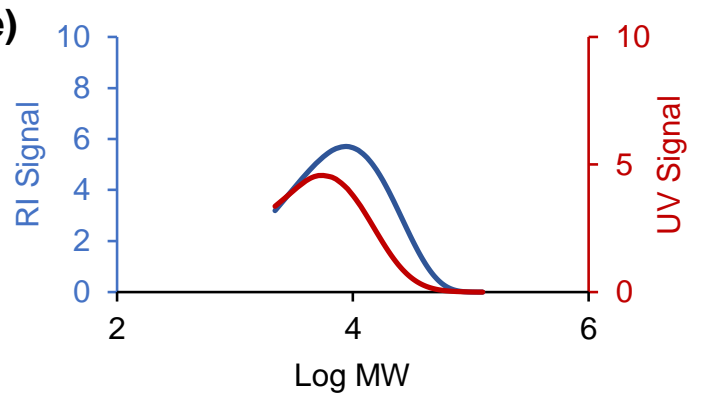

Figure S16. Data from the simulation of a polymerization reaction with a slow rate constant for $B$ hydride elimination $\left(\mathrm{k}_{\mathrm{H}}=0.005 \mathrm{~s}^{-1}\right)$. The conditions for this simulation are as follows: $\mathrm{k}_{\mathrm{i}}=1.0 \mathrm{M}^{-1} \mathrm{~s}^{-}$ ${ }^{1}, \mathrm{k}_{\mathrm{p}}=1.0 \mathrm{M}^{-1} \mathrm{~s}^{-1}, \mathrm{k}_{\mathrm{H}}=0.005 \mathrm{~s}^{-1}$, [cat $]_{0}=0.75 \mathrm{mM}$, and [monomer] $0=1.0 \mathrm{M}$. The UV signal is "mass scaled" for a more accurate comparison of the trace shape to the RI signal. For each simulated GPC trace, the UV signal is shown in red and the RI signal shown in blue. (a) Simulated RI-traces at varying conversion of monomer (10\% conversion after $150 \mathrm{~s}, 25 \%$ conversion after $400 \mathrm{~s}, 50 \%$ conversion after $900 \mathrm{~s}$, and 75\% conversion after $1800 \mathrm{~s}$ ). (b) Simulated UV- and RI-GPC traces at $10 \%$ monomer conversion (150 s). (c) Simulated UV- and RI-GPC traces at $25 \%$ monomer conversion (400 s). (d) Simulated UV- and RI-GPC traces at 50\% monomer conversion (900 s). (e) Simulated UV- and RI-GPC traces at 75\% monomer conversion (1800 s). 


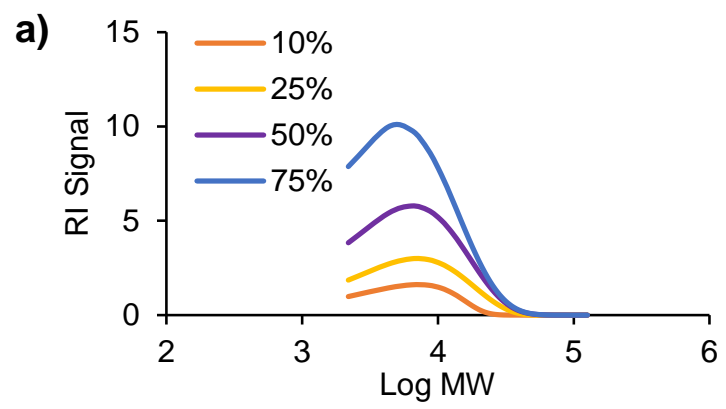

b)

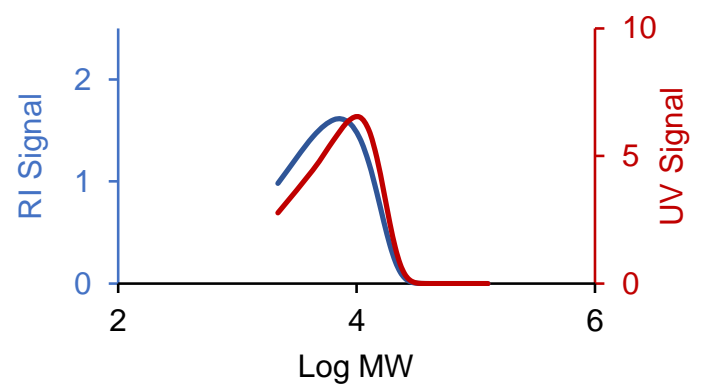

d)

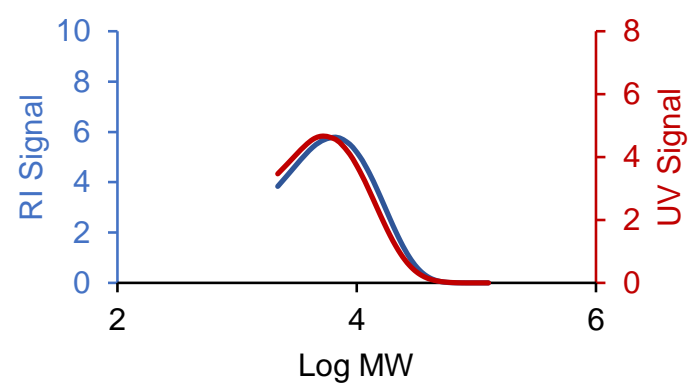

c)

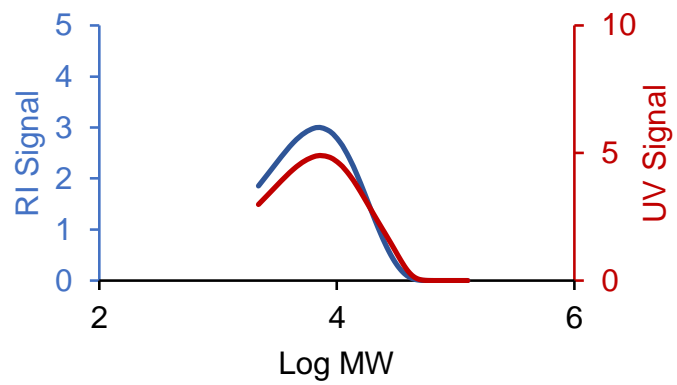

e)

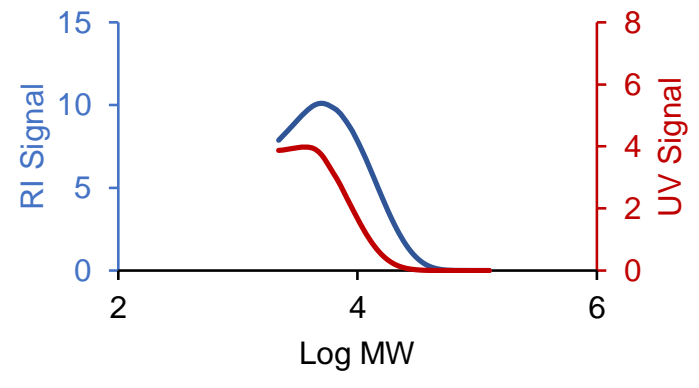

Figure S17. Data from the simulation of a polymerization reaction with a slow rate constant for $B-$ hydride elimination $\left(\mathrm{k}_{\mathrm{H}}=0.01 \mathrm{~s}^{-1}\right)$. The conditions for this simulation are as follows: $\mathrm{k}_{\mathrm{i}}=1.0 \mathrm{M}^{-1} \mathrm{~s}^{-}$ ${ }^{1}, \mathrm{k}_{\mathrm{p}}=1.0 \mathrm{M}^{-1} \mathrm{~s}^{-1}, \mathrm{k}_{\mathrm{H}}=0.01 \mathrm{~s}^{-1}$, [cat] $0=0.75 \mathrm{mM}$, and [monomer] $0=1.0 \mathrm{M}$. The UV signal is "mass scaled" for a more accurate comparison of the trace shape to the RI signal. For each simulated GPC trace, the UV signal is shown in red and the RI signal shown in blue. (a) Simulated RI-traces at varying conversion of monomer (10\% conversion after $150 \mathrm{~s}, 25 \%$ conversion after $400 \mathrm{~s}, 50 \%$ conversion after $900 \mathrm{~s}$, and 75\% conversion after $1800 \mathrm{~s}$ ). (b) Simulated UV- and RI-GPC traces at $10 \%$ monomer conversion (150 s). (c) Simulated UV- and RI-GPC traces at 25\% monomer conversion (400 s). (d) Simulated UV- and RI-GPC traces at 50\% monomer conversion (900 s). (e) Simulated UV- and RI-GPC traces at 75\% monomer conversion (1800 s). 


\section{Kinetic simulation of polymerization reactions featuring irreversible chain transfer}

In these kinetic simulations, polymerization reactions with irreversible chain transfer to a metalalkyl are considered. To achieve this, the rate constant for $k_{\text {ex2 }}$ is set to 0 and $k_{\text {ex }}$ is varied. Bhydride elimination is not considered in these simulations $\left(\mathrm{k}_{\mathrm{H}}=0\right)$. The catalyst concentration is set to $0.75 \mathrm{mM}$, the monomer concentration is set to $1.0 \mathrm{M}$, the chain transfer agent $\left(\mathrm{ZnEt}_{2}\right)$ concentration is set to $1.0 \mathrm{mM}, \mathrm{k}_{\mathrm{i}}$ is set to $1.0 \mathrm{M}^{-1} \mathrm{~s}^{-1}$, and $\mathrm{k}_{\mathrm{p}}$ is set to $1.0 \mathrm{M}^{-1} \mathrm{~s}^{-1}$. The $\mathrm{k}_{\mathrm{ex}}$ values used throughout these simulations are $1.0 \mathrm{M}^{-1} \mathrm{~s}^{-1}, 4.0 \mathrm{M}^{-1} \mathrm{~s}^{-1}, 8.0 \mathrm{M}^{-1} \mathrm{~s}^{-1}$, and $12 \mathrm{M}^{-1} \mathrm{~s}^{-1}$. The results of these kinetic simulations are shown in Figures S18 - S21.

a)

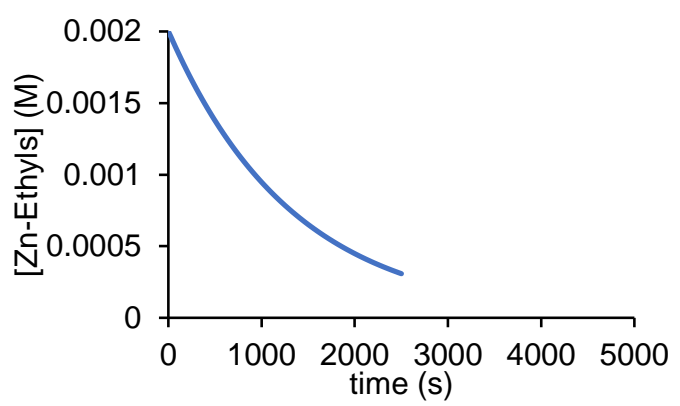

c)

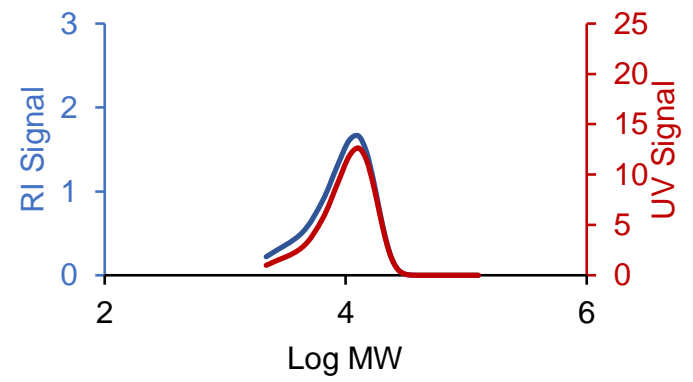

e)

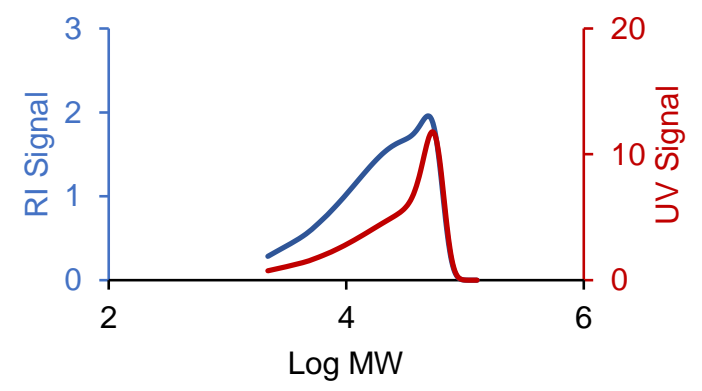

b)

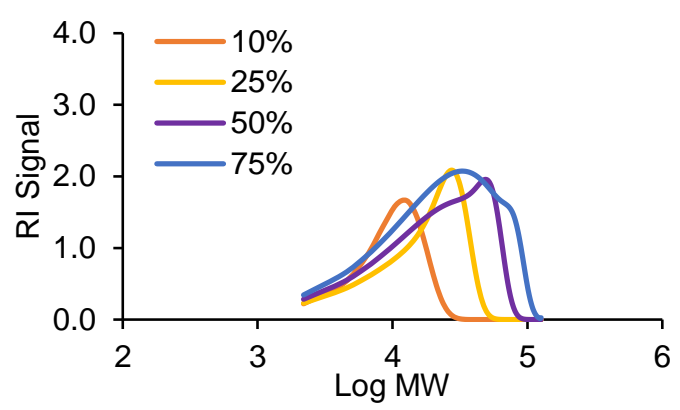

d)

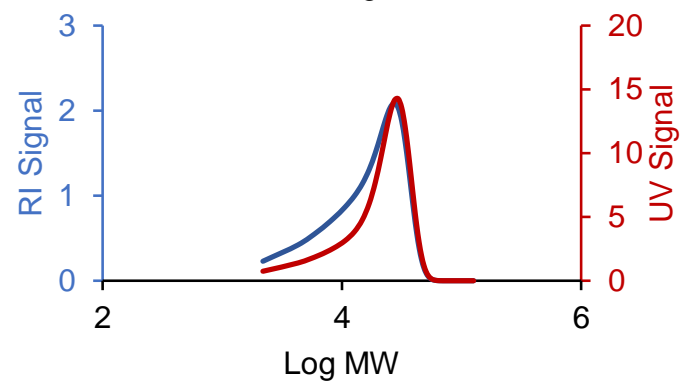

f)

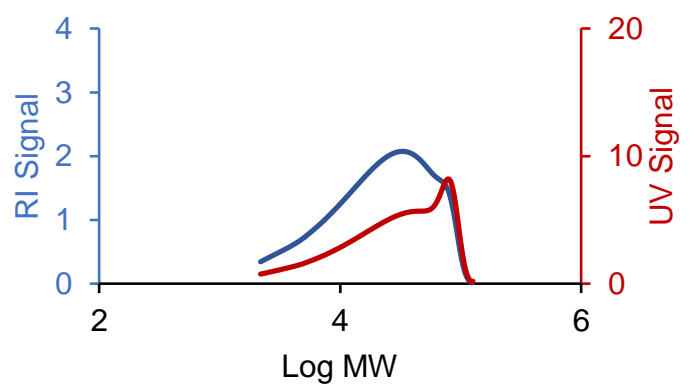

Figure S18. Data from the simulation of a polymerization reaction with irreversible chain transfer $\left(k_{\text {ex1 }}=1.0 \mathrm{M}^{-1} \mathrm{~s}^{-1}\right)$. The conditions for this simulation are as follows: $k_{i}=1.0 \mathrm{M}^{-1} \mathrm{~s}^{-1}, \mathrm{k}_{\mathrm{p}}=1.0 \mathrm{M}^{-1} \mathrm{~s}^{-1}$, $[\text { cat }]_{0}=0.75 \mathrm{mM}$, and [monomer] $]_{0}=1.0 \mathrm{M}$. The UV signal is "mass scaled" for a more accurate comparison of the trace shape to the RI signal. For each simulated GPC trace, the UV signal is shown in red and the RI signal shown in blue. (a) Temporal profile of conversion of $\mathrm{Zn}$-ethyls to Zn-polymeryls. (b) Simulated RI-traces at varying conversion of monomer (10\% conversion after 150 s, $25 \%$ conversion after 400 s, $50 \%$ conversion after 900 s, and $75 \%$ conversion after 1800 s). (c) Simulated UV- and RI-GPC traces at $10 \%$ monomer conversion (150 s). (d) Simulated UVand RI-GPC traces at $25 \%$ monomer conversion (400 s). (e) Simulated UV- and RI-GPC traces at $50 \%$ monomer conversion $(900 \mathrm{~s})$. (f) Simulated UV- and RI-GPC traces at $75 \%$ monomer conversion (1800 s). 
a)

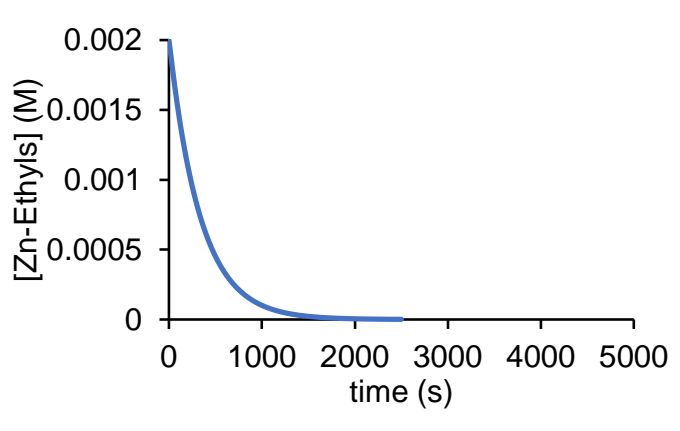

c)

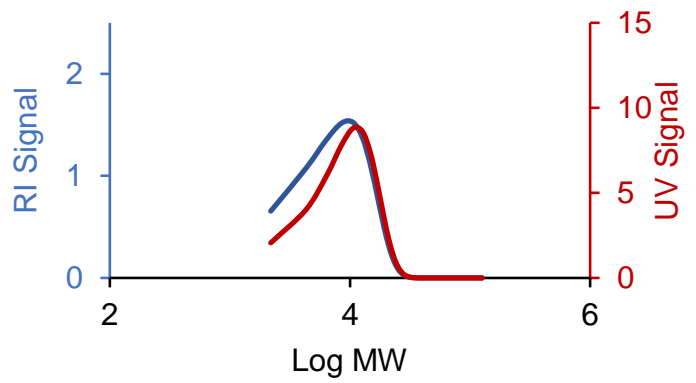

e)

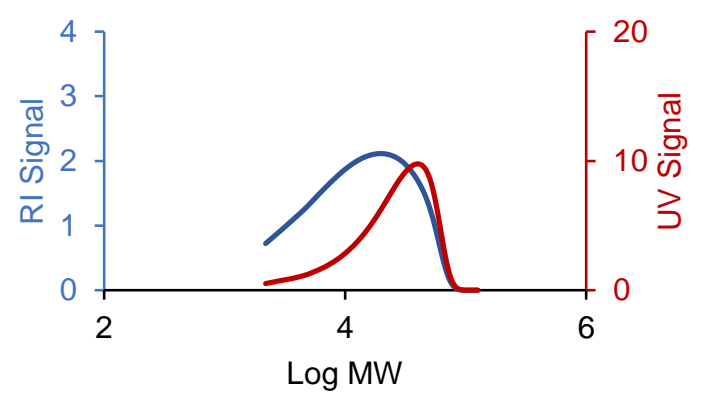

b)

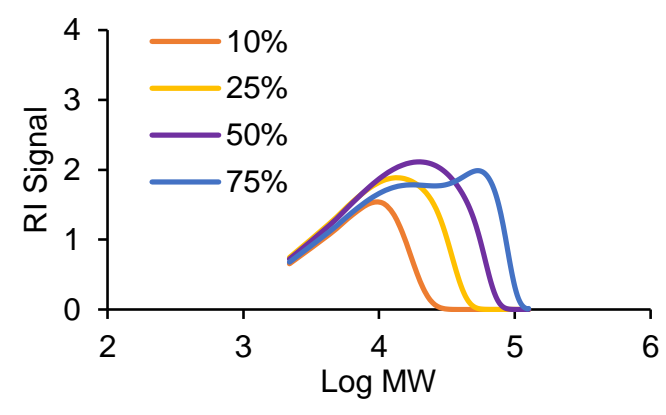

d)

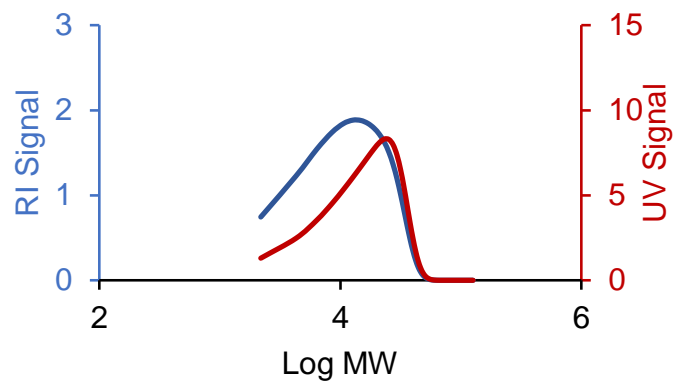

f)

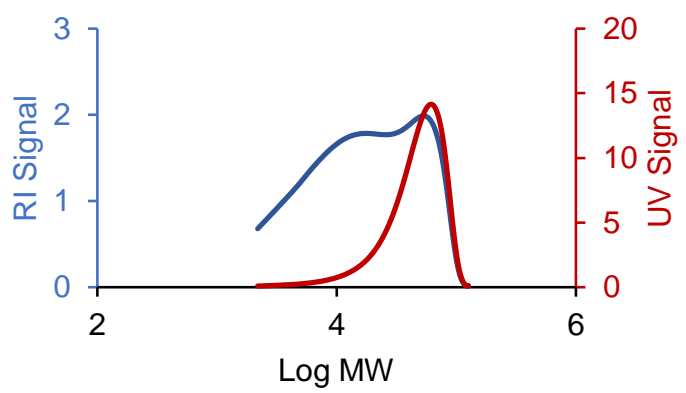

Figure S19. Data from the simulation of a polymerization reaction with irreversible chain transfer $\left(k_{e x 1}=4.0 \mathrm{M}^{-1} \mathrm{~s}^{-1}\right)$. The conditions for this simulation are as follows: $\mathrm{k}_{\mathrm{i}}=1.0 \mathrm{M}^{-1} \mathrm{~s}^{-1}, \mathrm{k}_{\mathrm{p}}=1.0 \mathrm{M}^{-1} \mathrm{~s}^{-1}$, [cat] $]_{0}=0.75 \mathrm{mM}$, and [monomer] $0=1.0 \mathrm{M}$. The UV signal is "mass scaled" for a more accurate comparison of the trace shape to the RI signal. For each simulated GPC trace, the UV signal is shown in red and the RI signal shown in blue. (a) Temporal profile of conversion of Zn-ethyls to Zn-polymeryls. (b) Simulated RI-traces at varying conversion of monomer (10\% conversion after 150 s, $25 \%$ conversion after 400 s, $50 \%$ conversion after 900 s, and $75 \%$ conversion after 1800 s). (c) Simulated UV- and RI-GPC traces at 10\% monomer conversion (150 s). (d) Simulated UVand RI-GPC traces at 25\% monomer conversion (400 s). (e) Simulated UV- and RI-GPC traces at $50 \%$ monomer conversion $(900 \mathrm{~s}$ ). (f) Simulated UV- and RI-GPC traces at $75 \%$ monomer conversion (1800 s). 
a)

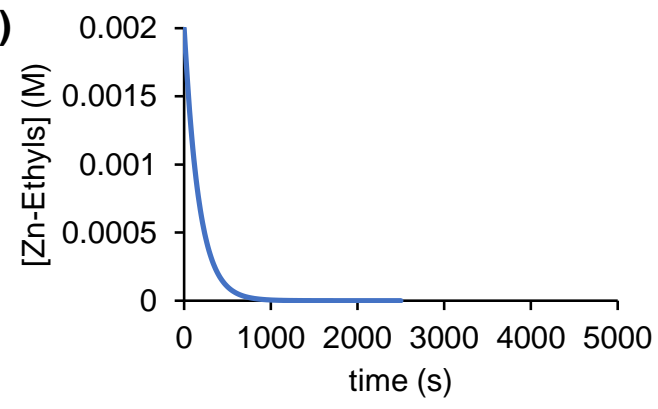

c)

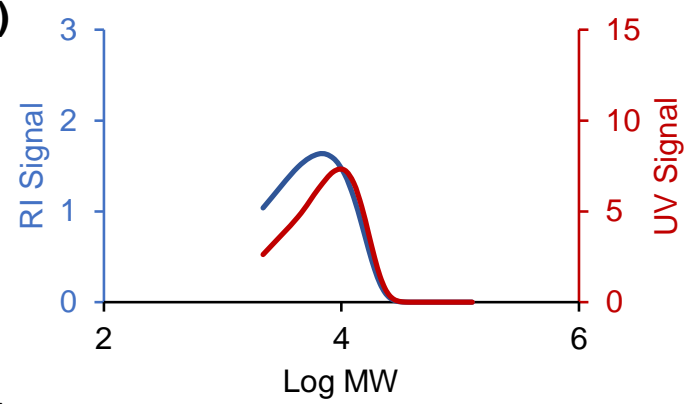

e)

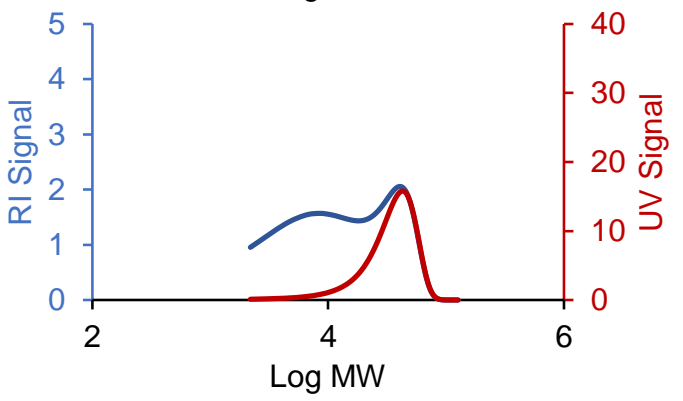

b) $5.0-10 \%$

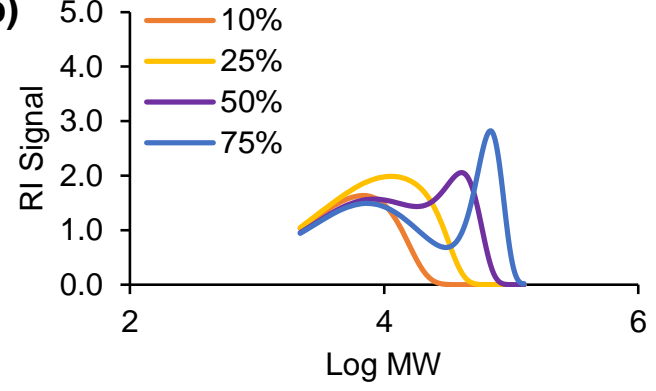

d)

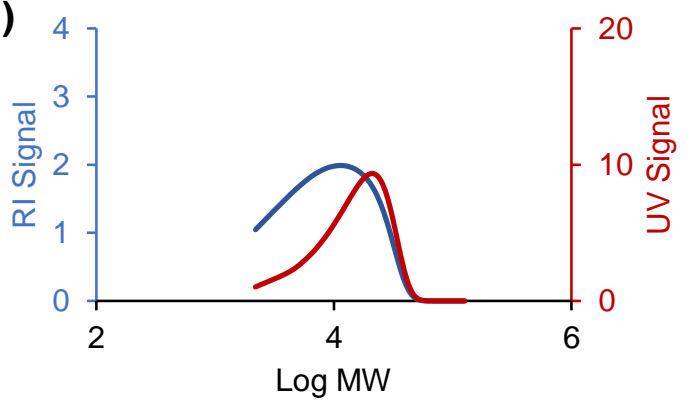

f)

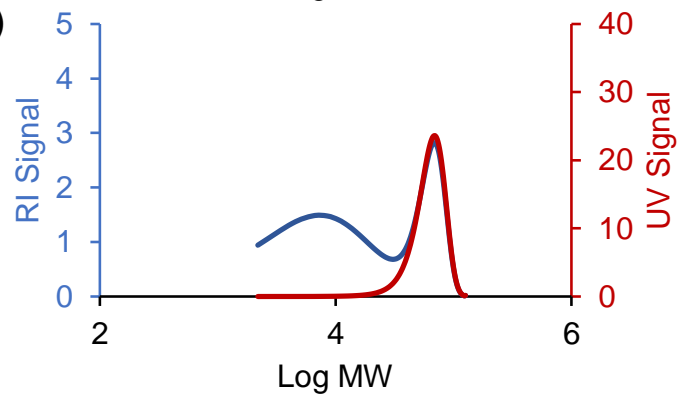

Figure S20. Data from the simulation of a polymerization reaction with irreversible chain transfer $\left(k_{\text {ex1 }}=8.0 \mathrm{M}^{-1} \mathrm{~s}^{-1}\right)$. The conditions for this simulation are as follows: $k_{i}=1.0 \mathrm{M}^{-1} \mathrm{~s}^{-1}, \mathrm{k}_{\mathrm{p}}=1.0 \mathrm{M}^{-1} \mathrm{~s}^{-1}$, $[\text { cat }]_{0}=0.75 \mathrm{mM}$, and [monomer] $]_{0}=1.0 \mathrm{M}$. The UV signal is "mass scaled" for a more accurate comparison of the trace shape to the RI signal. For each simulated GPC trace, the UV signal is shown in red and the RI signal shown in blue. (a) Temporal profile of conversion of $\mathrm{Zn}$-ethyls to Zn-polymeryls. (b) Simulated Rl-traces at varying conversion of monomer (10\% conversion after 150 s, $25 \%$ conversion after 400 s, $50 \%$ conversion after 900 s, and $75 \%$ conversion after 1800 s). (c) Simulated UV- and RI-GPC traces at $10 \%$ monomer conversion (150 s). (d) Simulated UVand RI-GPC traces at $25 \%$ monomer conversion (400 s). (e) Simulated UV- and RI-GPC traces at $50 \%$ monomer conversion $(900 \mathrm{~s})$. (f) Simulated UV- and RI-GPC traces at $75 \%$ monomer conversion (1800 s). 
a)

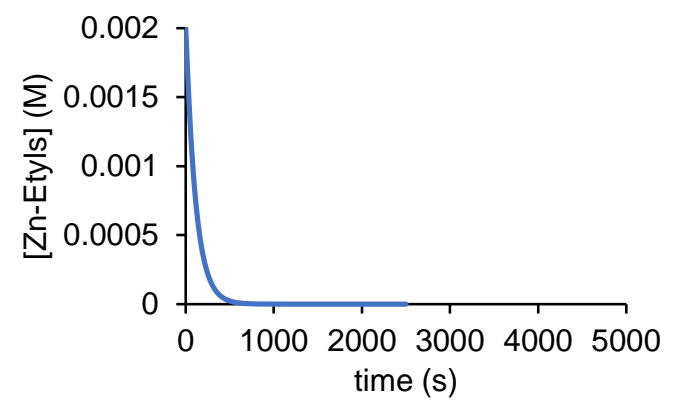

c)

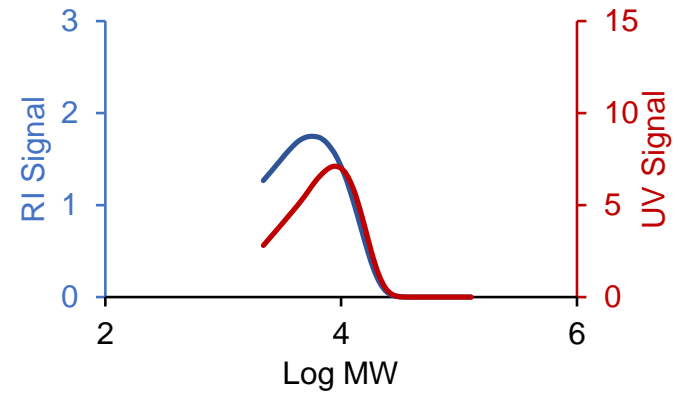

e)

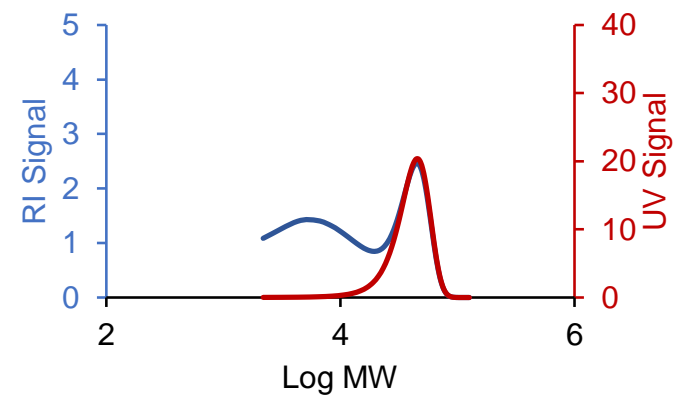

b)

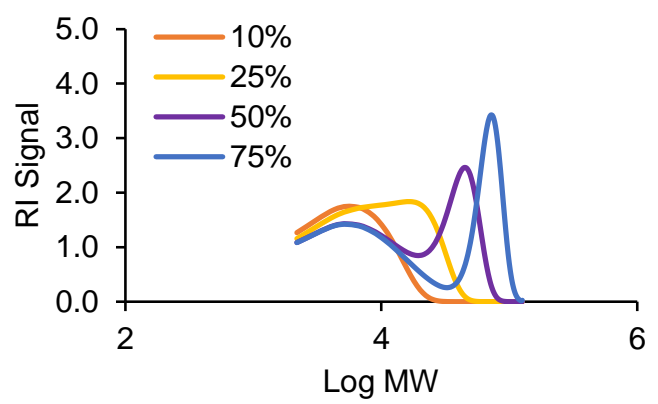

d)

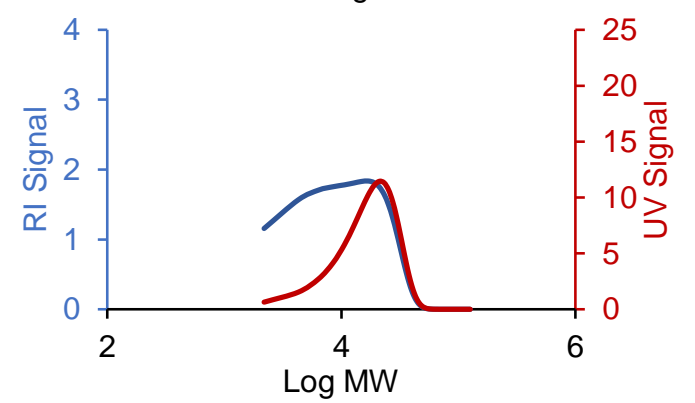

f)

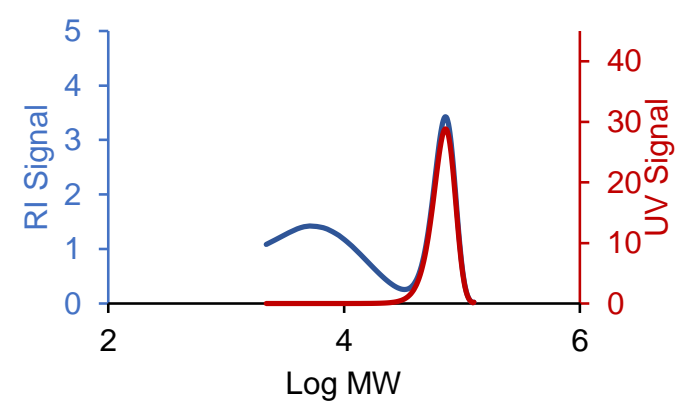

Figure S21. Data from the simulation of a polymerization reaction with irreversible chain transfer $\left(k_{e x 1}=12 \mathrm{M}^{-1} \mathrm{~s}^{-1}\right)$. The conditions for this simulation are as follows: $\mathrm{k}_{\mathrm{i}}=1.0 \mathrm{M}^{-1} \mathrm{~s}^{-1}, \mathrm{k}_{\mathrm{p}}=1.0 \mathrm{M}^{-1} \mathrm{~s}^{-1}$, [cat $]_{0}=0.75 \mathrm{mM}$, and [monomer $]_{0}=1.0 \mathrm{M}$. The UV signal is "mass scaled" for a more accurate comparison of the trace shape to the RI signal. For each simulated GPC trace, the UV signal is shown in red and the RI signal shown in blue. (a) Temporal profile of conversion of Zn-ethyls to Zn-polymeryls. (b) Simulated RI-traces at varying conversion of monomer (10\% conversion after 150 s, $25 \%$ conversion after 400 s, $50 \%$ conversion after 900 s, and $75 \%$ conversion after 1800 s). (c) Simulated UV- and RI-GPC traces at 10\% monomer conversion (150 s). (d) Simulated UVand RI-GPC traces at 25\% monomer conversion (400 s). (e) Simulated UV- and RI-GPC traces at $50 \%$ monomer conversion (900 s). (f) Simulated UV- and RI-GPC traces at $75 \%$ monomer conversion (1800 s). 


\section{Kinetic simulation of polymerization reactions featuring reversible chain transfer where $k_{\text {ex } 1}=k_{\text {ex2 }}$}

In these kinetic simulations, polymerization reactions with reversible chain transfer to a metalalkyl are considered. To achieve this, the rate constant for $k_{e x 2}$ and $k_{e x 1}$ are varied, but $k_{\text {ex } 1}=k_{\text {ex2 }}$. B-hydride elimination is not considered in these simulations $\left(\mathrm{k}_{\mathrm{H}}=0\right)$. The catalyst concentration is set to $0.75 \mathrm{mM}$, the monomer concentration is set to $1.0 \mathrm{M}$, the chain transfer agent $\left(\mathrm{ZnEt}_{2}\right)$ concentration is set to $1.0 \mathrm{mM}, \mathrm{k}_{\mathrm{i}}$ is set to $1.0 \mathrm{M}^{-1} \mathrm{~s}^{-1}$, and $\mathrm{k}_{\mathrm{p}}$ is set to $1.0 \mathrm{M}^{-1} \mathrm{~s}^{-1}$. The results of these kinetic simulations are shown in Figures S22 - S28.

a)

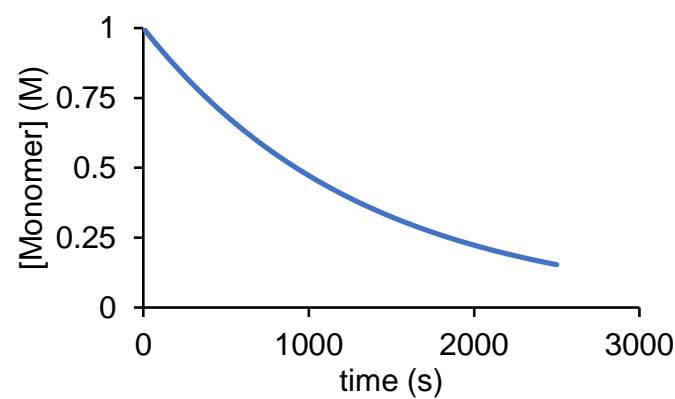

c)

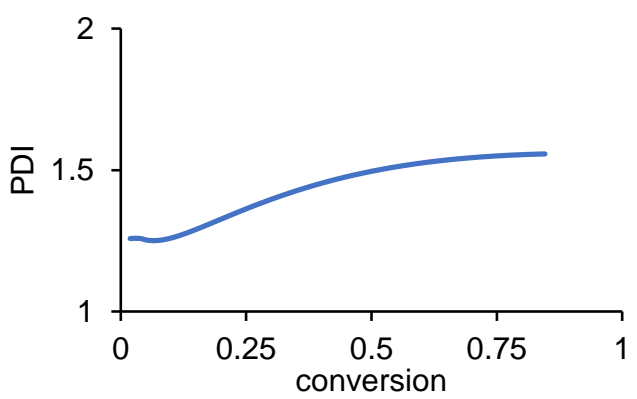

b)

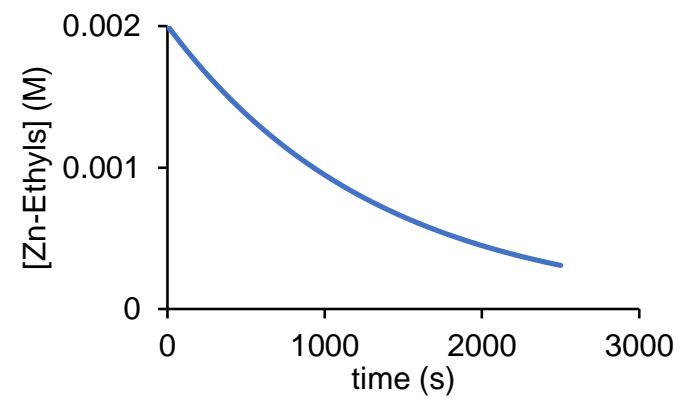

d)

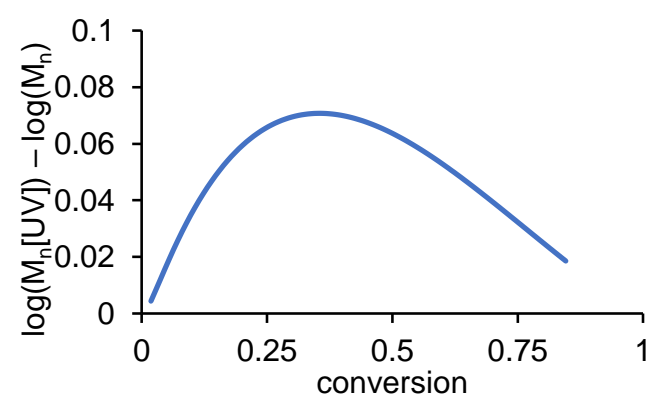

Figure S22. Data from the simulation of a polymerization reaction with reversible chain transfer $\left(k_{\mathrm{ex} 1}=\mathrm{k}_{\mathrm{ex} 2}=1.0 \mathrm{M}^{-1} \mathrm{~s}^{-1}\right)$. The conditions for this simulation are as follows: $\mathrm{k}_{\mathrm{i}}=1.0 \mathrm{M}^{-1} \mathrm{~s}^{-1}, \mathrm{k}_{\mathrm{p}}=1.0$ $\mathrm{M}^{-1} \mathrm{~s}^{-1}$, [cat $]_{0}=0.75 \mathrm{mM}$, and [monomer $]_{0}=1.0 \mathrm{M}$. (a) Temporal profile of the simulated conversion of monomer. (b) Temporal profile of the simulated conversion of $\mathrm{Zn}$-ethyls to $\mathrm{Zn}$-polymeryls. (c) Simulated PDI vs conversion of monomer (e) The simulated difference in the $\log \left(M_{n}\right)$ of the UVand RI-signals (catalyst-polymeryls and all polymeryls, respectively) plotted vs conversion of monomer. 


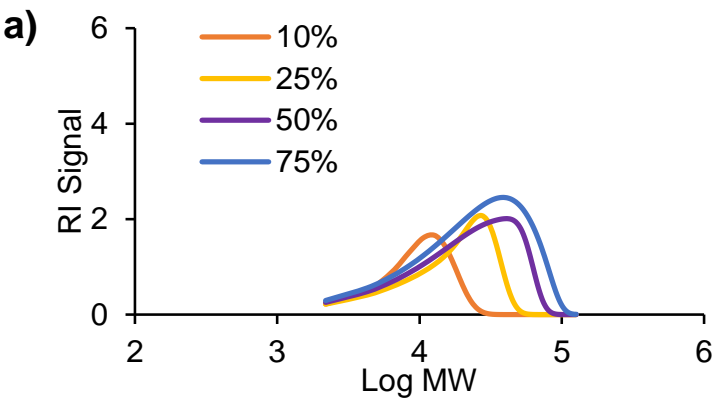

b)

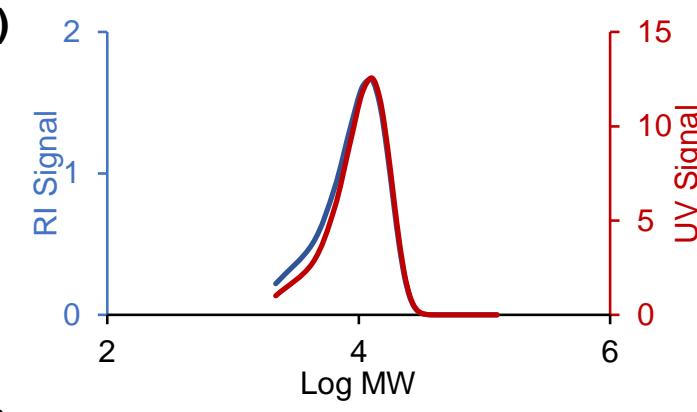

d)

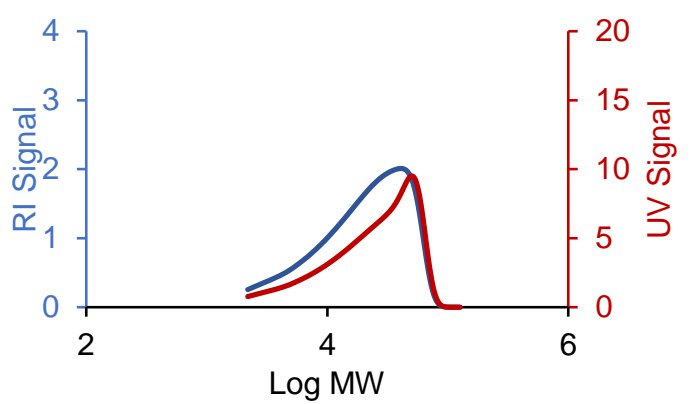

c)

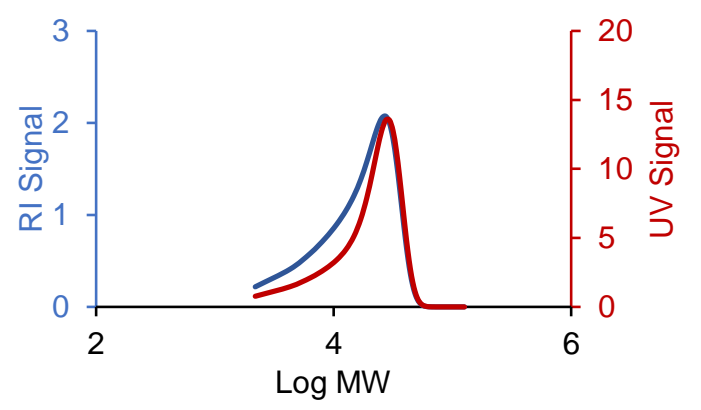

e)

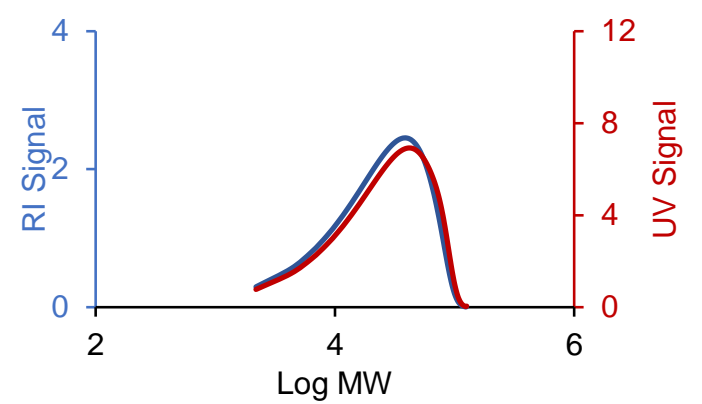

Figure S23. Data from the simulation of a polymerization reaction with reversible chain transfer $\left(k_{\text {ex1 }}=k_{\text {ex2 }}=1.0 \mathrm{M}^{-1} \mathrm{~s}^{-1}\right)$. The conditions for this simulation are as follows: $k_{i}=1.0 \mathrm{M}^{-1} \mathrm{~s}^{-1}, \mathrm{k}_{\mathrm{p}}=1.0$ $\mathrm{M}^{-1} \mathrm{~s}^{-1}$, [cat] $]_{0}=0.75 \mathrm{mM}$, and [monomer] $]_{0}=1.0 \mathrm{M}$. The UV signal is "mass scaled" for a more accurate comparison of the trace shape to the RI signal. For each simulated GPC trace, the UV signal is shown in red and the RI signal shown in blue. (a) Simulated RI-traces at varying conversion of monomer ( $10 \%$ conversion after $150 \mathrm{~s}, 25 \%$ conversion after $400 \mathrm{~s}, 50 \%$ conversion after $900 \mathrm{~s}$, and 75\% conversion after $1800 \mathrm{~s}$ ). (b) Simulated UV- and RI-GPC traces at $10 \%$ monomer conversion (150 s). (c) Simulated UV- and RI-GPC traces at $25 \%$ monomer conversion (400 s). (d) Simulated UV- and RI-GPC traces at 50\% monomer conversion (900 s). (e) Simulated UV- and RI-GPC traces at 75\% monomer conversion (1800 s). 


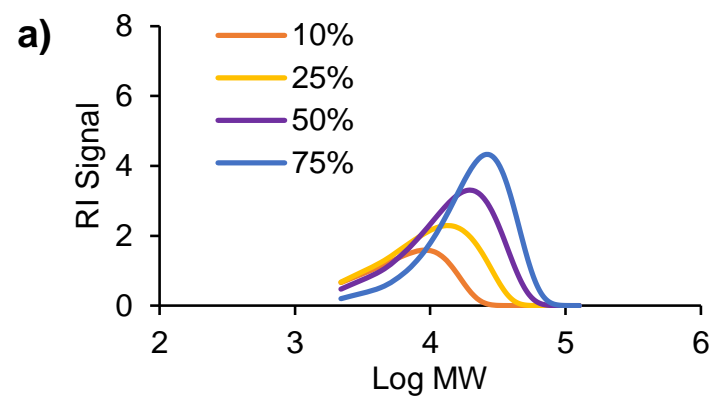

b)

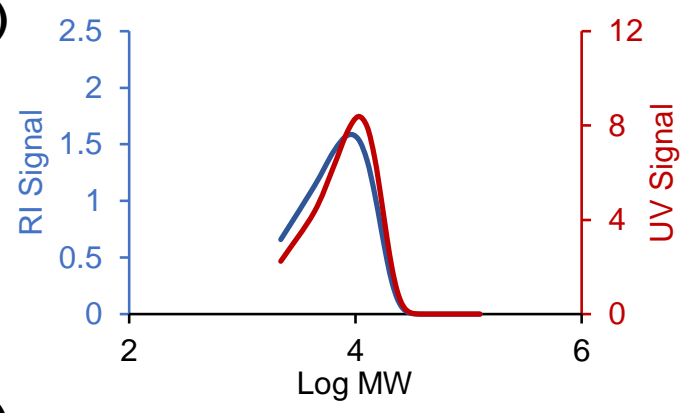

d)

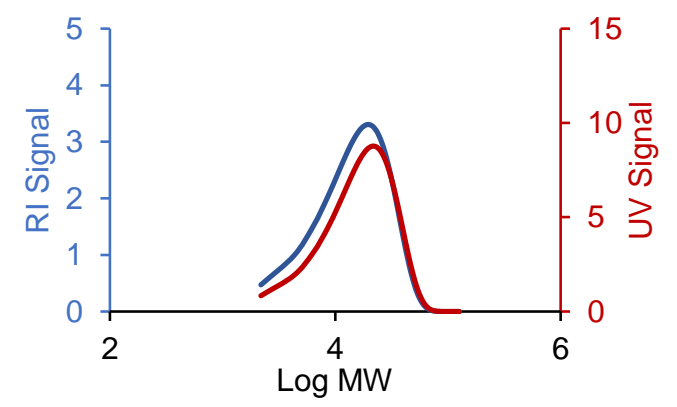

c)

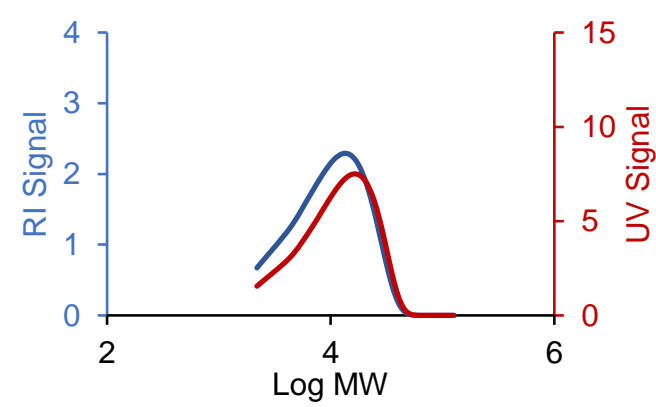

e)

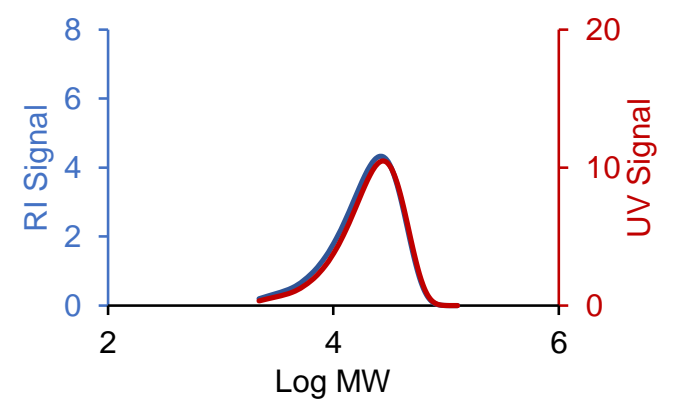

Figure S24. Data from the simulation of a polymerization reaction with reversible chain transfer $\left(k_{\text {ex } 1}=k_{e x 2}=4.0 \mathrm{M}^{-1} \mathrm{~s}^{-1}\right)$. The conditions for this simulation are as follows: $k_{i}=1.0 \mathrm{M}^{-1} \mathrm{~s}^{-1}, \mathrm{k}_{\mathrm{p}}=1.0$ $\mathrm{M}^{-1} \mathrm{~s}^{-1}$, [cat] $]_{0}=0.75 \mathrm{mM}$, and [monomer] $0=1.0 \mathrm{M}$. The UV signal is "mass scaled" for a more accurate comparison of the trace shape to the RI signal. For each simulated GPC trace, the UV signal is shown in red and the RI signal shown in blue. (a) Simulated RI-traces at varying conversion of monomer (10\% conversion after $150 \mathrm{~s}, 25 \%$ conversion after $400 \mathrm{~s}, 50 \%$ conversion after $900 \mathrm{~s}$, and $75 \%$ conversion after $1800 \mathrm{~s}$ ). (b) Simulated UV- and RI-GPC traces at $10 \%$ monomer conversion (150 s). (c) Simulated UV- and RI-GPC traces at $25 \%$ monomer conversion (400 s). (d) Simulated UV- and RI-GPC traces at 50\% monomer conversion (900 s). (e) Simulated UV- and RI-GPC traces at 75\% monomer conversion (1800 s). 


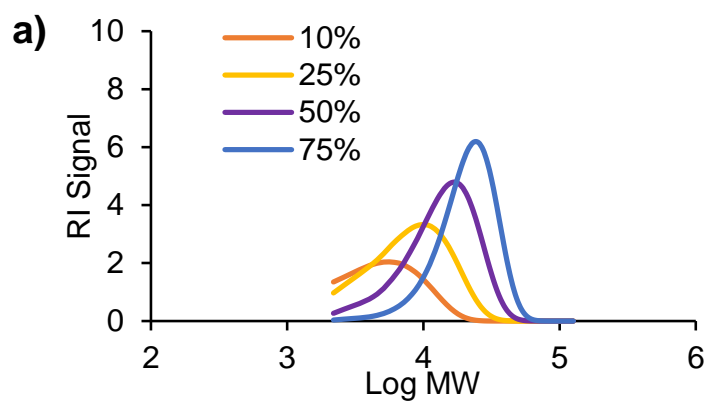

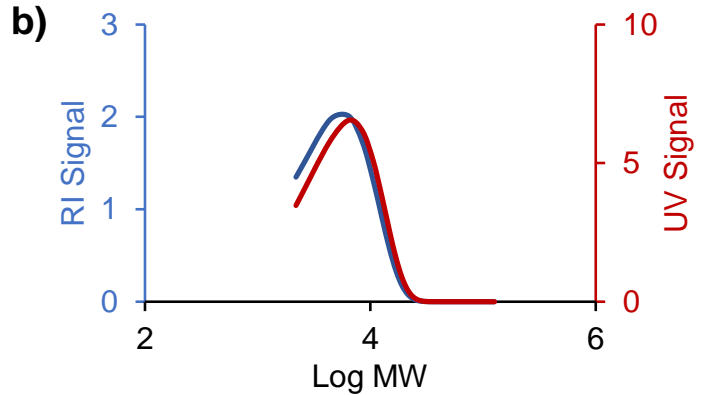

d)

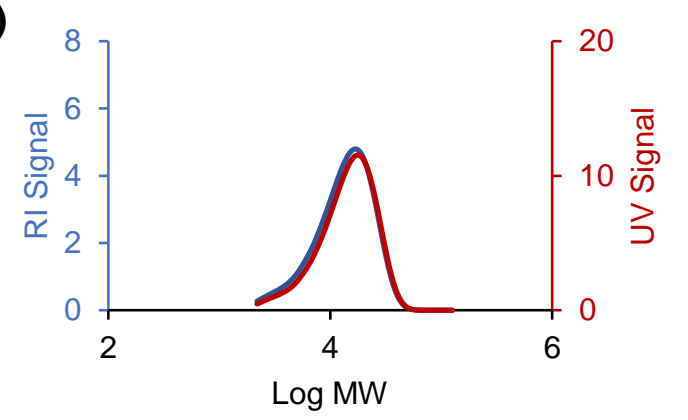

c)

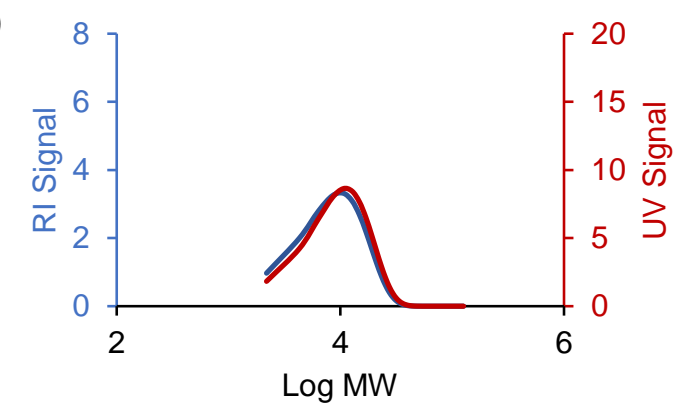

e)

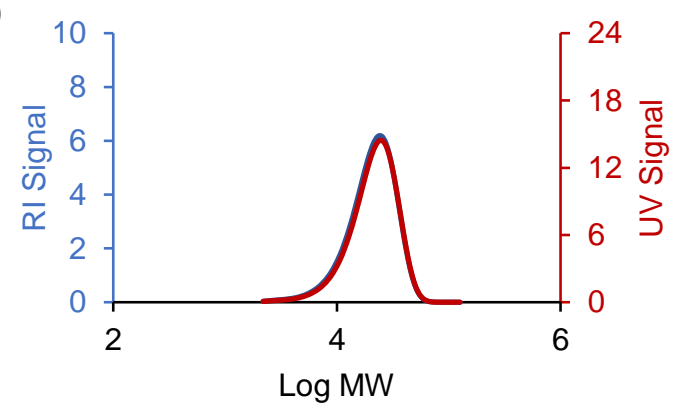

Figure S25. Data from the simulation of a polymerization reaction with reversible chain transfer $\left(k_{\text {ex1 }}=k_{\text {ex2 }}=12 \mathrm{M}^{-1} \mathrm{~s}^{-1}\right)$. The conditions for this simulation are as follows: $k_{i}=1.0 \mathrm{M}^{-1} \mathrm{~s}^{-1}, \mathrm{k}_{\mathrm{p}}=1.0$ $\mathrm{M}^{-1} \mathrm{~s}^{-1}$, [cat $]_{0}=0.75 \mathrm{mM}$, and [monomer] $0=1.0 \mathrm{M}$. The UV signal is "mass scaled" for a more accurate comparison of the trace shape to the RI signal. For each simulated GPC trace, the UV signal is shown in red and the RI signal shown in blue. (a) Simulated RI-traces at varying conversion of monomer ( $10 \%$ conversion after $150 \mathrm{~s}, 25 \%$ conversion after $400 \mathrm{~s}, 50 \%$ conversion after $900 \mathrm{~s}$, and 75\% conversion after $1800 \mathrm{~s}$ ). (b) Simulated UV-and RI-GPC traces at $10 \%$ monomer conversion (150 s). (c) Simulated UV- and RI-GPC traces at $25 \%$ monomer conversion (400 s). (d) Simulated UV- and RI-GPC traces at 50\% monomer conversion (900 s). (e) Simulated UV- and RI-GPC traces at 75\% monomer conversion (1800 s). 
a)

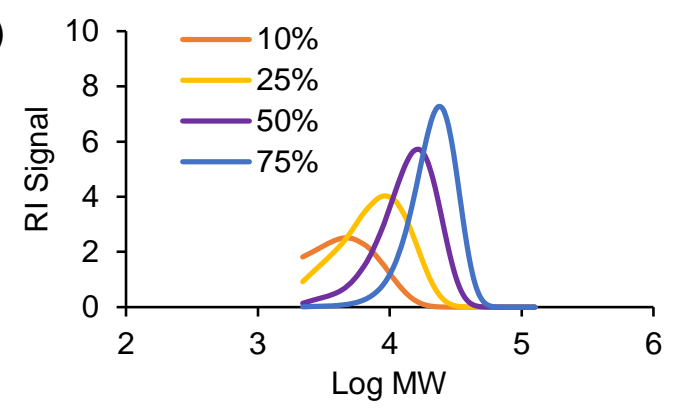

b)

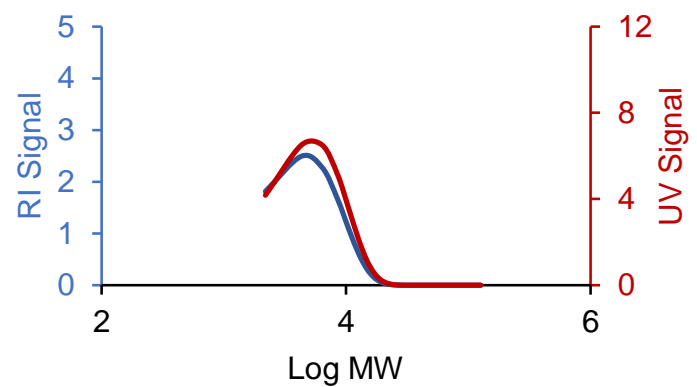

c)

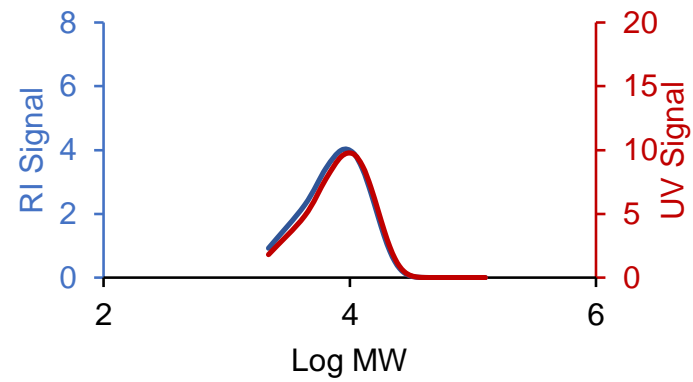

d)

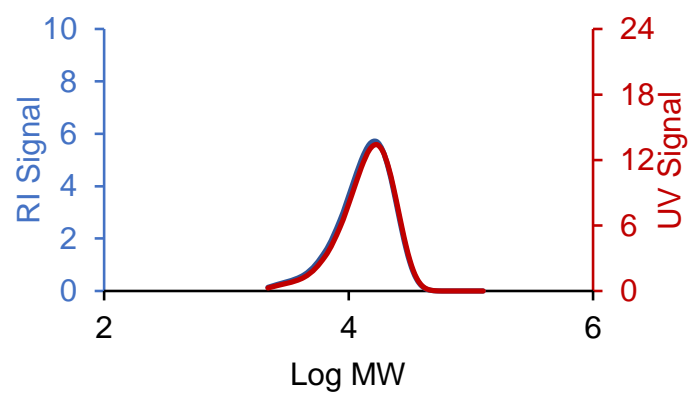

e)

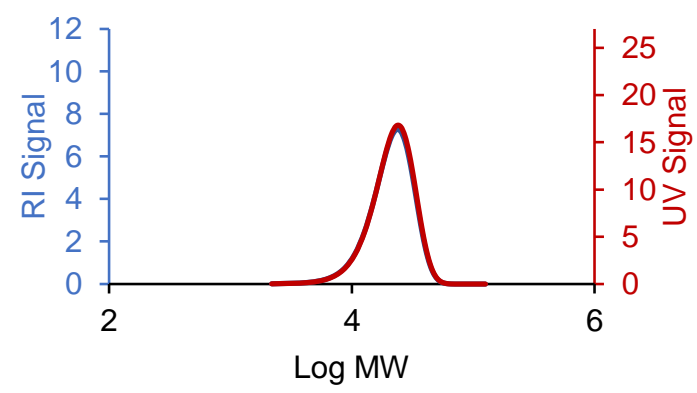

Figure S26. Data from the simulation of a polymerization reaction with reversible chain transfer $\left(k_{\text {ex1 }}=k_{\text {ex2 }}=25 \mathrm{M}^{-1} \mathrm{~s}^{-1}\right)$. The conditions for this simulation are as follows: $k_{i}=1.0 \mathrm{M}^{-1} \mathrm{~s}^{-1}, \mathrm{k}_{\mathrm{p}}=1.0$ $\mathrm{M}^{-1} \mathrm{~s}^{-1}$, [cat] $0=0.75 \mathrm{mM}$, and [monomer] $=1.0 \mathrm{M}$. The UV signal is "mass scaled" for a more accurate comparison of the trace shape to the RI signal. For each simulated GPC trace, the UV signal is shown in red and the $\mathrm{Rl}$ signal shown in blue. (a) Simulated RI-traces at varying conversion of monomer ( $10 \%$ conversion after $150 \mathrm{~s}, 25 \%$ conversion after $400 \mathrm{~s}, 50 \%$ conversion after $900 \mathrm{~s}$, and $75 \%$ conversion after $1800 \mathrm{~s}$ ). (b) Simulated UV- and RI-GPC traces at $10 \%$ monomer conversion (150 s). (c) Simulated UV- and RI-GPC traces at 25\% monomer conversion (400 s). (d) Simulated UV- and RI-GPC traces at 50\% monomer conversion (900 s). (e) Simulated UV- and RI-GPC traces at 75\% monomer conversion (1800 s). 
a)

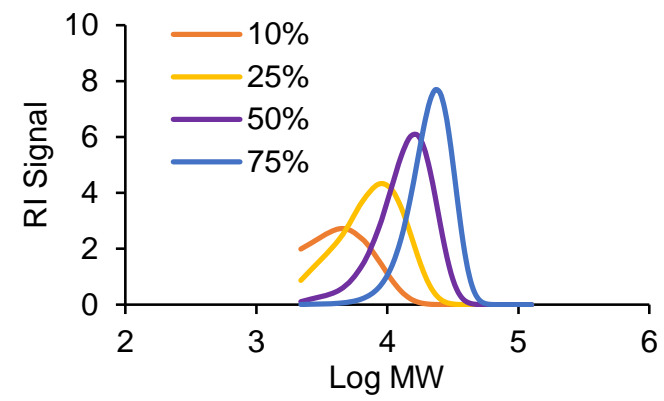

b)

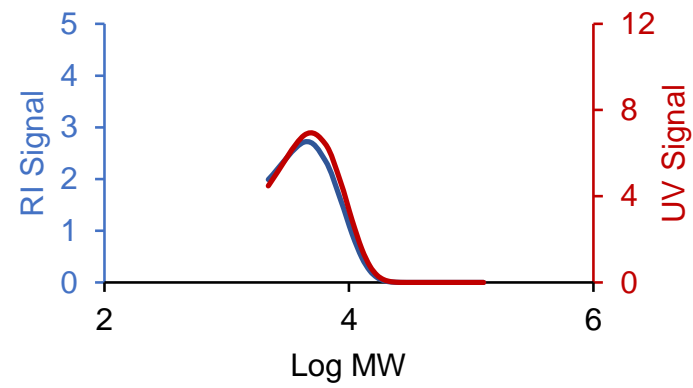

d)

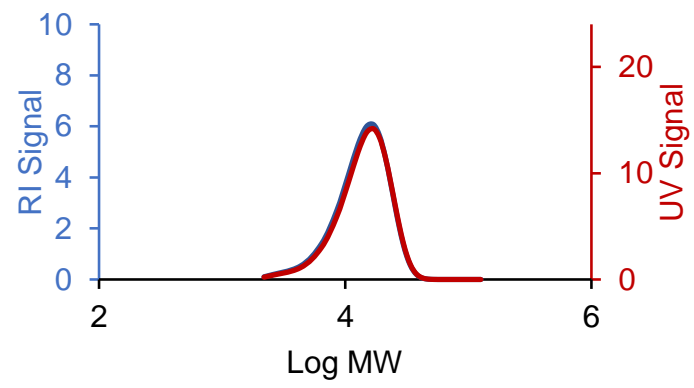

c)

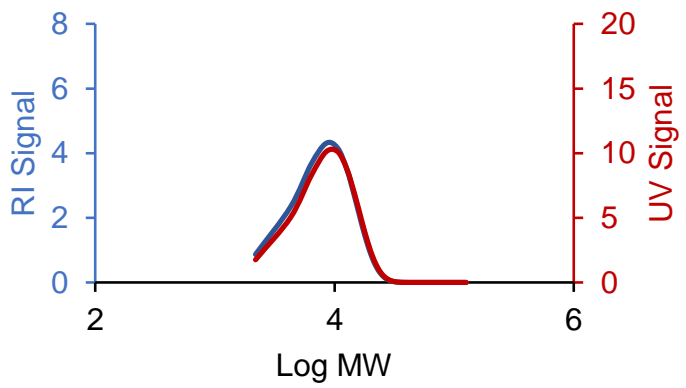

e)

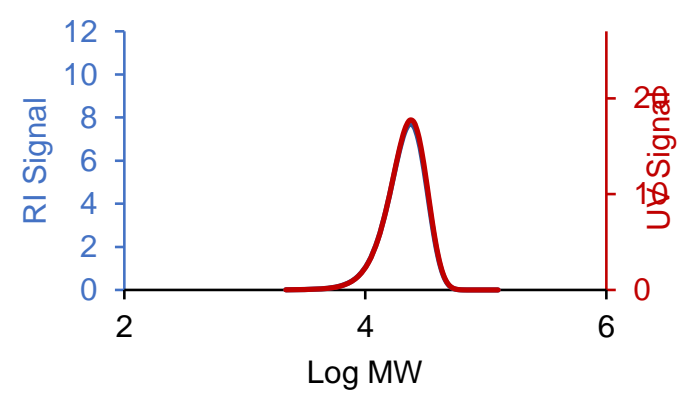

Figure S27. Data from the simulation of a polymerization reaction with reversible chain transfer $\left(k_{\text {ex } 1}=k_{\text {ex2 }}=36 \mathrm{M}^{-1} \mathrm{~s}^{-1}\right)$. The conditions for this simulation are as follows: $k_{i}=1.0 \mathrm{M}^{-1} \mathrm{~s}^{-1}, \mathrm{k}_{\mathrm{p}}=1.0$ $\mathrm{M}^{-1} \mathrm{~s}^{-1}$, [cat] $]_{0}=0.75 \mathrm{mM}$, and [monomer] $0=1.0 \mathrm{M}$. The UV signal is "mass scaled" for a more accurate comparison of the trace shape to the RI signal. For each simulated GPC trace, the UV signal is shown in red and the RI signal shown in blue. (a) Simulated RI-traces at varying conversion of monomer ( $10 \%$ conversion after $150 \mathrm{~s}, 25 \%$ conversion after $400 \mathrm{~s}, 50 \%$ conversion after $900 \mathrm{~s}$, and $75 \%$ conversion after $1800 \mathrm{~s}$ ). (b) Simulated UV- and RI-GPC traces at $10 \%$ monomer conversion (150 s). (c) Simulated UV- and RI-GPC traces at $25 \%$ monomer conversion (400 s). (d) Simulated UV- and RI-GPC traces at 50\% monomer conversion (900 s). (e) Simulated UV- and RI-GPC traces at 75\% monomer conversion (1800 s). 

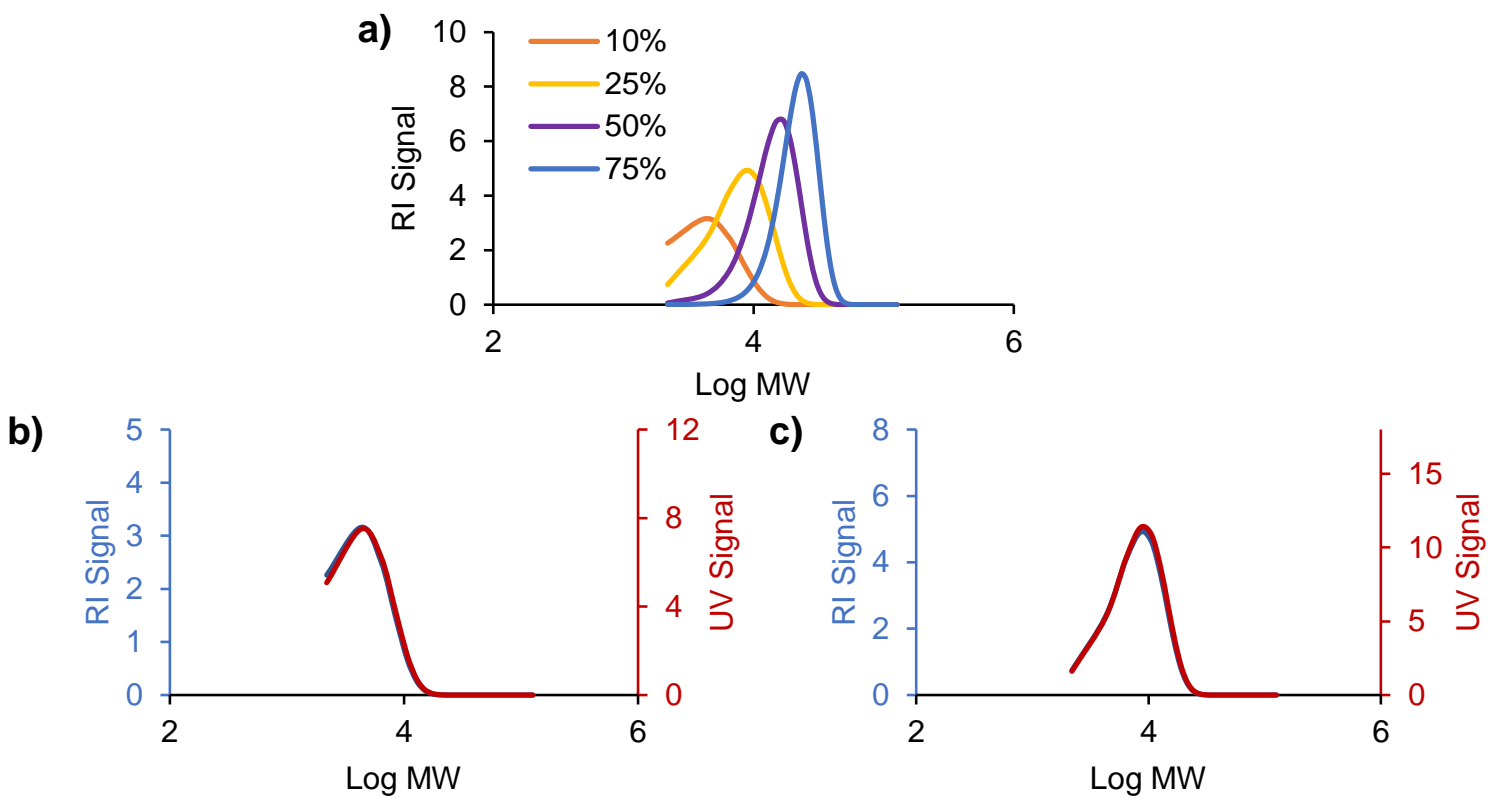

d)

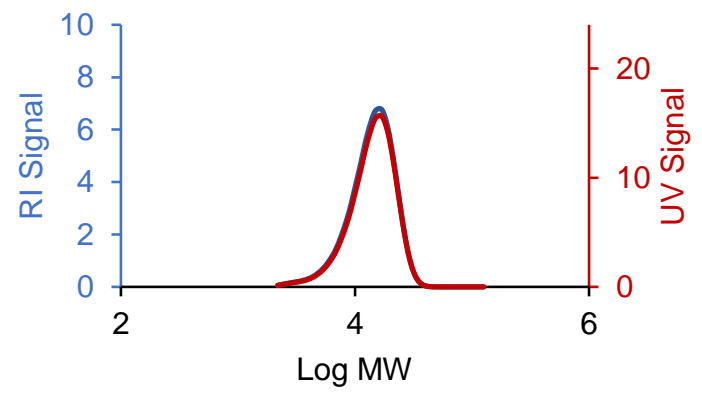

e)

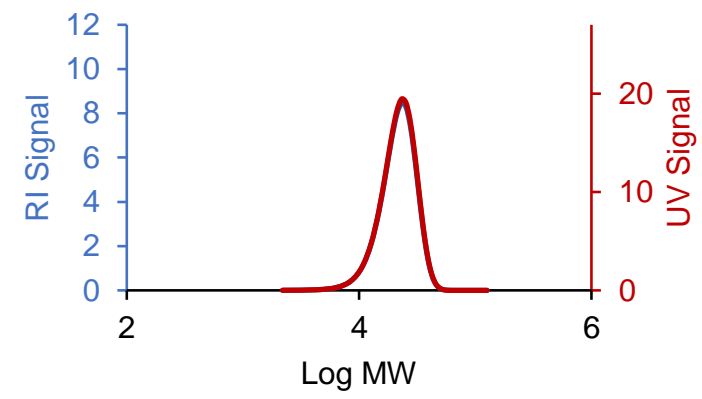

Figure S28. Data from the simulation of a polymerization reaction with reversible chain transfer $\left(k_{e x 1}=k_{e x 2}=100 \mathrm{M}^{-1} \mathrm{~s}^{-1}\right)$. The conditions for this simulation are as follows: $k_{i}=1.0 \mathrm{M}^{-1} \mathrm{~s}^{-1}, \mathrm{k}_{\mathrm{p}}=1.0$ $\mathrm{M}^{-1} \mathrm{~s}^{-1}$, [cat] $]_{0}=0.75 \mathrm{mM}$, and [monomer] $]_{0}=1.0 \mathrm{M}$. The UV signal is "mass scaled" for a more accurate comparison of the trace shape to the RI signal. For each simulated GPC trace, the UV signal is shown in red and the RI signal shown in blue. (a) Simulated RI-traces at varying conversion of monomer ( $10 \%$ conversion after $150 \mathrm{~s}, 25 \%$ conversion after $400 \mathrm{~s}, 50 \%$ conversion after $900 \mathrm{~s}$, and $75 \%$ conversion after $1800 \mathrm{~s}$ ). (b) Simulated UV- and RI-GPC traces at $10 \%$ monomer conversion (150 s). (c) Simulated UV- and RI-GPC traces at 25\% monomer conversion (400 s). (d) Simulated UV- and RI-GPC traces at 50\% monomer conversion (900 s). (e) Simulated UV- and RI-GPC traces at 75\% monomer conversion (1800 s). 


\section{Kinetic simulation of polymerization reactions featuring reversible chain transfer where $k_{\text {ex } 1} \neq k_{\text {ex2 }}$}

In these kinetic simulations, polymerization reactions with reversible chain transfer to a metalalkyl are considered. To achieve this, the rate constant for $k_{\text {ext }}$ is set to $4.0 \mathrm{M}^{-1} \mathrm{~s}^{-1}$ and $\mathrm{k}_{\mathrm{ex} 2}$ is varied (i.e., $\left.k_{\text {ex } 1} \neq k_{\text {ex2 }}\right)$. B-hydride elimination is not considered in these simulations $\left(k_{H}=0\right)$. The catalyst concentration is set to $0.75 \mathrm{mM}$, the monomer concentration is set to $1.0 \mathrm{M}$, the chain transfer agent $\left(\mathrm{ZnEt}_{2}\right)$ concentration is set to $1.0 \mathrm{mM}$, $\mathrm{k}_{\mathrm{i}}$ is set to $1.0 \mathrm{M}^{-1} \mathrm{~s}^{-1}$, and $\mathrm{k}_{\mathrm{p}}$ is set to $1.0 \mathrm{M}^{-1} \mathrm{~s}^{-1}$. The results of these kinetic simulations are shown in Figures S29 - S33.
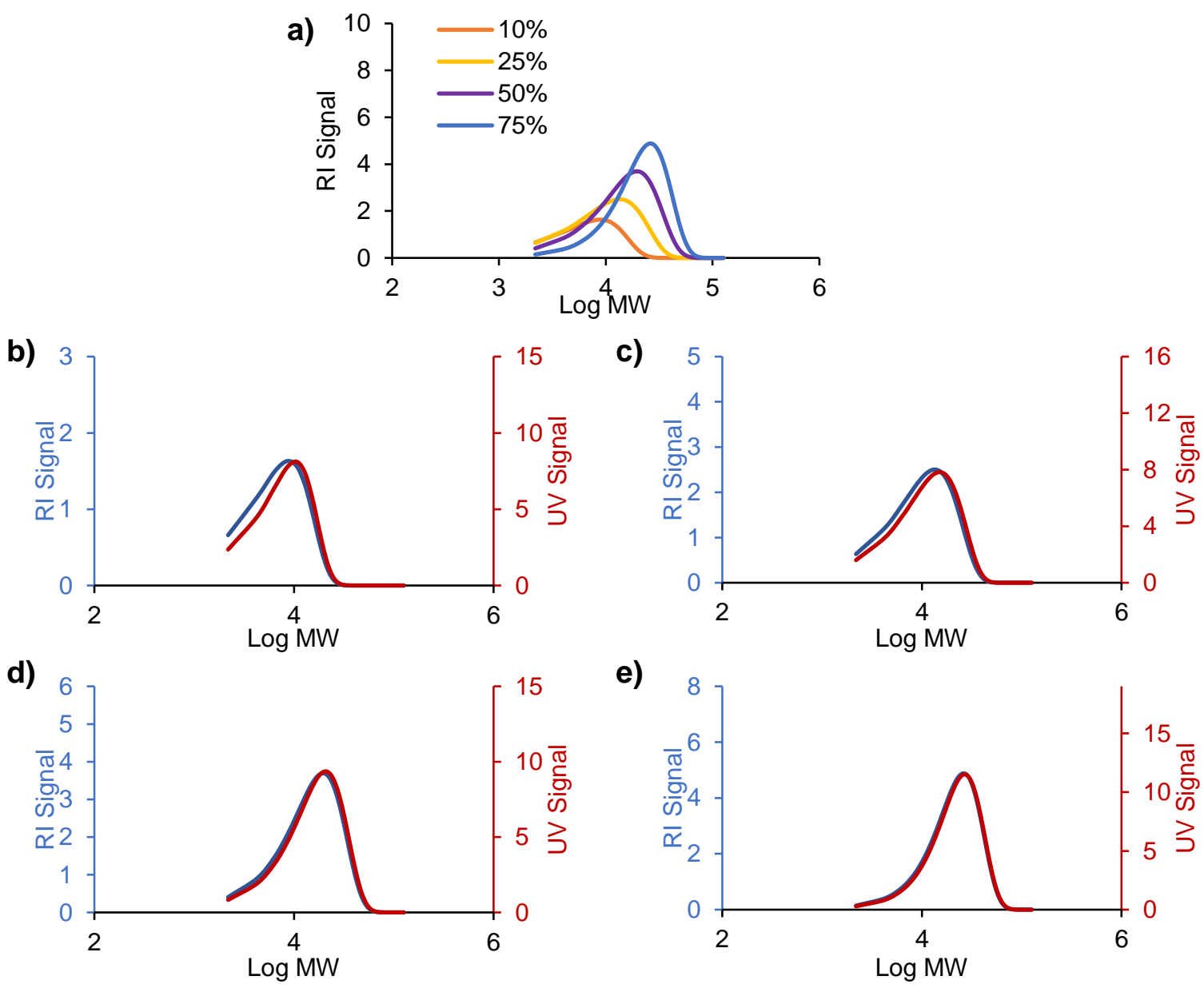

Figure S29. Data from the simulation of a polymerization reaction with reversible chain transfer $\left(k_{\text {ex1 }}=4.0 \mathrm{M} \mathrm{M}^{-1} \mathrm{~s}^{-1}\right.$ and $\left.\mathrm{k}_{\mathrm{ex} 2}=8.0 \mathrm{M}^{-1} \mathrm{~s}^{-1}\right)$. The conditions for this simulation are as follows: $\mathrm{k}_{\mathrm{i}}=1.0$ $\mathrm{M}^{-1} \mathrm{~s}^{-1}, \mathrm{k}_{\mathrm{p}}=1.0 \mathrm{M}^{-1} \mathrm{~s}^{-1},[\mathrm{cat}]_{0}=0.75 \mathrm{mM},\left[\mathrm{ZnEt}_{2}\right]_{0}=1.0 \mathrm{mM}$, and [monomer $]_{0}=1.0 \mathrm{M}$. The UV signal is "mass scaled" for a more accurate comparison of the trace shape to the RI signal. For each simulated GPC trace, the UV signal is shown in red and the RI signal shown in blue. (a) Simulated RI-traces at varying conversion of monomer ( $10 \%$ conversion after $150 \mathrm{~s}, 25 \%$ conversion after 400 s, $50 \%$ conversion after 900 s, and $75 \%$ conversion after 1800 s). (b) Simulated UV- and RIGPC traces at 10\% monomer conversion (150 s). (c) Simulated UV- and RI-GPC traces at $25 \%$ monomer conversion (400 s). (d) Simulated UV- and RI-GPC traces at 50\% monomer conversion (900 s). (e) Simulated UV- and RI-GPC traces at $75 \%$ monomer conversion (1800 s). 

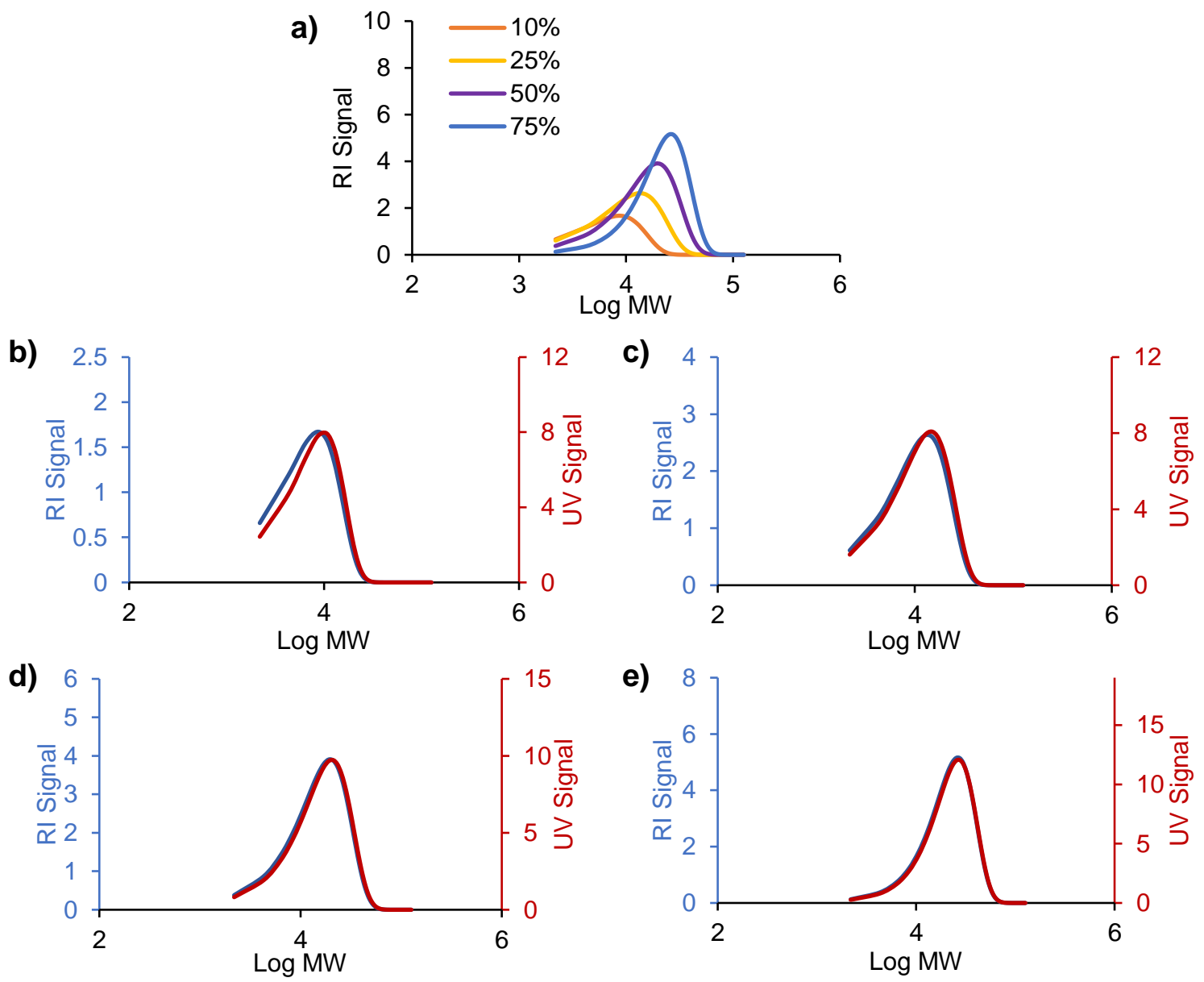

Figure S30. Data from the simulation of a polymerization reaction with reversible chain transfer $\left(k_{\text {ex1 }}=4.0 \mathrm{M}^{-1} \mathrm{~s}^{-1}\right.$ and $\left.k_{\text {ex2 }}=12 \mathrm{M}^{-1} \mathrm{~s}^{-1}\right)$. The conditions for this simulation are as follows: $\mathrm{k}_{\mathrm{i}}=1.0 \mathrm{M}^{-}$ ${ }^{1} \mathrm{~s}^{-1}, \mathrm{k}_{\mathrm{p}}=1.0 \mathrm{M}^{-1} \mathrm{~s}^{-1},[\mathrm{cat}]_{0}=0.75 \mathrm{mM},\left[\mathrm{ZnEt}_{2}\right]_{0}=1.0 \mathrm{mM}$, and [monomer $]_{0}=1.0 \mathrm{M}$. The UV signal is "mass scaled" for a more accurate comparison of the trace shape to the RI signal. For each simulated GPC trace, the UV signal is shown in red and the RI signal shown in blue. (a) Simulated RI-traces at varying conversion of monomer ( $10 \%$ conversion after $150 \mathrm{~s}, 25 \%$ conversion after 400 s, $50 \%$ conversion after 900 s, and $75 \%$ conversion after 1800 s). (b) Simulated UV- and RIGPC traces at $10 \%$ monomer conversion (150 s). (c) Simulated UV- and RI-GPC traces at $25 \%$ monomer conversion (400 s). (d) Simulated UV- and RI-GPC traces at 50\% monomer conversion (900 s). (e) Simulated UV- and RI-GPC traces at $75 \%$ monomer conversion (1800 s). 


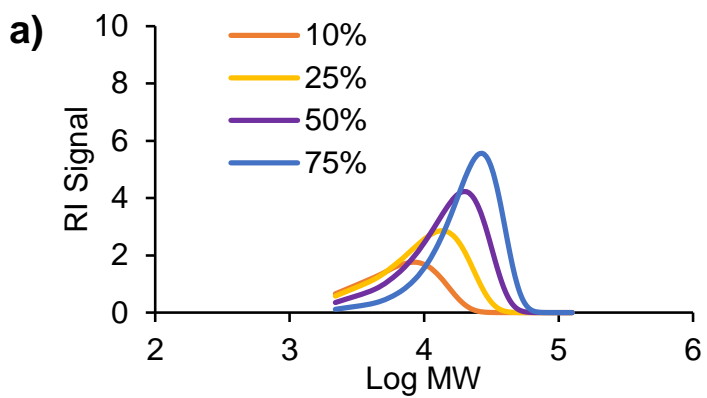

b)

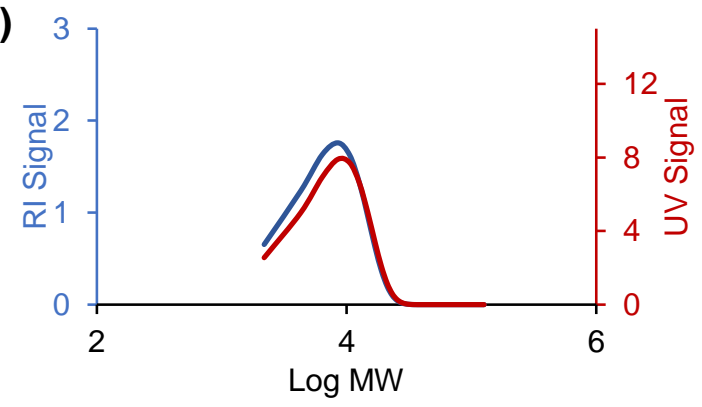

d)

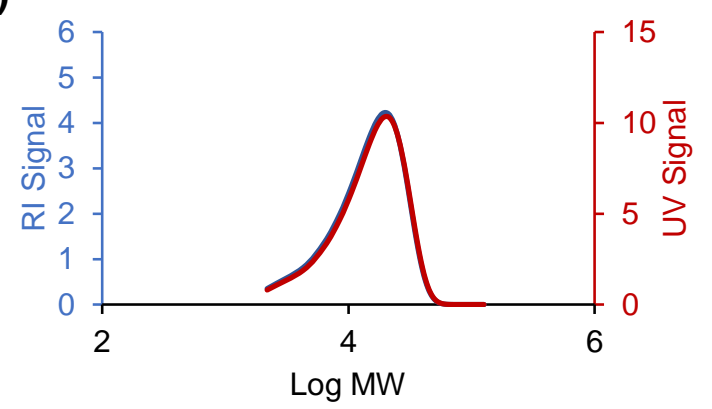

c)

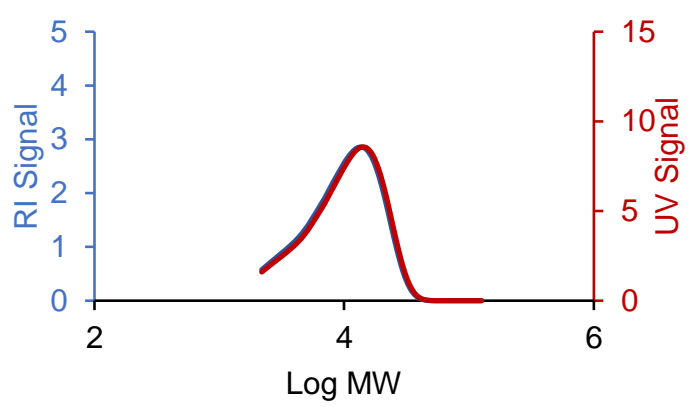

e)

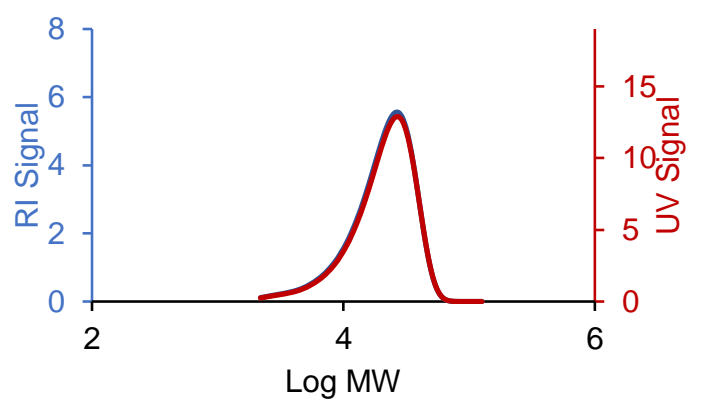

Figure S31. Data from the simulation of a polymerization reaction with reversible chain transfer $\left(k_{e x 1}=4.0 \mathrm{M}^{-1} \mathrm{~s}^{-1}\right.$ and $\left.\mathrm{k}_{\mathrm{ex} 2}=24 \mathrm{M}^{-1} \mathrm{~s}^{-1}\right)$. The conditions for this simulation are as follows: $\mathrm{k}_{\mathrm{i}}=1.0 \mathrm{M}^{-}$ ${ }^{1} \mathrm{~s}^{-1}, \mathrm{k}_{\mathrm{p}}=1.0 \mathrm{M}^{-1} \mathrm{~s}^{-1}$, [cat $]_{0}=0.75 \mathrm{mM},\left[\mathrm{ZnEt}_{2}\right]_{0}=1.0 \mathrm{mM}$, and [monomer $]_{0}=1.0 \mathrm{M}$. The UV signal is "mass scaled" for a more accurate comparison of the trace shape to the RI signal. For each simulated GPC trace, the UV signal is shown in red and the RI signal shown in blue. (a) Simulated Rl-traces at varying conversion of monomer (10\% conversion after $150 \mathrm{~s}, 25 \%$ conversion after 400 s, $50 \%$ conversion after 900 s, and 75\% conversion after 1800 s). (b) Simulated UV- and RIGPC traces at 10\% monomer conversion (150 s). (c) Simulated UV- and RI-GPC traces at 25\% monomer conversion (400 s). (d) Simulated UV- and RI-GPC traces at 50\% monomer conversion (900 s). (e) Simulated UV- and RI-GPC traces at 75\% monomer conversion (1800 s). 


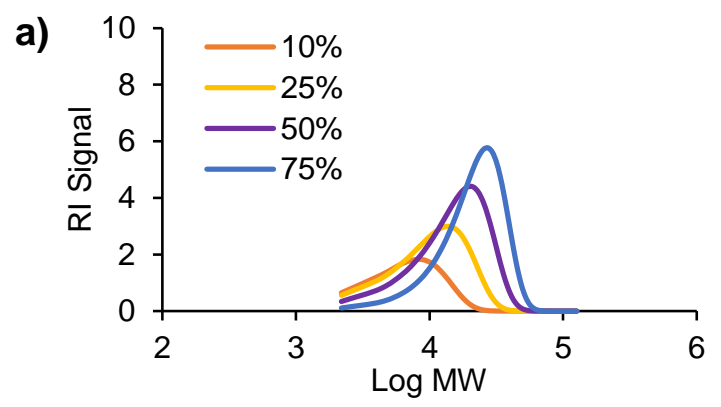

b)

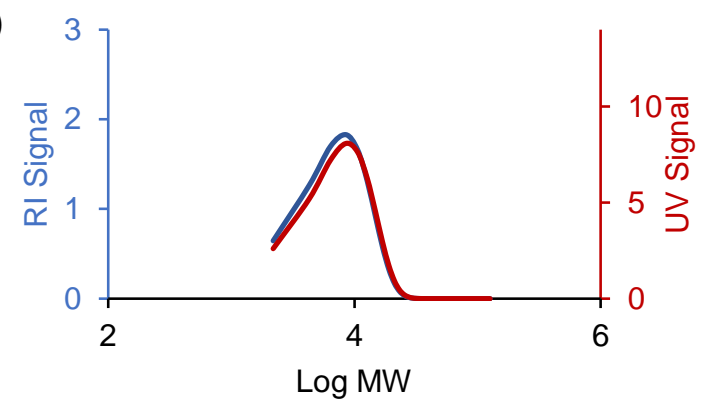

d)

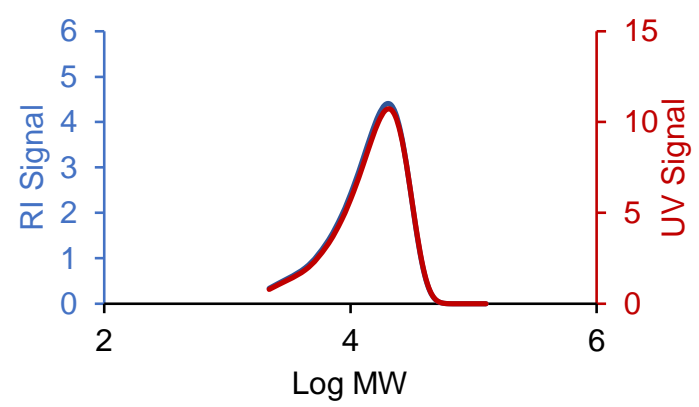

c)

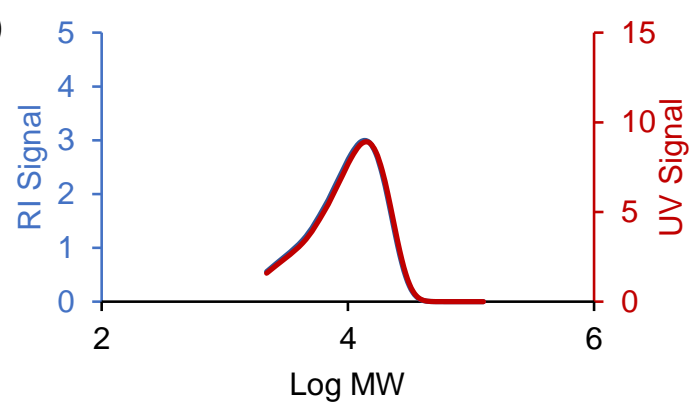

e)

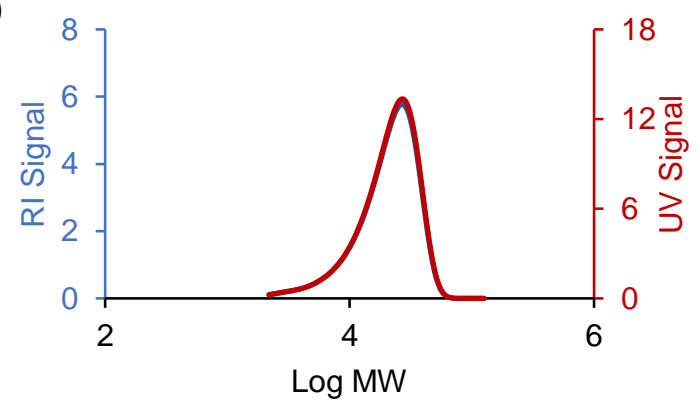

Figure S32. Data from the simulation of a polymerization reaction with reversible chain transfer $\left(k_{e x 1}=4.0 \mathrm{M}^{-1} \mathrm{~s}^{-1}\right.$ and $\left.\mathrm{k}_{\mathrm{ex} 2}=40 \mathrm{M}^{-1} \mathrm{~s}^{-1}\right)$. The conditions for this simulation are as follows: $\mathrm{k}_{\mathrm{i}}=1.0 \mathrm{M}^{-}$ ${ }^{1} \mathrm{~s}^{-1}, \mathrm{k}_{\mathrm{p}}=1.0 \mathrm{M}^{-1} \mathrm{~s}^{-1}$, [cat $]_{0}=0.75 \mathrm{mM},\left[\mathrm{ZnEt}_{2}\right]_{0}=1.0 \mathrm{mM}$, and [monomer $]_{0}=1.0 \mathrm{M}$. The UV signal is "mass scaled" for a more accurate comparison of the trace shape to the RI signal. For each simulated GPC trace, the UV signal is shown in red and the RI signal shown in blue. (a) Simulated Rl-traces at varying conversion of monomer (10\% conversion after $150 \mathrm{~s}, 25 \%$ conversion after 400 s, $50 \%$ conversion after 900 s, and 75\% conversion after 1800 s). (b) Simulated UV- and RIGPC traces at 10\% monomer conversion (150 s). (c) Simulated UV- and RI-GPC traces at $25 \%$ monomer conversion (400 s). (d) Simulated UV- and RI-GPC traces at 50\% monomer conversion (900 s). (e) Simulated UV- and RI-GPC traces at 75\% monomer conversion (1800 s). 

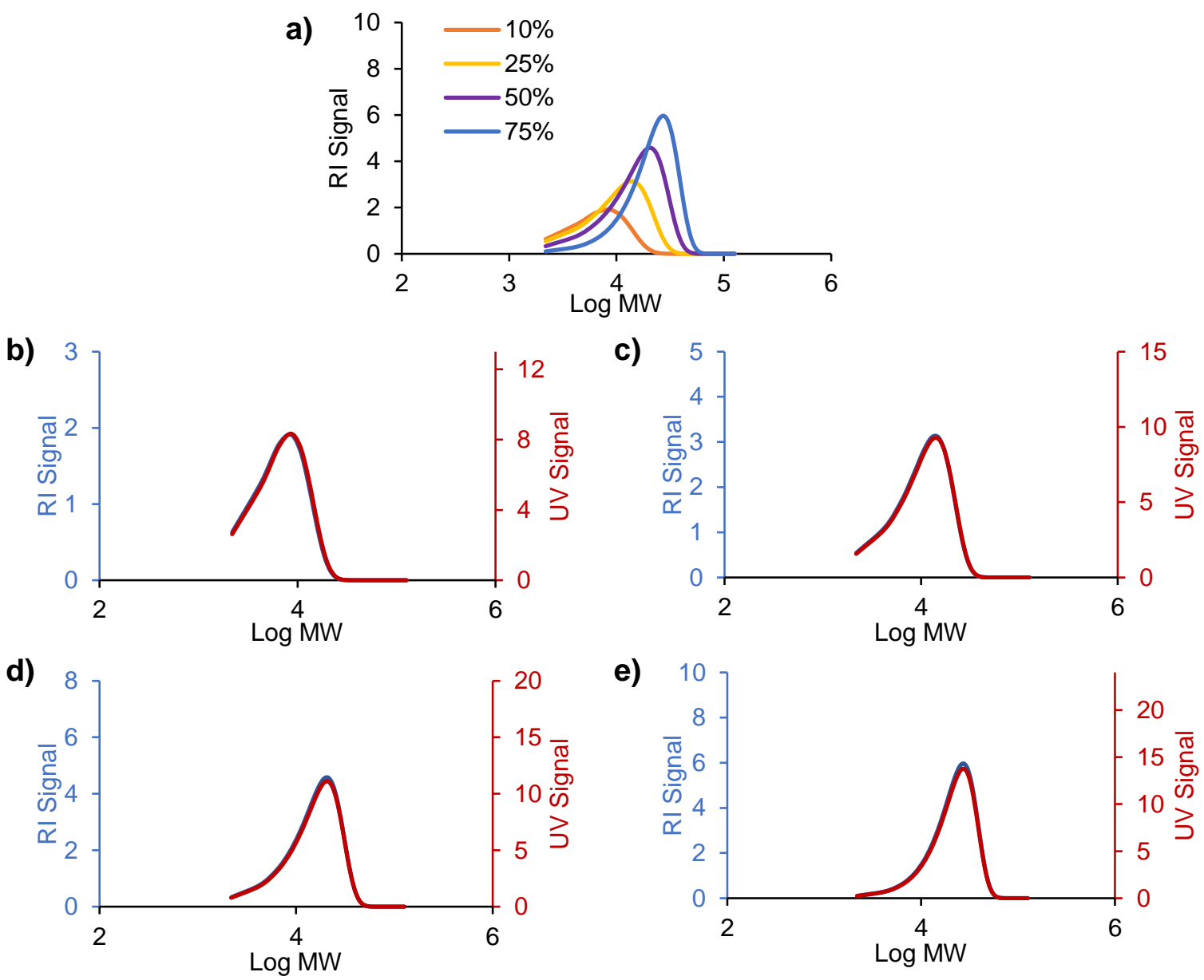

Figure S33. Data from the simulation of a polymerization reaction with reversible chain transfer $\left(k_{\text {ex1 }}=4.0 \mathrm{M}^{-1} \mathrm{~s}^{-1}\right.$ and $\left.k_{\text {ex } 2}=80 \mathrm{M}^{-1} \mathrm{~s}^{-1}\right)$. The conditions for this simulation are as follows: $k_{i}=1.0 \mathrm{M}^{-}$ ${ }^{1} \mathrm{~s}^{-1}, \mathrm{k}_{\mathrm{p}}=1.0 \mathrm{M}^{-1} \mathrm{~s}^{-1}$, [cat $]_{0}=0.75 \mathrm{mM},\left[\mathrm{ZnEt}_{2}\right]_{0}=1.0 \mathrm{mM}$, and [monomer $]_{0}=1.0 \mathrm{M}$. The UV signal is "mass scaled" for a more accurate comparison of the trace shape to the RI signal. For each simulated GPC trace, the UV signal is shown in red and the RI signal shown in blue. (a) Simulated RI-traces at varying conversion of monomer ( $10 \%$ conversion after $150 \mathrm{~s}, 25 \%$ conversion after 400 s, $50 \%$ conversion after 900 s, and $75 \%$ conversion after 1800 s). (b) Simulated UV- and RIGPC traces at 10\% monomer conversion (150 s). (c) Simulated UV- and RI-GPC traces at $25 \%$ monomer conversion (400 s). (d) Simulated UV- and RI-GPC traces at 50\% monomer conversion (900 s). (e) Simulated UV- and RI-GPC traces at $75 \%$ monomer conversion (1800 s). 


\section{Kinetic simulation of polymerization reactions featuring reversible chain transfer where $k_{\text {ex1 }}=k_{\text {ex2 }}$ with a continuous monomer feed}

While batch polymerization reactions are common in research laboratory settings especially for liquid monomers (e.g. 1-hexene and 1-octene), gas-fed reactions and industrial polymerization reactors (e.g. ethylene and propylene polymerizations and CSTRs) often feed monomer to the reaction continuously..$^{5-9}$ Thus, non-batch reactions (i.e. continuously fed reactions) are worth considering. These non-batch simulations are conducted by fixing the monomer concentration as constant. During non-batch polymerization reactions, the $Đ$ decreases with time even when the rates of exchange are equal to the rate of propagation. When the $k_{e x} / k_{p} \geq 12$, the observed $Đ s$ drop below 1.1 over the simulated time course, compared to the $k_{e x} / k_{p} \geq 30$ required to achieve a $Ð<1.1$ in batch reactions. This discrepancy in the temporal profile of $\boxminus$ is the direct result of differences between batch and continuous fed reactions. Because the monomer concentration remains constant in continuously fed reactions, the rate of new polymer growth remains constant.

In these kinetic simulations, polymerization reactions with reversible chain transfer to a metalalkyl are considered. To achieve this, the rate constant for $\mathrm{k}_{\mathrm{ex2}}$ and $\mathrm{k}_{\mathrm{ex} 1}$ are varied, but $\mathrm{k}_{\mathrm{ex} 1}=\mathrm{k}_{\mathrm{ex} 2}$. In these simulations the monomer is continuously fed to the polymerization reaction (i.e. concentration of monomer is constant throughout the reaction). The catalyst concentration is set to $0.75 \mathrm{mM}$, the monomer concentration is set to $1.0 \mathrm{M}$ and remains constant throughout the simulation, the CTA ( $\left.\mathrm{ZnEt}_{2}\right)$ is set to $1.0 \mathrm{mM}$, $\mathrm{k}_{\mathrm{i}}$ is set to $1.0 \mathrm{M}^{-1} \mathrm{~s}^{-1}$, and $\mathrm{k}_{\mathrm{p}}$ is set to $1.0 \mathrm{M}^{-1} \mathrm{~s}^{-1}$. The results of these kinetic simulations are shown in Figures S34-S38. It must be pointed out that a continuous feed of monomer would serve to slowly dilute the [cat] and [CTA] over time. These factors were not taken into account here as there is not a simple and obvious mechanism for addressing this issue in the current kinetic model. However, the effect of dilution will likely be subtle and not significantly impact the qualitative insights presented here. 


\section{Continuously Fed Reactions}

a)

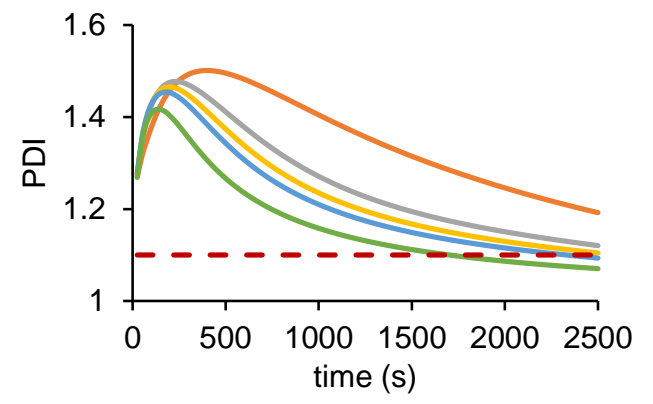

\section{Batch Reactions}

c)

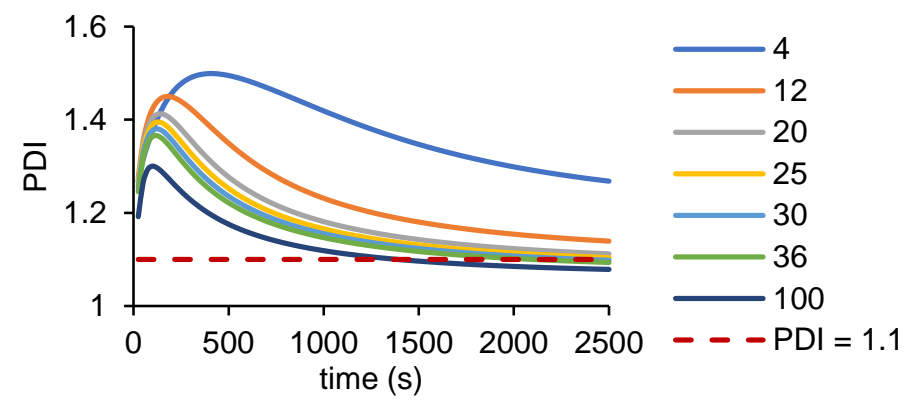

b)

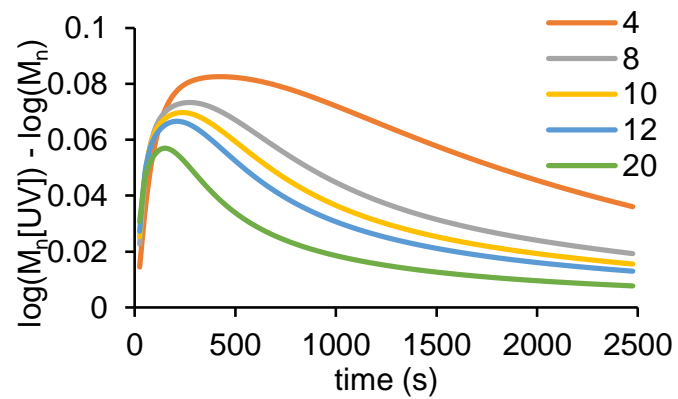

Figure 34. A comparison between simulations of polymerization reactions where monomer is continuously fed to the reaction (i.e. monomer concentration remains constant throughout the reaction) and batch reactions (where monomer is depleted via propagation). The initial concentrations of monomer, catalyst, and $\mathrm{ZnEt}_{2}$ are identical in the continuously fed reaction and batch reaction. (a) The simulated PDI vs time for continuously fed polymerization reactions varying the rate constant for chain transfer $\left(\mathrm{k}_{\mathrm{ex} 1}=\mathrm{k}_{\mathrm{ex} 2}=\right.$ varied). (b) The simulated difference in the $\log \left(M_{n}\right)$ of the UV- and RI-signals (catalyst-polymeryls and all polymeryls, respectively) plotted vs time during continuously fed polymerization reactions varying the rate constant for chain transfer $\left(\mathrm{k}_{\mathrm{ex} 1}=\mathrm{k}_{\mathrm{ex} 2}=\right.$ varied). (c) The simulated PDI vs time for batch polymerization reactions varying the rate constant for chain transfer $\left(k_{\text {ex1 }}=k_{\text {ex2 }}=\right.$ varied $)$. (d) The simulated difference in the $\log \left(\mathrm{M}_{\mathrm{n}}\right)$ of the UV- and RI-signals (catalyst-polymeryls and all polymeryls, respectively) plotted vs time during batch polymerization reactions varying the rate constant for chain transfer $\left(\mathrm{k}_{\mathrm{ex}}=\right.$ $\mathrm{k}_{\mathrm{ex} 2}=$ varied). Conditions for these polymerization reactions: $\mathrm{k}_{\mathrm{i}}=1.0 \mathrm{M}^{-1} \mathrm{~s}^{-1}, \mathrm{k}_{\mathrm{p}}=1.0 \mathrm{M}^{-1} \mathrm{~s}^{-1}$, [cat] $=0.75 \mathrm{mM},\left[\mathrm{ZnEt}_{2}\right]_{0}=1.0 \mathrm{mM},[\text { monomer }]_{0}=1.0 \mathrm{M}$, and $\mathrm{k}_{\mathrm{ex} 1}=\mathrm{k}_{\mathrm{ex} 2}=$ varied . 


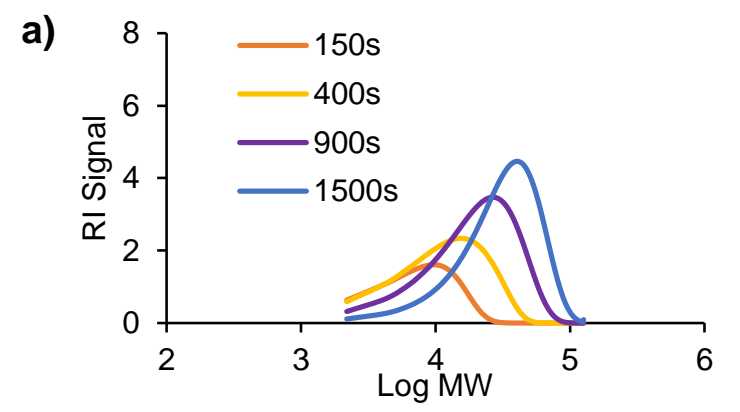

b)

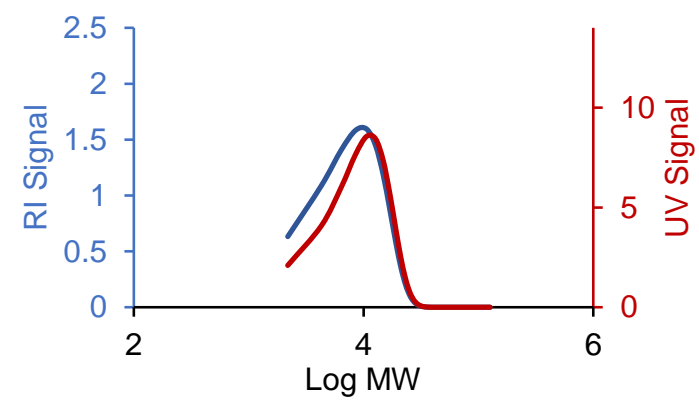

d)

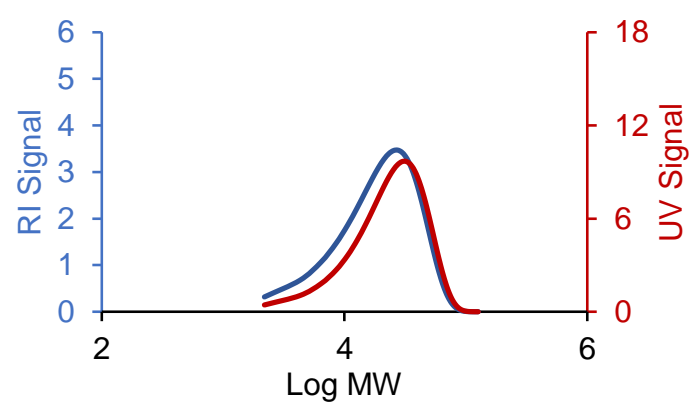

c)

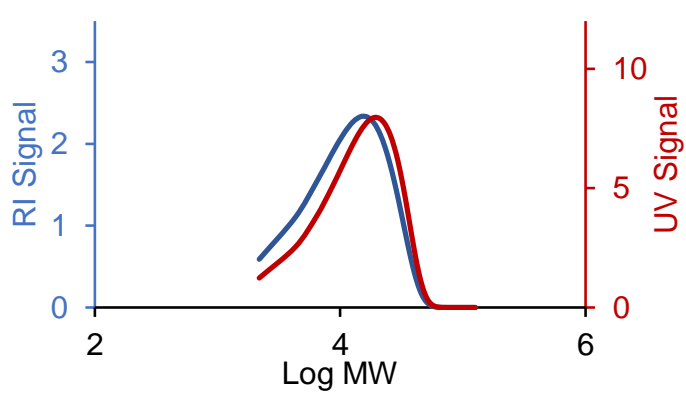

e)

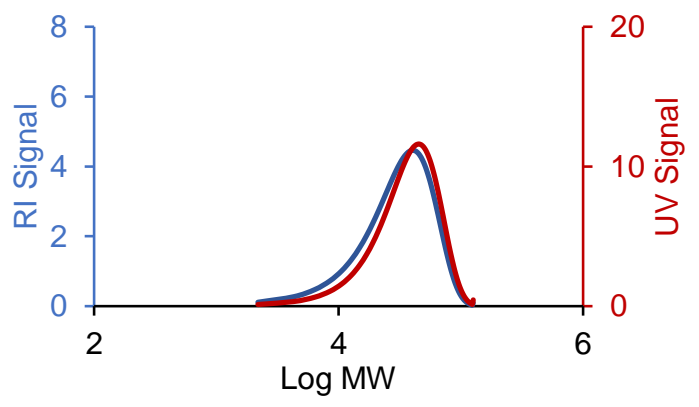

Figure S35. Data from the simulation of a polymerization reaction with reversible chain transfer $\left(k_{e x 1}=k_{e x 2}=4.0 ~ M^{-1} s^{-1}\right)$ with a continuous monomer feed (i.e. monomer concentration remained constant throughout the reaction). The conditions for this simulation are as follows: $\mathrm{k}_{\mathrm{i}}=1.0 \mathrm{M}^{-1} \mathrm{~s}^{-}$ ${ }^{1}, \mathrm{k}_{\mathrm{p}}=1.0 \mathrm{M}^{-1} \mathrm{~s}^{-1}$, [cat $]_{0}=0.75 \mathrm{mM},\left[\mathrm{ZnEt}_{2}\right]_{0}=1.0 \mathrm{mM}$, and [monomer $]_{0}=1.0 \mathrm{M}$. The UV signal is "mass scaled" for a more accurate comparison of the trace shape to the RI signal. For each simulated GPC trace, the UV signal is shown in red and the RI signal shown in blue. (a) Simulated RI-traces at varying polymerization reaction time (150 s, $400 \mathrm{~s}, 900 \mathrm{~s}$, and $1500 \mathrm{~s}$ ). (b) Simulated UV- and RI-GPC traces after 150 s. (c) Simulated UV- and RI-GPC traces after 400 s. (d) Simulated UV- and RI-GPC traces after 900 s. (e) Simulated UV- and RI-GPC traces after 1500 s. 


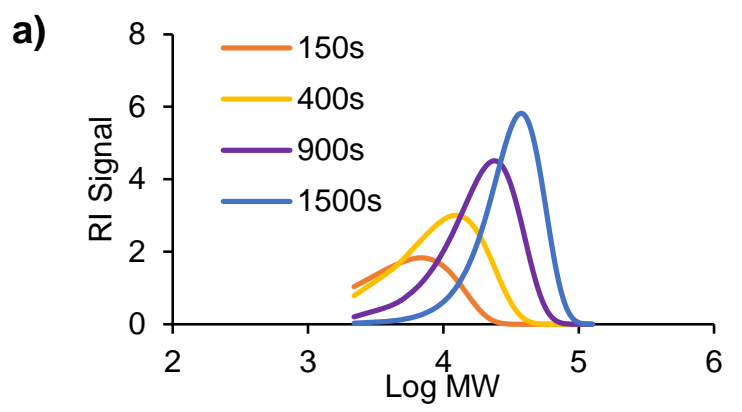

b)

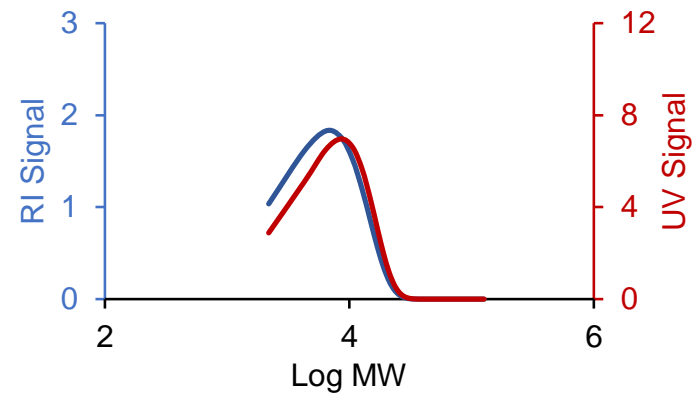

c)

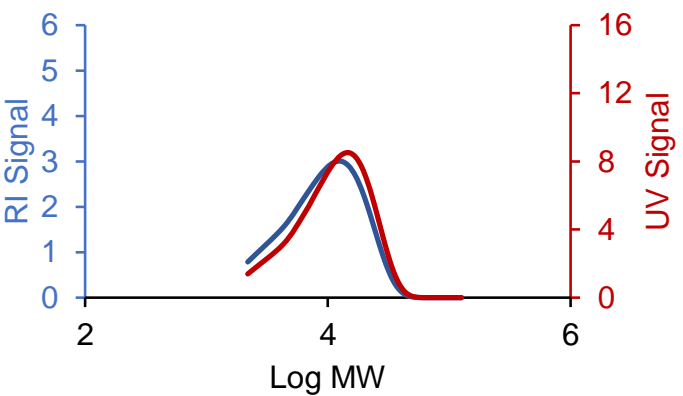

d)

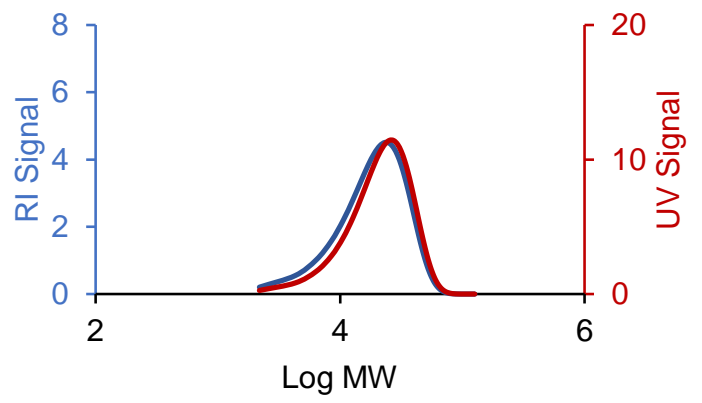

e)

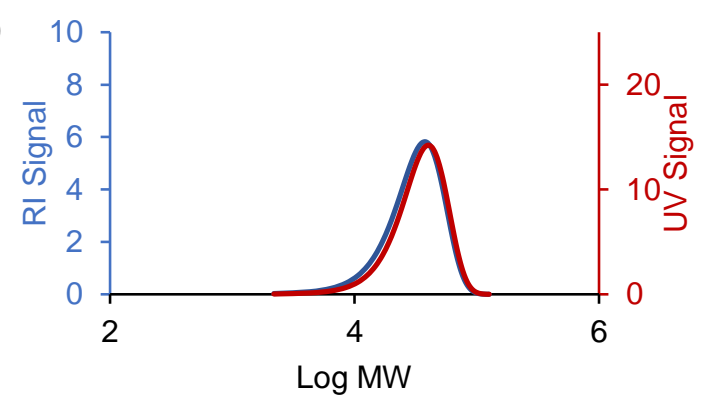

Figure S36. Data from the simulation of a polymerization reaction with reversible chain transfer $\left(k_{\text {ex1 }}=k_{\text {ex2 }}=8.0 \mathrm{M}^{-1} \mathrm{~s}^{-1}\right)$ with a continuous monomer feed (i.e. monomer concentration remained constant throughout the reaction). The conditions for this simulation are as follows: $\mathrm{k}_{\mathrm{i}}=1.0 \mathrm{M}^{-1} \mathrm{~s}^{-}$ ${ }^{1}, \mathrm{k}_{\mathrm{p}}=1.0 \mathrm{M}^{-1} \mathrm{~s}^{-1}$, [cat $]_{0}=0.75 \mathrm{mM},\left[\mathrm{ZnEt}_{2}\right]_{0}=1.0 \mathrm{mM}$, and [monomer $]_{0}=1.0 \mathrm{M}$. The UV signal is "mass scaled" for a more accurate comparison of the trace shape to the RI signal. For each simulated GPC trace, the UV signal is shown in red and the RI signal shown in blue. (a) Simulated Rl-traces at varying polymerization reaction time (150 s, 400 s, $900 \mathrm{~s}$, and $1500 \mathrm{~s}$ ). (b) Simulated UV- and RI-GPC traces after 150 s. (c) Simulated UV- and RI-GPC traces after 400 s. (d) Simulated UV- and RI-GPC traces after 900 s. (e) Simulated UV- and RI-GPC traces after 1500 S. 


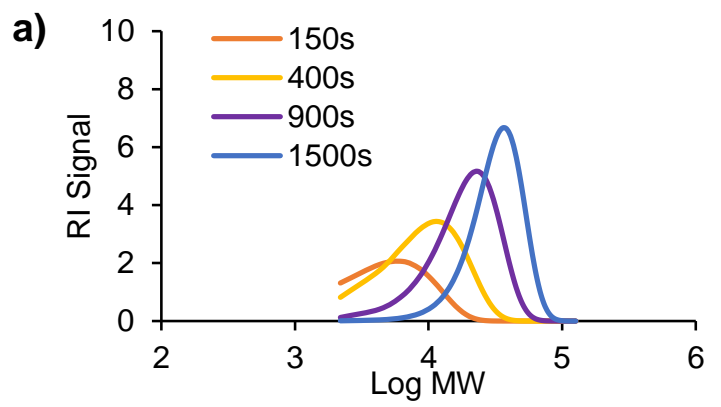

b)

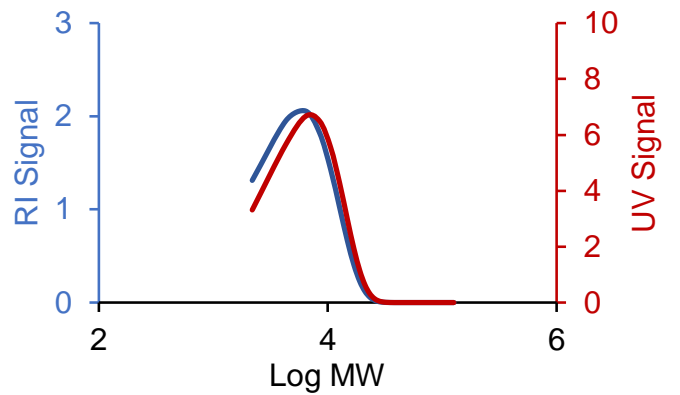

d)

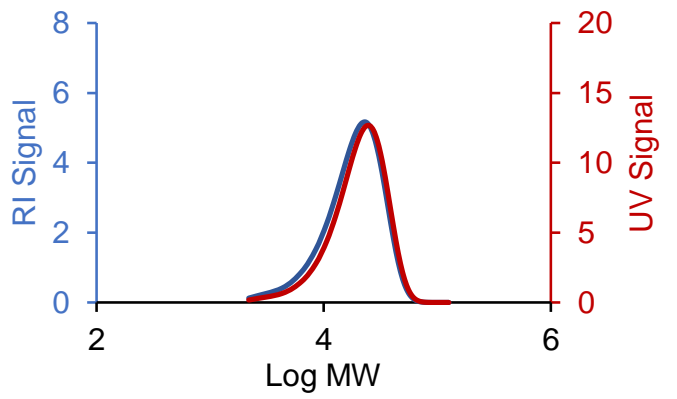

c)

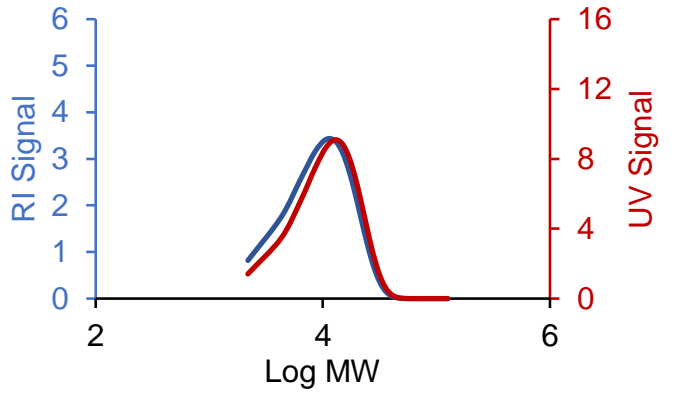

e)

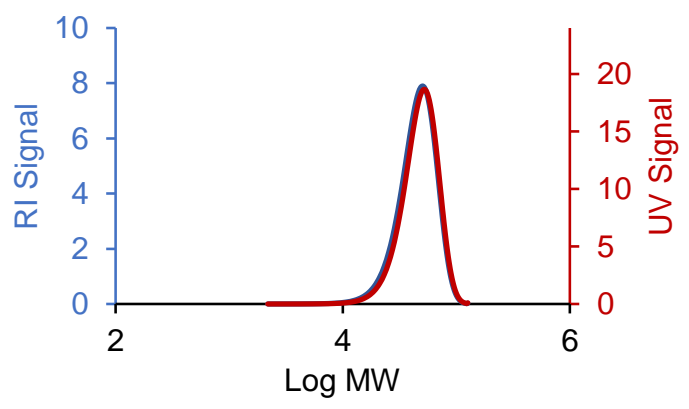

Figure S37. Data from the simulation of a polymerization reaction with reversible chain transfer $\left(\mathrm{k}_{\mathrm{ex} 1}=\mathrm{k}_{\mathrm{ex} 2}=12 \mathrm{M}^{-1} \mathrm{~s}^{-1}\right)$ with a continuous monomer feed (i.e. monomer concentration remained constant throughout the reaction). The conditions for this simulation are as follows: $\mathrm{k}_{\mathrm{i}}=1.0 \mathrm{M}^{-1} \mathrm{~s}^{-}$ ${ }^{1}, \mathrm{k}_{\mathrm{p}}=1.0 \mathrm{M}^{-1} \mathrm{~s}^{-1}$, [cat $]_{0}=0.75 \mathrm{mM},\left[\mathrm{ZnEt}_{2}\right]_{0}=1.0 \mathrm{mM}$, and [monomer] $]_{0}=1.0 \mathrm{M}$. The UV signal is "mass scaled" for a more accurate comparison of the trace shape to the RI signal. For each simulated GPC trace, the UV signal is shown in red and the RI signal shown in blue. (a) Simulated RI-traces at varying polymerization reaction time (150 s, 400 s, 900 s, and 1500 s). (b) Simulated UV- and RI-GPC traces after 150 s. (c) Simulated UV- and RI-GPC traces after 400 s. (d) Simulated UV- and RI-GPC traces after 900 s. (e) Simulated UV- and RI-GPC traces after 1500 S. 

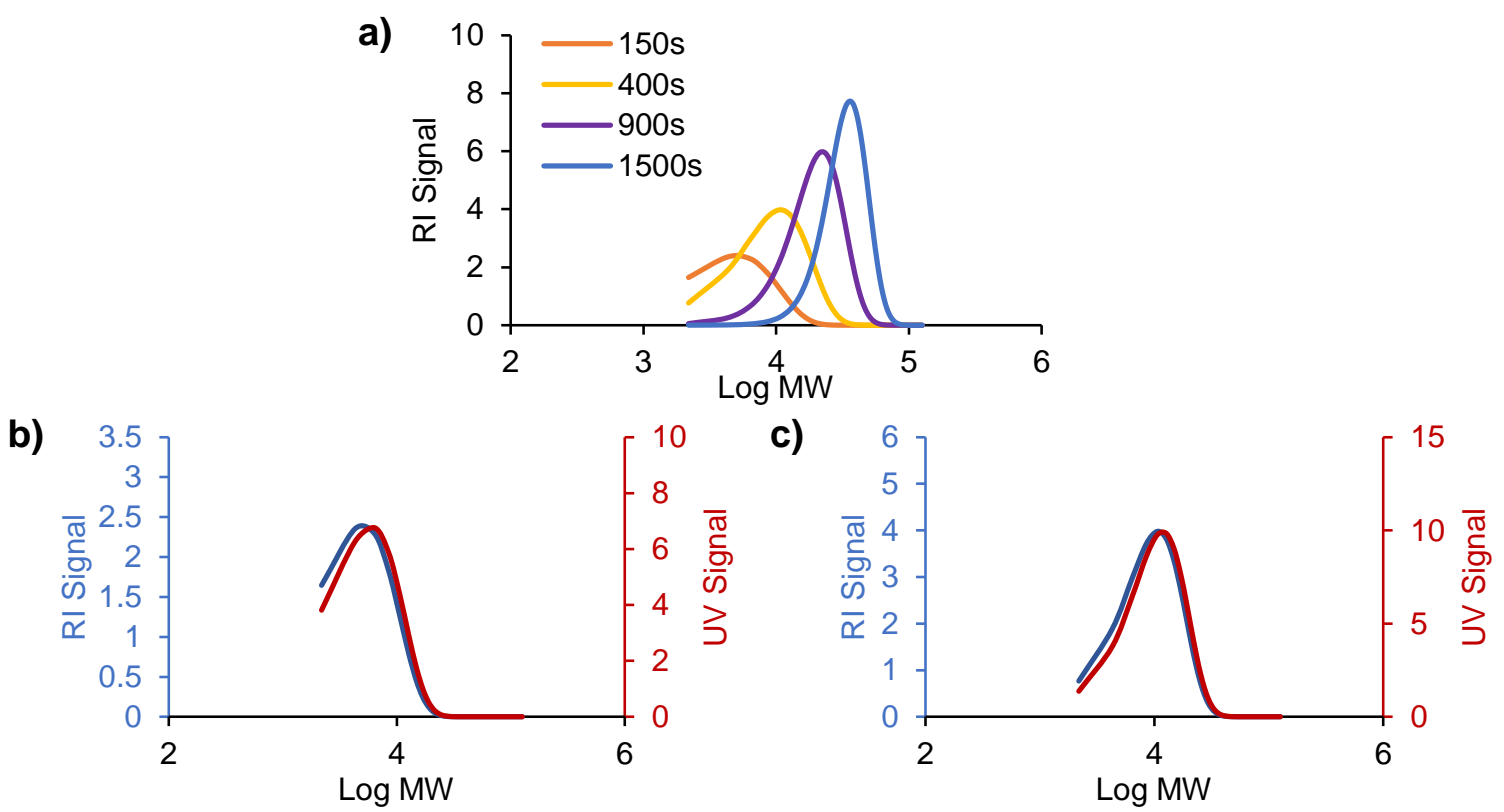

d)

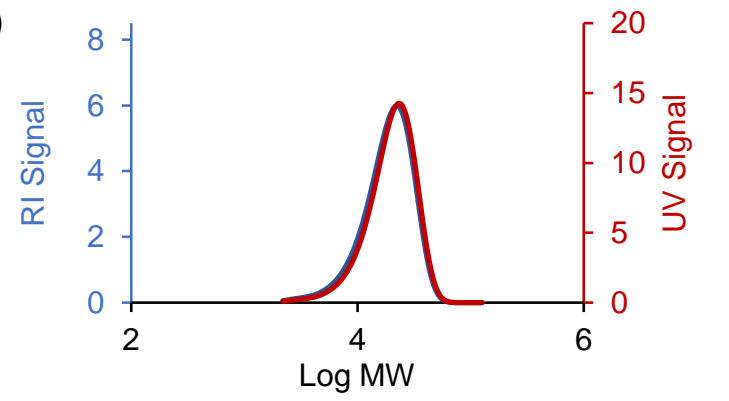

e)

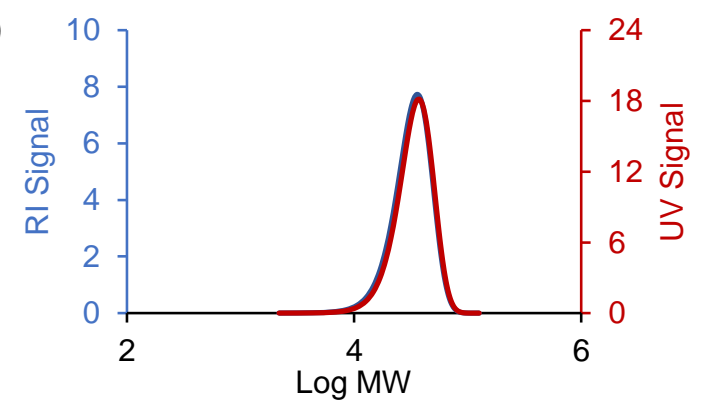

Figure S38. Data from the simulation of a polymerization reaction with reversible chain transfer $\left(k_{\text {ex1 }}=k_{\text {ex } 2}=20 \mathrm{M}^{-1} \mathrm{~s}^{-1}\right)$ with a continuous monomer feed (i.e. monomer concentration remained constant throughout the reaction). The conditions for this simulation are as follows: $\mathrm{k}_{\mathrm{i}}=1.0 \mathrm{M}^{-1} \mathrm{~s}^{-}$ ${ }^{1}, \mathrm{k}_{\mathrm{p}}=1.0 \mathrm{M}^{-1} \mathrm{~s}^{-1},[\mathrm{cat}]_{0}=0.75 \mathrm{mM},\left[\mathrm{ZnEt}_{2}\right]_{0}=1.0 \mathrm{mM}$, and [monomer $]_{0}=1.0 \mathrm{M}$. The UV signal is "mass scaled" for a more accurate comparison of the trace shape to the RI signal. For each simulated GPC trace, the UV signal is shown in red and the RI signal shown in blue. (a) Simulated RI-traces at varying polymerization reaction time $(150 \mathrm{~s}, 400 \mathrm{~s}, 900 \mathrm{~s}$, and $1500 \mathrm{~s})$. (b) Simulated UV- and RI-GPC traces after $150 \mathrm{~s}$. (c) Simulated UV- and RI-GPC traces after $400 \mathrm{~s}$. (d) Simulated UV- and RI-GPC traces after 900 s. (e) Simulated UV- and RI-GPC traces after 1500 $\mathrm{s}$. 


\section{Kinetic simulation of polymerization reactions featuring reversible chain transfer where $k_{\text {ex } 1}=k_{\text {ex2 }}=30 \mathrm{M}^{-1} \mathrm{~s}^{-1}$ with varying initial monomer concentrations}

The polymerization conditions can impact the temporal profile of $\boxminus$ during reversible chain transfer reactions even with the same rate constants for polymerization. To demonstrate this phenomenon, the initial monomer concentration is varied $(0.5-3.0 \mathrm{M})$ in these kinetic simulations, but the $k_{\mathrm{ex} 1}$ and $\mathrm{k}_{\mathrm{ex} 2}$ are kept constant $\left(k_{\mathrm{ex} 1}=\mathrm{k}_{\mathrm{ex} 2}=30 \mathrm{M}^{-1} \mathrm{~s}^{-1}\right)$. B-hydride elimination is not considered in these simulations $\left(\mathrm{k}_{\mathrm{H}}=0\right)$. The catalyst concentration is set to $0.75 \mathrm{mM}$, the chain transfer agent $\left(\mathrm{ZnEt}_{2}\right)$ concentration is set to $1.0 \mathrm{mM}, \mathrm{k}_{\mathrm{i}}$ is set to $1.0 \mathrm{M}^{-1} \mathrm{~s}^{-1}$, and $\mathrm{k}_{\mathrm{p}}$ is set to $1.0 \mathrm{M}^{-1} \mathrm{~s}^{-1}$. The results of these kinetic simulations are shown in Figures S39.

a)

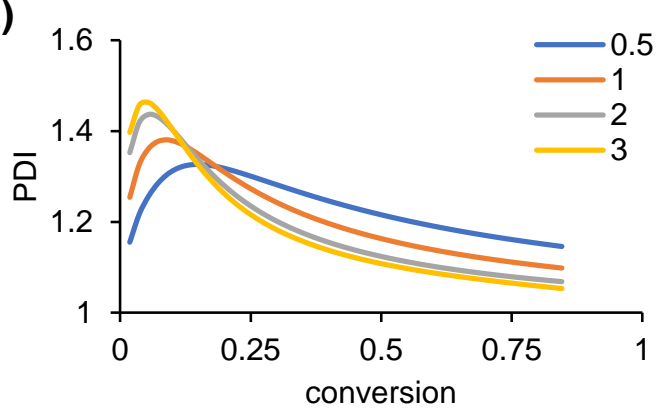

b)

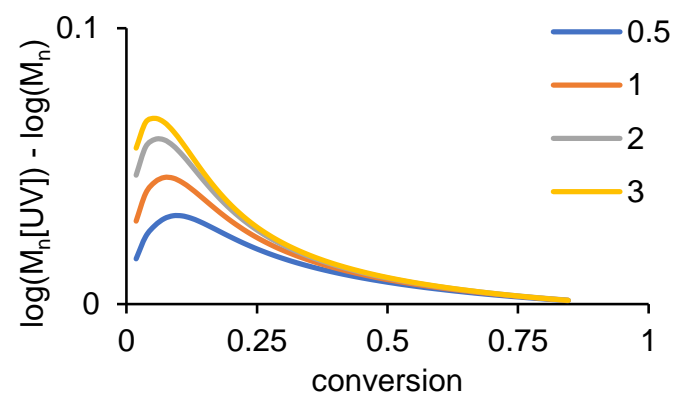

Figure 39. A comparison of kinetic simulations where the initial concentration of monomer is varied during batch polymerization reactions with reversible chain transfer where $k_{\mathrm{ex} 1}=\mathrm{k}_{\mathrm{ex} 2}=30$ $\mathrm{M}^{-1} \mathrm{~s}^{-1}$. (a) The simulated PDI vs conversion for batch polymerization reactions varying the initial concentration of monomer $(0.5-3.0 \mathrm{M})$. (b) The simulated difference in the $\log \left(\mathrm{M}_{\mathrm{n}}\right)$ of the UVand RI-signals (catalyst-polymeryls and all polymeryls, respectively) plotted vs conversion during batch polymerization reactions varying the initial concentration of monomer $(0.5-3.0 \mathrm{M})$. Conditions for these polymerization reactions: $\mathrm{k}_{\mathrm{i}}=1.0 \mathrm{M}^{-1} \mathrm{~s}^{-1}, \mathrm{k}_{\mathrm{p}}=1.0 \mathrm{M}^{-1} \mathrm{~s}^{-1}$, [cat] $0=0.75 \mathrm{mM}$, $\left[\mathrm{ZnEt}_{2}\right]_{0}=1.0 \mathrm{mM}$, [monomer $]_{0}=$ varied, and $\mathrm{k}_{\mathrm{ex} 1}=\mathrm{k}_{\mathrm{ex} 2}=30 \mathrm{M}^{-1} \mathrm{~s}^{-1}$.

\section{Kinetic simulation of polymerization reactions featuring slow initiation along with reversible chain transfer}

In these kinetic simulations, polymerization reactions with a slow rate constant for initiation along with reversible chain transfer to a metal-alkyl are considered. To achieve this, the rate constant for $k_{e \times 2}$ and $k_{e x 1}$ are set to $12 \mathrm{M}^{-1} \mathrm{~s}^{-1}$ and $\mathrm{k}_{\mathrm{i}}$ is varied. B-hydride elimination is not considered in these simulations $\left(\mathrm{k}_{\mathrm{H}}=0\right)$. The catalyst concentration is set to $0.75 \mathrm{mM}$, the monomer concentration is set to $1.0 \mathrm{M}$, the chain transfer agent $\left(\mathrm{ZnEt}_{2}\right)$ concentration is set to $1.0 \mathrm{mM}$, and $\mathrm{k}_{\mathrm{p}}$ is set to $1.0 \mathrm{M}^{-1} \mathrm{~s}^{-1}$. The results of these kinetic simulations are shown in Figures $\mathrm{S} 40-\mathrm{S} 42$. 
a)

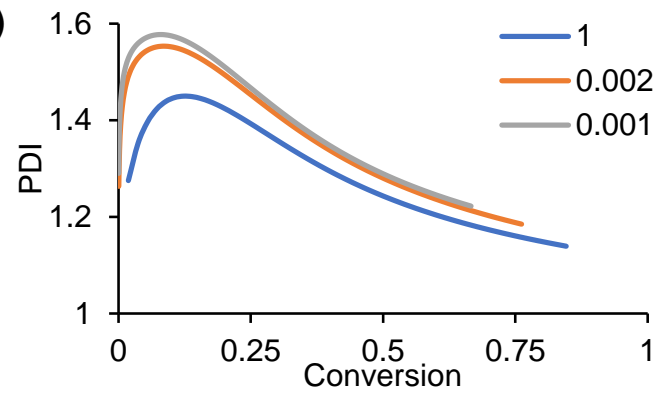

b)

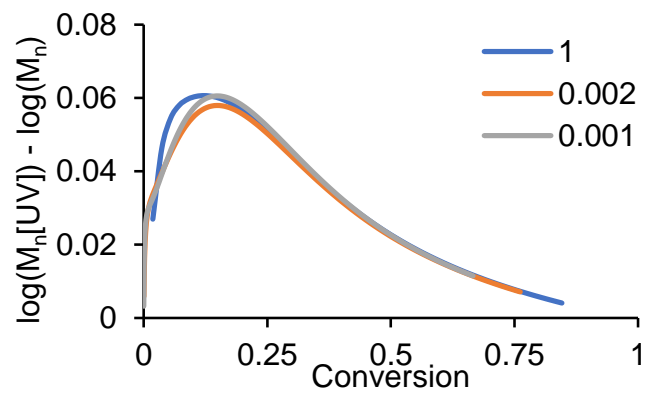

Figure S40. Data comparison of simulations of polymerizations with reversible chain transfer ( $k_{\text {ex } 1}$ $\left.=\mathrm{k}_{\mathrm{ex} 2}=12 \mathrm{M}^{-1} \mathrm{~s}^{-1}\right)$ varying the rate constant for initiation $\left(\mathrm{k}_{\mathrm{i}}=1,0.002\right.$, and $\left.0.001 \mathrm{M}^{-1} \mathrm{~s}^{-1}\right)$. (a) The simulated PDI vs conversion varying the rate constant of initiation $\left(\mathrm{k}_{\mathrm{i}}\right)$. (b) The simulation of the difference in the $\log \left(\mathrm{M}_{\mathrm{n}}\right)$ of the UV- and RI-signals (i.e. catalyst-polymeryls and all polymeryls, respectively) plotted vs the conversion of monomer varying the rate constant of initiation $\left(\mathrm{k}_{\mathrm{i}}\right)$. The conditions for this simulation are as follows: $\mathrm{k}_{\mathrm{i}}=$ varied, $\mathrm{k}_{\mathrm{p}}=1.0 \mathrm{M}^{-1} \mathrm{~s}^{-1}, \mathrm{k}_{\mathrm{ex} 1}=\mathrm{k}_{\mathrm{ex} 2}=12 \mathrm{M}^{-1} \mathrm{~s}^{-1}$, [cat] 0 $=0.75 \mathrm{mM},\left[\mathrm{ZnEt}_{2}\right]_{0}=1.0 \mathrm{mM}$, and $[\text { monomer }]_{0}=1.0 \mathrm{M}$. 

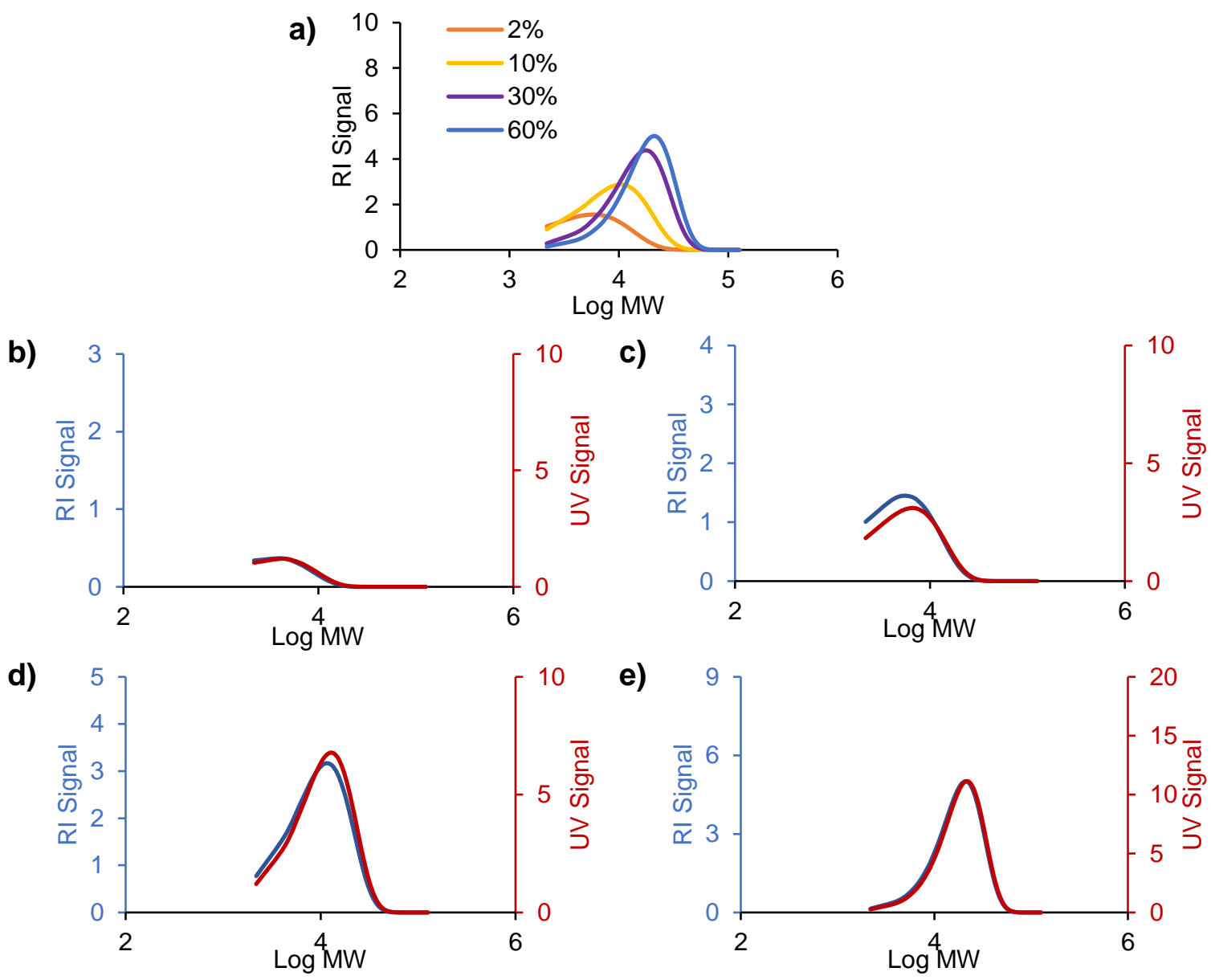

Figure S41. Data from the simulation of a polymerization reaction with reversible chain transfer $\left(k_{\text {ex } 1}=k_{\text {ex2 }}=12 \mathrm{M}^{-1} \mathrm{~s}^{-1}\right)$ with a slow rate constant for initiation $\left(k_{i}=0.002 \mathrm{M}^{-1} \mathrm{~s}^{-1}\right)$ The conditions for this simulation are as follows: $\mathrm{k}_{\mathrm{p}}=1.0 \mathrm{M}^{-1} \mathrm{~s}^{-1}$, [cat $]_{0}=0.75 \mathrm{mM},\left[\mathrm{ZnEt}_{2}\right]_{0}=1.0 \mathrm{mM}$, and [monomer $]_{0}$ $=1.0 \mathrm{M}$. The UV signal is "mass scaled" for a more accurate comparison of the trace shape to the RI signal. For each simulated GPC trace, the UV signal is shown in red and the RI signal shown in blue. (a) Simulated RI-traces at varying conversion of monomer ( $2 \%$ conversion after 150 s, $10 \%$ conversion after 400 s, 30\% conversion after 900 s, and $60 \%$ conversion after 1800 s). (b) Simulated UV- and RI-GPC traces at $2 \%$ monomer conversion (150 s). (c) Simulated UVand RI-GPC traces at 10\% monomer conversion (400 s). (d) Simulated UV- and RI-GPC traces at 30\% monomer conversion (900 s). (e) Simulated UV- and RI-GPC traces at $60 \%$ monomer conversion (1800 s). 

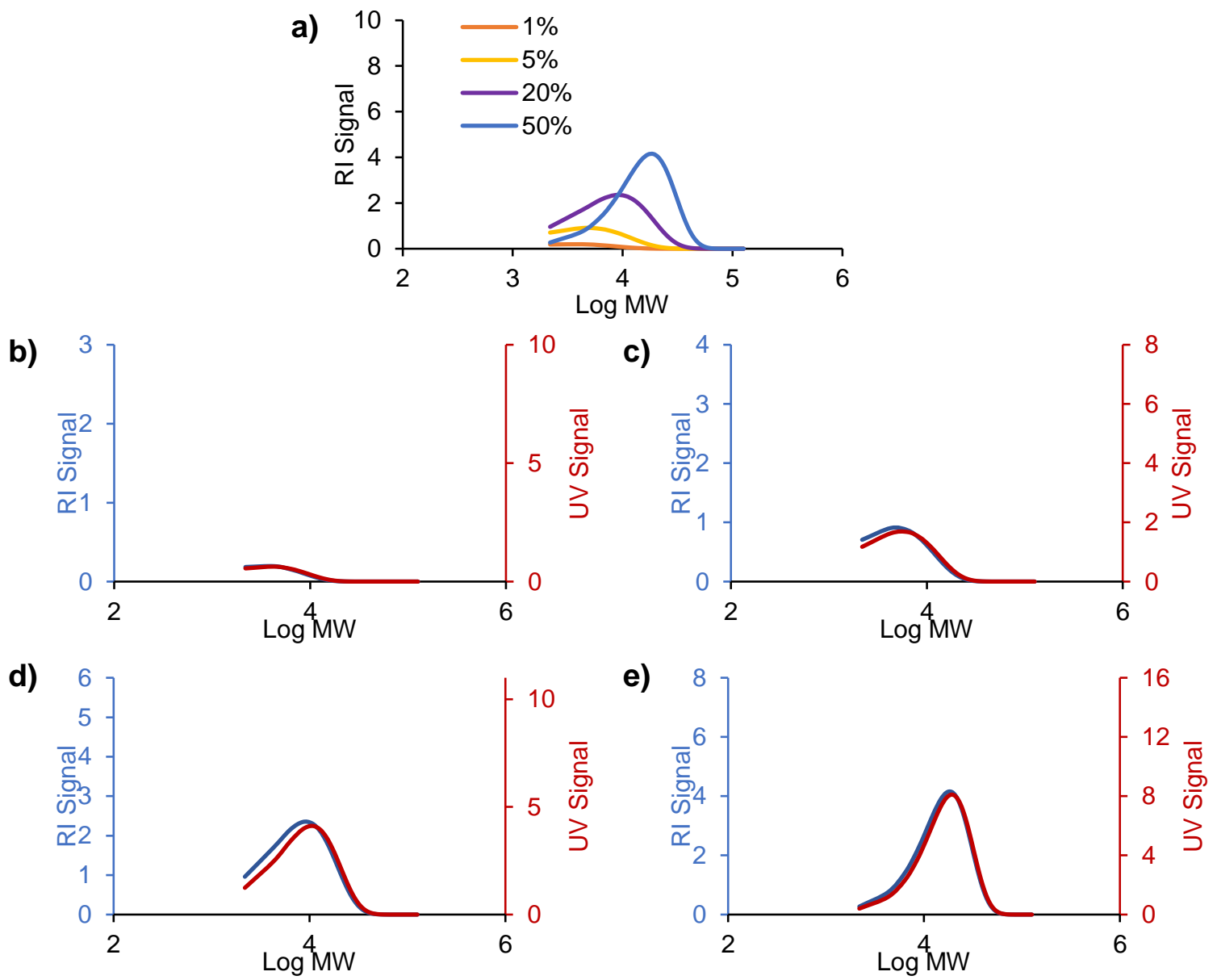

Figure S42. Data from the simulation of a polymerization reaction with reversible chain transfer $\left(k_{\text {ex1 }}=k_{\mathrm{ex} 2}=12 \mathrm{M}^{-1} \mathrm{~s}^{-1}\right)$ with a slow rate constant for initiation $\left(\mathrm{ki}=0.001 \mathrm{M}^{-1} \mathrm{~s}^{-1}\right)$ The conditions for this simulation are as follows: $\mathrm{k}_{\mathrm{p}}=1.0 \mathrm{M}^{-1} \mathrm{~s}^{-1}$, [cat $]_{0}=0.75 \mathrm{mM},\left[\mathrm{ZnEt}_{2}\right]_{0}=1.0 \mathrm{mM}$, and [monomer $]_{0}$ $=1.0 \mathrm{M}$. The UV signal is "mass scaled" for a more accurate comparison of the trace shape to the RI signal. For each simulated GPC trace, the UV signal is shown in red and the RI signal shown in blue. (a) Simulated Rl-traces at varying conversion of monomer (1\% conversion after 150 s, $5 \%$ conversion after 400 s, $20 \%$ conversion after 900 s, and 50\% conversion after 1800 s). (b) Simulated UV- and RI-GPC traces at 1\% monomer conversion (150 s). (c) Simulated UV- and RI-GPC traces at 5\% monomer conversion (400 s). (d) Simulated UV- and RI-GPC traces at 20\% monomer conversion (900 s). (e) Simulated UV- and RI-GPC traces at 50\% monomer conversion (1800 s). 


\section{Kinetic simulation of polymerization reactions featuring B-hydride elimination along with reversible chain transfer}

In this kinetic simulation, a polymerization reaction with a slow rate constant for ß-hydride elimination along with reversible chain transfer to a metal-alkyl is considered. To achieve this, the rate constant for $k_{\text {ex2 }}$ and $k_{\text {ex1 }}$ are set to $12 \mathrm{M}^{-1} \mathrm{~s}^{-1}$ and $\mathrm{k}_{\mathrm{H}}$ is set to $0.001 \mathrm{~s}^{-1}$. The catalyst concentration is set to $0.75 \mathrm{mM}$, the monomer concentration is set to $1.0 \mathrm{M}$, the chain transfer agent $\left(\mathrm{ZnEt}_{2}\right)$ concentration is set to $1.0 \mathrm{mM}$, and $\mathrm{k}_{\mathrm{p}}$ is set to $1.0 \mathrm{M}^{-1} \mathrm{~s}^{-1}$. The results of this kinetic simulation are shown in Figure S43.
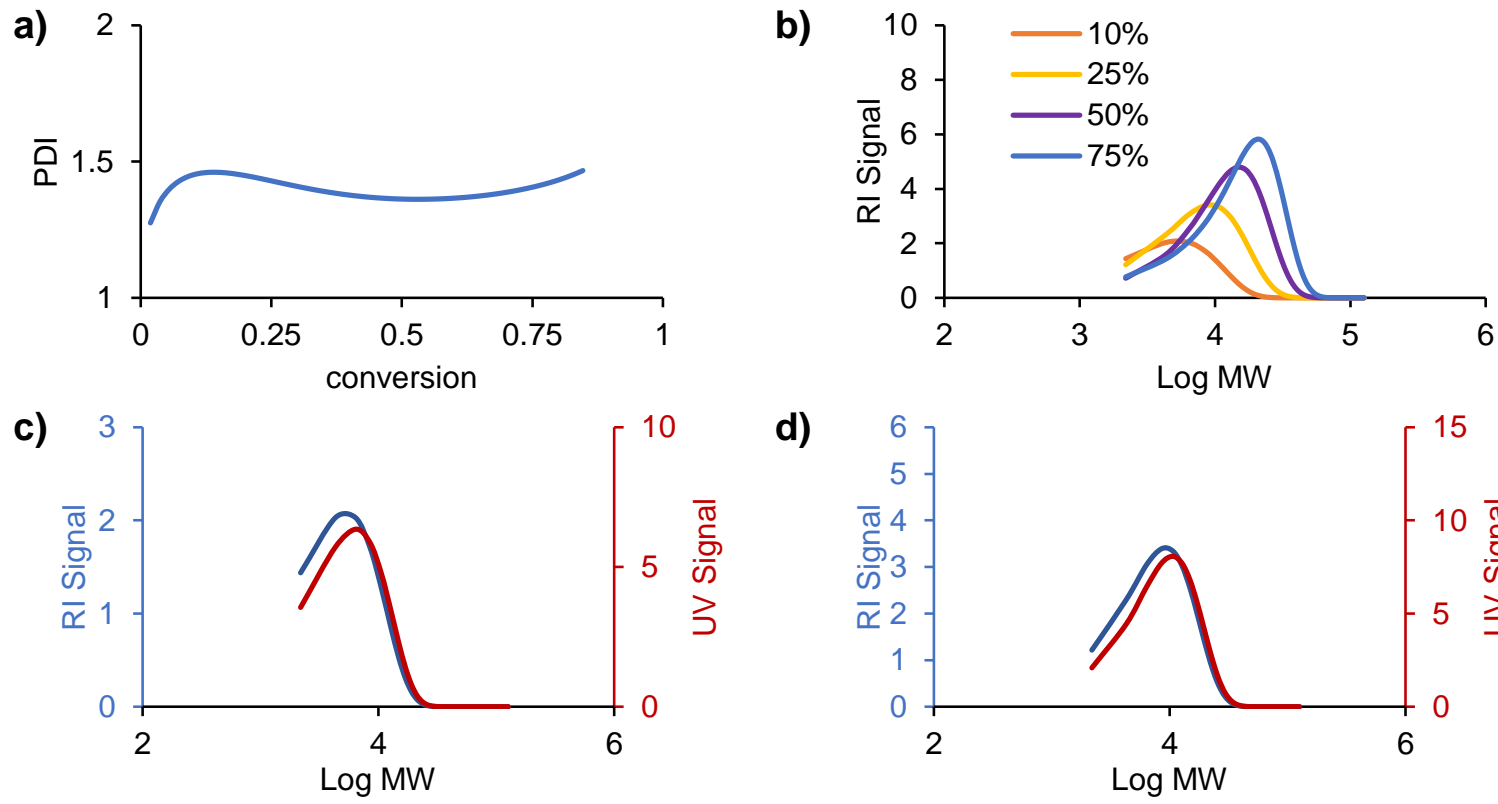

d)
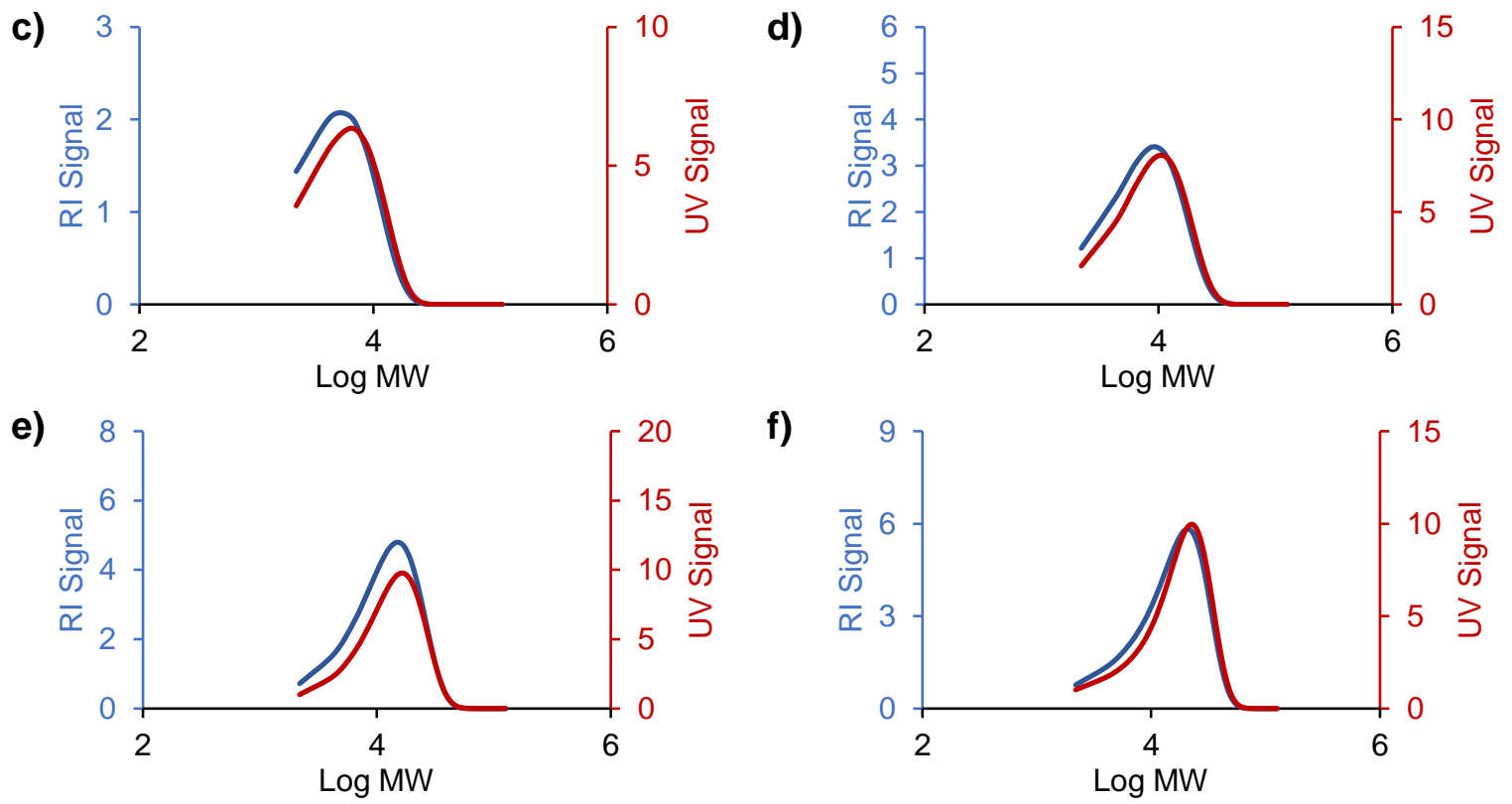

Figure 43. Data from the simulation of a polymerization reaction with reversible chain transfer $\left(k_{\text {ex1 }}=k_{\text {ex2 }}=12 \mathrm{M}^{-1} \mathrm{~s}^{-1}\right)$ along with a slow rate constant for B-hydride elimination $\left(k_{H}=0.001 \mathrm{~s}^{-1}\right)$ The conditions for this simulation are as follows: $\mathrm{k}_{\mathrm{p}}=1.0 \mathrm{M}^{-1} \mathrm{~s}^{-1}, \mathrm{k}_{\mathrm{i}}=1.0 \mathrm{M}^{-1} \mathrm{~s}^{-1}$, [cat] $0=0.75 \mathrm{mM}$, $\left[\mathrm{ZnEt}_{2}\right]_{0}=1.0 \mathrm{mM}$, and [monomer] $]_{0}=1.0 \mathrm{M}$. The UV signal is "mass scaled" for a more accurate comparison of the trace shape to the RI signal. For each simulated GPC trace, the UV signal is shown in red and the RI signal shown in blue. (a) The simulated PDI vs monomer conversion. (b) Simulated RI-traces at varying conversion of monomer (10\% conversion after $150 \mathrm{~s}, 25 \%$ conversion after $400 \mathrm{~s}, 50 \%$ conversion after $900 \mathrm{~s}$, and $75 \%$ conversion after $1800 \mathrm{~s}$ ). (c) Simulated UV- and RI-GPC traces at 10\% monomer conversion (150 s). (d) Simulated UV- and RI-GPC traces at $25 \%$ monomer conversion (400 s). (e) Simulated UV- and RI-GPC traces at $50 \%$ monomer conversion (900 s). (f) Simulated UV- and RI-GPC traces at $75 \%$ monomer conversion (1800 s). 


\section{References}

1. Nelsen, D. L.; Anding, B. J.; Sawicki, J. L.; Christianson, M. D.; Arriola, D. J.; Landis, C. R., Chromophore Quench-Labeling: An Approach to Quantifying Catalyst Speciation As Demonstrated for (EBI)ZrMe2/B(C6F5)3-Catalyzed Polymerization of 1-Hexene. ACS Catal. 2016, 6, 7398-7408.

2. Johnson, H. C.; Cueny, E. S.; Landis, C. R., Chain Transfer with Dialkyl Zinc During HafniumPyridyl Amido-Catalyzed Polymerization of 1-Octene: Relative Rates, Reversibility, and Kinetic Models. ACS Catal. 2018, 8, 4178-4188.

3. Cueny, E. S.; Sita, L. R.; Landis, C. R., Quantitative Validation of the Living Coordinative ChainTransfer Polymerization of 1-Hexene Using Chromophore Quench Labeling. Macromolecules 2020, 53, 5816-5825.

4. Cueny, E. S.; Johnson, H. C.; Anding, B. J.; Landis, C. R., Mechanistic Studies of HafniumPyridyl Amido-Catalyzed 1-Octene Polymerization and Chain Transfer Using Quench-Labeling Methods. J. Am. Chem. Soc. 2017, 139, 11903-11912.

5. Arriola, D. J.; Carnahan, E. M.; Hustad, P. D.; Kuhlman, R. L.; Wenzel, T. T., Catalytic Production of Olefin Block Copolymers via Chain Shuttling Polymerization. Science 2006, 312, 714-719.

6. Wang, W.-J.; Kolodka, E.; Zhu, S.; Hamielec, A. E., Continuous solution copolymerization of ethylene and octene-1 with constrained geometry metallocene catalyst. J. Polym. Sci., Part A: Polym. Chem. 1999, 37, 2949-2957.

7. Frazier, K. A.; Froese, R. D.; He, Y.; Klosin, J.; Theriault, C. N.; Vosejpka, P. C.; Zhou, Z.; Abboud, K. A., Pyridylamido Hafnium and Zirconium Complexes: Synthesis, Dynamic Behavior, and Ethylene/1-Octene and Propylene Polymerization Reactions. Organometallics 2011, 30, 3318-3329.

8. Kuhlman, R. L.; Klosin, J., Tuning Block Compositions of Polyethylene Multi-Block Copolymers by Catalyst Selection. Macromolecules 2010, 43, 7903-7904.

9. Hustad, P. D.; Kuhlman, R. L.; Arriola, D. J.; Carnahan, E. M.; Wenzel, T. T., Continuous Production of Ethylene-Based Diblock Copolymers Using Coordinative Chain Transfer Polymerization. Macromolecules 2007, 40, 7061-7064. 